Universidade de São Paulo

Faculdade de Medicina de Ribeirão Preto

Departamento de Fisiologia

IMPORTÂNCIA DO TECIDO ADIPOSO MARROM NA ATIVAÇÃO DA TERMOGÊNESE INDUZIDA PELA INJEÇÃO CENTRAL DO C75, UM INIBIDOR DA ÁCIDO GRAXO SINTASE

Priscila Cassolla

Prof. Dr. Luiz Carlos Carvalho Navegantes

Ribeirão Preto

2012 
Universidade de São Paulo

Faculdade de Medicina de Ribeirão Preto

Departamento de Fisiologia

\section{IMPORTÂNCIA DO TECIDO ADIPOSO MARROM NA ATIVAÇÃO DA TERMOGÊNESE INDUZIDA PELA INJEÇÃO CENTRAL DO C75, UM INIBIDOR DA ÁCIDO GRAXO SINTASE}

Tese apresentada ao Departamento de Fisiologia da Faculdade de Medicina de Ribeirão Preto - Universidade de São Paulo para a obtenção do Título de Doutor em Ciências. Área de concentração: Fisiologia.

Priscila Cassolla

Prof. Dr. Luiz Carlos Carvalho Navegantes

Ribeirão Preto 
Autorizo a reprodução e divulgação total ou parcial deste trabalho, por qualquer meio convencional ou eletrônico, para fins de estudo e pesquisa, desde que citada a fonte.

FICHA CATALOGRÁFICA

Cassolla, Priscila

Importância do tecido adiposo marrom na ativação da termogênese induzida pela injeção central do $\mathrm{C75}$, um inibidor da ácido graxo sintase. Ribeirão Preto, 2012.

xi, 150 p.: 35 il.; $30 \mathrm{~cm}$

Tese de Doutorado apresentada à Faculdade de Medicina de Ribeirão Preto/USP, Departamento de Fisiologia. Programa: Fisiologia.

Orientador: Navegantes, Luiz Carlos Carvalho.

1. Termogênese. 2. Tecido adiposo marrom. 3. C75. 4. Sistema nervoso simpático. 5. Rato. 
Aos meus queridos:

Lourdes e Edison, Patrícia, Poliane e Penélope, com carinho e alegria, pelo amor e incentivo incondicionais. 


\section{AGRADECIMENTOS}

Agradeço, primeiramente, Àqueles em que tenho fé e creio terem me guiado nessa caminhada árdua, instigante e compensadora: ao Pai Eterno, à Mãe de todas as mães, a Santo Expedito e aos Anjos da Guarda.

Aos meus amados pais, Edison e Lourdes, pilares que sustentam a minha estrutura ética, moral, psicológica e educacional, sem os quais nada seria possível. Meus exemplos de vida!

Às minhas irmãs, Patrícia (Zá), Poliane (Zoli) e Penélope (Zené), queridas parceiras e confidentes, pela força e cumplicidade.

Ao Adriano Álvaro, com carinho, pelo companheirismo, compreensão, atenção e por, muitas vezes, me fazer enxergar que aquilo que julgo ser um tsunami pode ser só mais uma gota d'água por entre as pedras.

Ao Dr. Luiz Carlos Carvalho Navegantes, pela orientação e ensinamentos, pela confiança no meu trabalho, pela seriedade e serenidade profissional, e pelas saudáveis e leves conversas que me ajudaram a vencer uma fase difícil da vida.

À Dra. Isis do Carmo Kettelhut, por acreditar no meu potencial e permitir a minha inserção no Laboratório de Controle do Metabolismo Intermediário, pela co-orientação, pelos valiosos conselhos e pelo cuidado maternal. Um exemplo de coragem, garra e perseverança.

À Maria Antonieta Rissato Garófalo, pelo excelente apoio técnico e disponibilidade na resolução de problemas, com seu carisma e atenção, pela amizade e conversas tão agradáveis.

À Elza Aparecida Filippin, à Lílian do Carmo Zorzenon e à Neusa Maria Zanon, pela prestatividade nos experimentos, apoio técnico, e pelos momentos de descontração durante o café.

Ao Victor Diaz Galban, pela ajuda nos softwares e hardwares, e pelas discussões tecnológicas enriquecedoras. À Amanda Araújo e ao Leandro Garcia, pelo apoio técnico e pela amizade.

Ao Dr. Cândido Celso Coimbra, pela disponibilidade, sugestões sobre o trabalho e por liberar seus alunos, Juliana Bohnen Guimarães e Frederico Sander Mansur Machado, cujos os quais também agradeço por me ensinarem o método e a análise dos dados de telemetria.

Ao Dr. Nilton de Almeida Brito, pela disposição em ensinar a medida da temperatura no tecido adiposo marrom, pelo empréstimo do aparelho e dos sensores, e pelos conselhos e sugestões sobre o trabalho. 
À Dra. Lucila Leico Kagohara Elias e ao Dr. José Antunes Rodrigues, por permitirem a execução da análise de imunohistoquímica no Laboratório de Neuroendocrinologia, pelo incentivo e discussão de resultados. À Maria Valci Aparecida dos Santos pelo apoio técnico para perfusão dos animais para imunohistoquímica e para a extração de corticosterona plasmática.

Ao Ernane Torres Uchôa pela sua dedicação e prestatividade, por ensinar todos os passos para a análise da proteína c-Fos, pela amizade e longas conversas.

Ao José Roberto da Silva, técnico do Laboratório de Imunoensaios, e ao $\underline{\text { Dr. Ayrton Custódio }}$ Moreira, pela dosagem de corticosterona. À Gisele, técnica do Laboratório de Tireóide e Screening Neonatal, e à Dra. Léa Maria Zanini Maciel, pela dosagem dos hormônios tiroidianos. Ao Dr. Eduardo Brandt de Oliveira e ao Dr. Leonardo dos Reis Silveira, pelo auxílio na realização do ensaio de atividade enzimática da citrato sintase.

Aos amigos do Laboratório de Controle do Metabolismo Intermediário, Dawit Albieiro Pinheiro Gonçalves (irmão empolgado da biologia molecular), Lidiany Góis (parceira de todas as horas), Rafael Rossi Valentim ("carrasco" criativo), Leandro Henrique Manfredi ("carrasco" corinthiano), Flávia Aparecida Graça (poço de lágrimas sorridente), Sílvia de Paula Gomes (amiga do coração e dos cardiomiócitos), Wilian de Assis Silveira (neurótico murphyfílico), Franciele Przygodda (fran-jinha), Graziella Nascimento Ferreira Sodré (gliceroneogênica), Juliano Machado (paniquete), Danilo Lustrino (o que resolve problemas pessoais), Natália Lautherbach Ennes da Silva (Nem) e Samyra Lopes Buzelle (geração saúde), pelo alegre convívio, pela colaboração experimental e pelas elucubrações científicas!

À Dra. Amanda Martins Baviera, à Dra. Valéria Ernestânia Chaves e ao Dr. Eduardo Carvalho Lira pelo incentivo, ensinamentos, conselhos, dicas e pela amizade.

Aos funcionários do Departamento de Fisiologia, em especial a Cláudia, Elisa, Andréa e Fernando, e do Departamento de Bioquímica e Imunologia, em especial a Ivone, Lúcia e Ronaldo, pela disponibilidade, competência e por sempre ajudarem nas questões burocráticas.

Aos bioteristas Eduardo, Leonardo e $\underline{\text { Paulinho }}$, pela ajuda na manutenção dos animais de laboratório.

Aos meus colegas de turma do "cursão": $\underline{\text { Paulinha, }} \underline{\text { Renata, Melina }}, \underline{\text { Ricardo }}, \underline{\text { André, }}$ Iracema Davi, Luís Fernando, Paula e Víctor, pelo espírito de união e por fazerem esse período pesado das disciplinas compulsórias se tornar menos sofrível.

Aos meus amigos e familiares que compartilharam os bons e maus momentos dessa etapa, e que oraram e/ou torceram por mim.

À CAPES e à FAPESP pelo financiamento da minha bolsa de estudos e do projeto de pesquisa, respectivamente. 
Seja a mudanca que você deseja ver no mundo

- Mahatma Gandhi 


\section{SUMÁRIO}

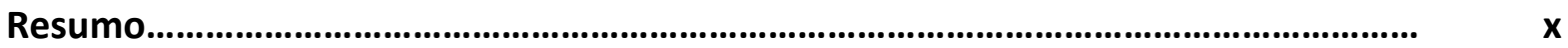

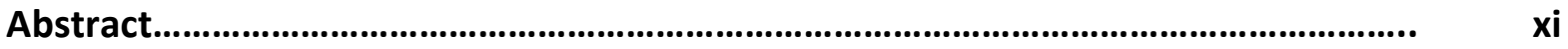

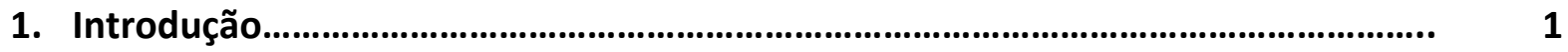

1.1. Morfologia e função do tecido adiposo marrom........................................... 4

1.2. Inervação simpática e regulação da atividade do tecido adiposo marrom... 8

1.3. Regulação da temperatura corporal............................................................ 12

1.4. Inibidores da ácido graxo sintase................................................................ 15

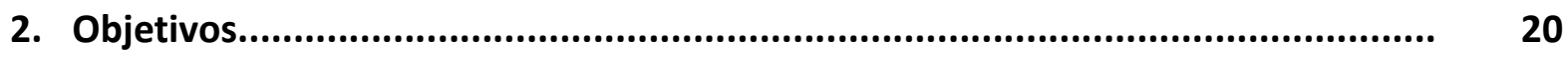

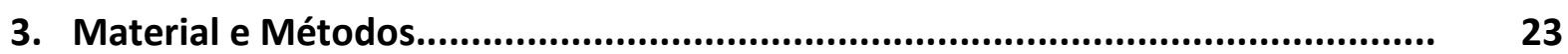

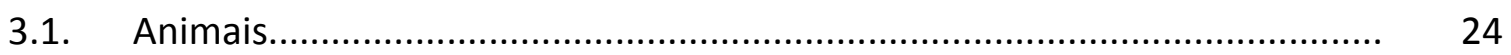

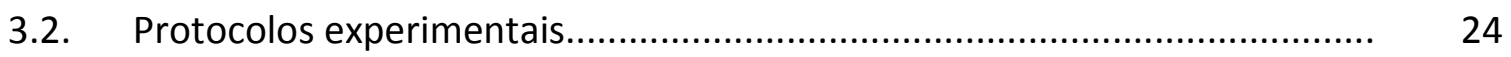

3.2.1. Investigação da ingestão alimentar e hídrica, e ganho de peso corporal................................................................................. 24

3.2.2. Avaliação das concentrações plasmáticas de metabólitos................. 25

3.2.3. Avaliação das concentrações plasmáticas de hormônios e marcadores da atividade simpática e da termogênese......

3.2.4. Análise da temperatura corporal interna, do TAM e da pele, e atividade locomotora.

3.2.5. Análise das áreas centrais ativadas

3.3. Procedimentos cirúrgicos e de registro. 
3.3.3. Implante do sensor para registro da temperatura interna e da atividade locomotora.

3.3.4. Implante do sensor para obtenção da temperatura do TAM

3.3.5. Registro da temperatura corporal interna e da atividade locomotora

3.3.6. Registro da temperatura no TAM.

3.3.7. Registro da temperatura da pele da cauda

3.4. Procedimentos laboratoriais.

3.4.1. Determinação das concentrações plasmáticas de glicose e ácidos graxos livres

3.4.2. Determinação da concentração plasmática de insulina

3.4.3. Determinação da concentração plasmática de corticosterona

3.4.4. Determinação da concentração plasmática de tiroxina total.

3.4.5. Determinação das catecolaminas no plasma e no TAM

3.4.6. Atividade enzimática da citocromo c oxidase

3.4.7. Atividade enzimática da citrato sintase.

3.4.8. Conteúdo de gordura total no TAM

3.4.9. RT-PCR em tempo real. 
3.5. Análise estatística.

4. Resultados

4.1. Efeito do C75 na ingestão (alimentar e hídrica) e no ganho de peso corporal.

4.2. Efeito do C75 sobre a glicemia e a concentração plasmática de ácidos graxos livres.

4.3. Efeito do $\mathrm{C} 75$ nas concentrações plasmáticas de insulina, tiroxina total, catecolaminas e no conteúdo de noradrenalina no TAM.

4.4. Efeito do C75 na temperatura corporal interna e atividade locomotora espontânea

4.5. Efeito do C75 na temperatura do TAM

4.6. Efeito do C75 sobre a perda de calor.

4.7. Efeito do C75 no conteúdo de gordura total, atividade de enzimas oxidativas e expressão gênica da UCP-1.

4.8. Efeito da cerulenina na ingestão (alimentar e hídrica) e ganho de peso corporal.

4.9. Efeito da cerulenina na temperatura corporal interna e atividade locomotora espontânea......

4.10. Efeito da cerulenina na temperatura do TAM

4.11. Efeito do C75 na atividade neuronal - análise da proteína c-Fos 


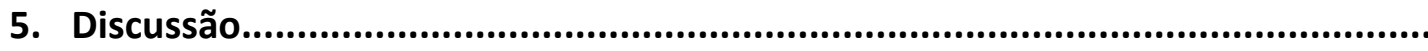

6. Referências Bibliográficas......................................................................... 108

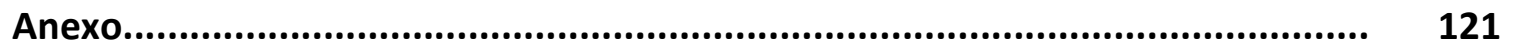




\section{RESUMO}

C75, um inibidor sintético da ácido graxo sintase, causa anorexia e perda de peso em roedores, mas os mecanismos envolvidos com esses efeitos ainda não são totalmente conhecidos. A hipótese testada nesse trabalho foi que o tecido adiposo marrom (TAM), um órgão com importante função no controle da termogênese, poderia estar envolvido nos efeitos mediados pelos inibidores da ácido graxo sintase. Para isso, ratos Wistar foram submetidos ao implante de cânula no ventrículo lateral direito seguido, ou não, pela desnervação simpática cirúrgica do TAM. Sete dias após, C75 $\left(150 \mu \mathrm{g} .7,5 \mu \mathrm{L}^{-1}\right)$, cerulenina, um inibidor natural da ácido graxo sintase, (150 $\left.\mu \mathrm{g} .7,5 \mu \mathrm{L}^{-1}\right)$ ou RPMI (veículo) foi administrado nos animais com privação alimentar de 24 horas. Foi demonstrado que uma única injeção intracerebroventricular de C75 reduziu a ingestão alimentar no primeiro dia e induziu perda de peso por dois dias. Além disso, as análises de telemetria mostraram que o C75 promoveu um rápido aumento na temperatura corporal interna, maior taxa de estoque de calor de 30 minutos a 6 horas da administração, e um aumento na dissipação de calor por 4 horas. A desnervação do TAM atenuou os efeitos do C75 sobre a regulação térmica bem como seu efeito sobre o peso corporal e a ingestão alimentar. Em paralelo, o C75 induziu aumento na temperatura do TAM (até 8 horas após a injeção), no conteúdo de noradrenalina e na atividade da citocromo c oxidase mitocondrial e da expressão do RNAm da UCP-1 no tecido. Todos esses efeitos foram abolidos com a desnervação simpática do TAM. Tal como o C75, a cerulenina, também induziu um aumento na temperatura corporal interna e do TAM, o qual também foi abolido pela desnervação do TAM. A atividade locomotora espontânea não foi alterada por nenhum inibidor da ácido graxo sintase. A imunohistoquímica para c-Fos revelou que o C75 aumentou o número de células imunorreativas a c-Fos na área pré-óptica, núcleo paraventricular, dorsomedial do hipotálamo, ventromedial do hipotálamo, locus coeruleus e rafe pálida, regiões que estão envolvidas com a regulação central da temperatura. Estes dados sugerem um papel do TAM no aumento da temperatura corporal evocado pelos inibidores da ácido graxo sintase e provêm novos mecanismos para explicar a hipofagia e o aumento do gasto energético observados com a administração desses compostos. 


\section{ABSTRACT}

C75, a synthetic inhibitor of fatty acid synthase, causes anorexia and weight loss in rodents, but the underlying mechanisms are not totally known. Thus, the hypothesis tested in this work was that brown adipose tissue (BAT), an organ with important role for control of thermogenesis, could be involved in the anti-obesity effects of fatty acid synthase inhibitors. To address this issue, Wistar rats were submitted to cannula implant into right lateral ventricle and following, or not, by surgical sympathetic denervation of BAT. Seven days later,

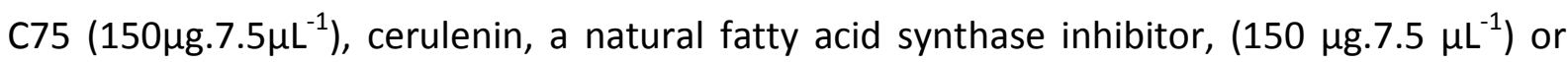
RPMI (vehicle) was administered in $24 \mathrm{~h}$-fasted animals. It was demonstrated that a single intracerebroventricular injection of $\mathrm{C75}$ decreased the food intake on the first day, and induced weight loss for two days. Furthermore, telemetry analyzes shown that the C75 induced a rapid increase in core body temperature, a higher heat storage rate from 30 minutes until 6 hours of injection, and an increase in heat dissipation for 4 hours. The BAT denervation attenuated the thermoregulatory effects of $\mathrm{C75}$ as well as its effect on body weight and food intake. In parallel, C75 induced an increase in BAT temperature (up to 8 hours of the injection), higher content of norepinephrine, and an increase in the activity of cytochrome c oxidase and mRNA expression of UCP-1 in the tissue. All these effects were abolished by sympathetic denervation. Like C75, the central administration of cerulenin also induced an increase in the BAT and core body temperature, which was also abolished by BAT denervation. The spontaneous locomotor activity was not altered by any fatty acid synthase inhibitor. The immunohistochemistry for c-Fos revealed that the $\mathrm{C} 75$ increased numbers of Fos-immunoreactive cells in preoptica area, paraventricular nucleus, dorsomedial hypothalamus, ventromedial hypothalamus, locus coeruleus and raphe pallidus, regions which are involved in the central thermoregulation. These data implicate a role for BAT in the fatty acid synthase inhibitors-evoked increase in body temperature and provide new mechanisms to explain hypophagia and increased energy expenditure observed with the administration of these compounds. 


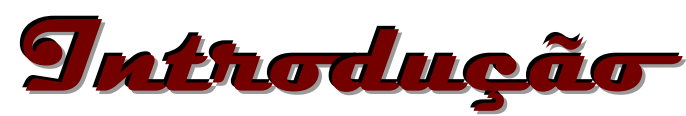




\section{Introdução}

A obesidade é um dos principais problemas de saúde pública mundial. A taxa de prevalência em adultos está aumentando em cerca de 10\% a 35\% na região euro-americana (Hainer et al., 2008). A obesidade é uma doença complexa caracterizada pelo excesso de tecido adiposo branco resultante de alterações na regulação do balanço energético corporal e está associada a numerosas complicações, tais como diabetes mellitus, hipertensão, dislipidemia, osteoartrite e diversos tipos de câncer (Korner \& Aronne, 2003; Yun, 2010).

Drogas para o tratamento da obesidade têm sido desenvolvidas para auxiliar na perda de peso em combinação com mudanças no estilo de vida, e para diminuir o risco de doenças relacionadas (Hainer et al., 2008). Entretanto, em estudos de redução de peso a longo-prazo de crianças e adultos, têm sido observado que aproximadamente $80 \%$ a $90 \%$ retornam ao peso prévio ao tratamento. Essa ineficácia de manutenção da perda de peso é um reflexo das ações potentes e redundantes dos sistemas metabólico, neuroendócrino e autonômico (hipótese adipostática) que defendem o organismo contra alterações do peso corporal (Rosenbaum \& Leibel, 2010).

Assim, novas alternativas para o tratamento da obesidade estão surgindo a partir de recentes avanços na compreensão do complexo circuito do controle da homeostase energética (Korner \& Aronne, 2003). Dentre essas, destacamos a ativação da termogênese, em especial, do tecido adiposo marrom (TAM). A termogênese desafia a hipótese adipostática do controle de peso corporal, uma vez que a sua ativação gera um gasto energético que, geralmente, não é compensado com aumento da ingestão alimentar (Cannon \& Nedergaard, 2004). 
O TAM é cientificamente novo como órgão. A produção de calor como função do TAM foi demonstrada há 50 anos (Smith, 1961) e somente nos últimos 20 anos tem-se estudado o envolvimento deste tecido com diversos tipos de ineficiência metabólica (Cannon \& Nedergaard, 2004). Baseada em análises morfológicas pós-morte em humanos, a presença do TAM foi inicialmente detectada em neonatos e crianças, mas muito pouco em adultos (Heaton, 1972). Dessa forma, foi considerado como um tecido fisiologicamente irrelevante em humanos adultos, sendo, por muito tempo, estudado apenas em pequenos roedores. No entanto, trabalhos publicados no ano de 2009 demonstraram, por meio de tomografia de emissão de pósitron combinada à tomografia computadorizada (PET/CT), que o TAM está presente e é funcional em adultos (Cypess et al., 2009; van Marken Lichtenbelt et al., 2009; Virtanen et al., 2009), fato que reacendeu o interesse da comunidade científica pela função deste tecido.

Os depósitos de TAM em humanos adultos foram encontrados na região que se estende da porção anterior do pescoço ao tórax. O TAM foi mais frequentemente detectado em pacientes mulheres (razão 2:1, mulheres:homens) e sua presença foi inversamente proporcional ao índice de massa corporal (especialmente em adultos mais velhos), à idade, à temperatura ambiente fora da sala no momento do escaneamento, e ao uso de betabloqueadores adrenérgicos (Cypess et al., 2009).

Outro estudo mostrou que a atividade metabólica relativamente alta do TAM em homens jovens, encontrada em $96 \%$ dos indivíduos expostos ao frio $\left(16{ }^{\circ} \mathrm{C}\right)$, foi menor em sujeitos com sobrepeso ou obesos. Como esperado, observou-se que a função do TAM está diretamente relacionada com o metabolismo energético, visto que houve correlação positiva entre sua atividade e a taxa metabólica de repouso (van Marken Lichtenbelt et al., 2009). 
Virtanen et al. (2009) realizaram análises morfológicas, bioquímicas e moleculares em biópsias de TAM da área supraclavicular em indivíduos saudáveis, as quais foram comparadas com biópsias de tecido adiposo branco (TAB). Todas as análises reforçaram as discrepâncias entre o TAM e o TAB, e reiteraram as semelhanças entre o TAM humano com o TAM de ratos, apontando as mesmas características histológicas e funcionais como, por exemplo, a alta capacidade de aumentar a captação de glicose no frio e a grande expressão de genes específicos da termogênese, como a proteína desacopladora do tipo 1 (UCP-1). A partir desses estudos sugeriu-se que a atividade do TAM em humanos possa ser regulada da mesma forma que em roedores (ver 1.2.).

A partir das evidências atuais que apontam para a importância do TAM no controle do metabolismo em humanos e sua semelhança com o TAM em roedores e os estudos em modelos animais de obesidade que mostram uma atividade defeituosa deste tecido e o consequente déficit no gasto energético (Himms-Hagen, 1989a); é evidente que o entendimento da regulação da atividade do TAM em animais tornou-se um alvo em potencial na investigação para o tratamento da obesidade e outras desordens metabólicas.

\subsection{Morfologia e função do tecido adiposo marrom}

O TAM está distribuído em discretos depósitos pelo corpo que variam de acordo com a espécie (Nechad apud Himms-Hagen, 1989a). Em ratos e camundongos, o maior depósito é o interscapular, composto em $40 \%$ por adipócitos marrons maduros, além de préadipócitos, mastócitos, e células intersticiais e endoteliais (Bukowiecki et al., 1982, 1986).

De acordo com a revisão de Tseng et al. (2010), os adipócitos marrons do TAM interscapular são derivados, originalmente, de células progenitoras miogênicas do 
mesoderma (que expressam MYF5), as quais também dão origem às células musculares. Por outro lado, adipócitos marrons sistêmicos são originados a partir de células progenitoras não miogênicas (que não expressam MYF5) quando, por exemplo, emergem do tecido adiposo branco em resposta à estimulação $\beta_{3}$-adrenérgica.

Os adipócitos marrons são multiloculares, pois contem numerosas gotículas lipídicas contendo triacilglicerol, e apresentam alta quantidade de mitocôndrias posicionadas próximas à membrana plasmática (Himms-Hagen, 1989a). As mitocôndrias do TAM possuem numerosas cristas paralelas caracterizadas pela presença da UCP-1 e pela pequena quantidade da enzima ATP sintase (Krauss et al., 2005).

A UCP-1 é específica do tecido e confere a propriedade termogênica do TAM. A UCP-1 é essencial para o processo de produção de calor, conhecido como termogênese facultativa independente de tremor. A termogênese representa um importante mecanismo regulatório para a manutenção da temperatura corporal interna dentro de uma estreita faixa de variação (Himms-Hagen, 1989b). A produção de calor pelo TAM é resultado da ineficiência da cadeia respiratória em produzir ATP devido ao desacoplamento do gradiente de prótons entre o espaço intermembranas e a matriz mitocondrial induzido pela atividade da UCP-1. Portanto, a capacidade das células do TAM em promover termogênese é determinada pela concentração de UCP-1 (Cannon \& Nedergaard, 2004).

A atividade da UCP-1 é regulada, principalmente, pelos ácidos graxos que representam os principais substratos para a oxidação durante a termogênese, fornecendo $\mathrm{NADH}$ e $\mathrm{FADH}_{2}$ para suprir a cadeia respiratória e garantir o gradiente de prótons. Embora se saiba que os ácidos graxos possam atuar diretamente na atividade da UCP-1 para promover o desacoplamento de prótons, o mecanismo relacionado a este efeito ainda não está bem 
definido (Krauss et al., 2005). Há apenas teorias que tentam explicá-lo. Por exemplo, de acordo com o modelo proposto por Skulachev, Garlid e Jezek, a UCP-1 é um carreador da forma reduzida dos ácidos graxos (ânion), os quais são oxidados no espaço intermembranas e retornam passivamente para a matriz, onde são reduzidos para liberar o próton (Skulachev, 1991; Garlid et al., 2000; Skulachev, 1998).

Outro modelo que também considera o ácido graxo como co-fator é o de Klingenberg, no qual o ácido graxo tem um papel integral na UCP-1. Desse modo, os grupamentos carboxil dos ácidos graxos atuariam como pontos de carreamento no canal da UCP-1 permitindo a passagem de prótons (Klingenberg \& Huang, 1999). Outras teorias baseiam-se no fato de que nucleotídeos purínicos, tais como ATP, ADP, GTP e GDP interagem com o sítio de ligação para nucleotídeo da UCP-1 e atraem resíduos carregados positivamente. Diante dessa modificação conformacional essas moléculas atuam como inibidores da atividade da UCP-1 (Krauss et al., 2005).

Acredita-se que os ácidos graxos possam superar a inibição dos nucleotídeos por meio da competição direta dos seus sítios de ligação atuando, assim, como fatores regulatórios. Já Nicholls e Rial descrevem um mecanismo de ativação mediada pela interação direta dos ácidos graxos na UCP-1 em um outro sítio de ligação, o qual é dessensibilizado após a interação com os nucleotídeos (Rial \& Nicholls, 1987). Sugere-se ainda a existência de um metabólito, ainda não identificado, denominado ativador fisiológico intracelular, o qual seria estimulado pelos ácidos graxos para competir com os nucleotídeos pelo mesmo sítio de ligação (Cannon et al., 1977).

Independentemente do mecanismo de ativação da UCP-1 pelos ácidos graxos, sabe-se que a primeira etapa do processo intracelular da termogênese é iniciada com a 
ativação do sistema nervoso simpático e de seus receptores adrenérgicos no TAM (Nedergaard et al., 2001). Em adipócitos marrons maduros, a norepinefrina possui um papel primário no controle funcional e de proliferação celular. A noradrenalina interage com os dois tipos de receptores $(\beta$ e $\alpha$ ), os quais estão associados com a ativação de diferentes vias de sinalização. A via mais significativa e mais estudada é a via da estimulação $\beta$-adrenérgica da termogênese. Dos três subtipos de receptores $\beta$-adrenérgicos, o $\beta_{3}$-adrenorreceptor é o mais importante. Enquanto o receptor $\beta_{1}$ está relacionado com produção de AMPc em préadipócitos, o receptor $\beta_{2}$, embora também presente no tecido, não é expresso no adipócito, mas predominantemente localizado no sistema vascular (Cannon \& Nedergaard, 2004).

O $\beta_{3}$-adrenorreceptor geralmente acopla-se a proteínas Gs para promover a termogênese no TAM. A partir dessa etapa, o sinal termogênico da noradrenalina é mediado pela adenilil ciclase que, uma vez ativa, converte o ATP em AMPc. Em seguida, este segundomensageiro ativa a proteína quinase A, a qual pode fosforilar proteínas citosólicas, tais como a lipase hormônio sensível (ativação) e a perilipina (desativação), a fim de estimular a via lipolítica; e proteínas nucleares, como o fator de transcrição CREB, o qual ativa a transcrição de genes, incluindo o gene da UCP-1 (Collins et al., 2010).

A fosforilação da lipase hormônio sensível e da perilipina estimulam a lipólise do triaciglicerol das gotículas de gordura do adipócito, resultando em liberação de glicerol e de ácidos graxos dentro da célula. Embora os ácidos graxos possam ser degradados inicialmente por peroxissomos, a maioria deles é conduzida para a mitocôndria, onde servem como substrato para a termogênese e atuam como ativadores da UCP-1 (Cannon \& Nedergaard, 2004). 
A via $\beta_{3}$-adrenérgica/APMc e a exposição ao frio aumentam a expressão do coativador-1 do receptor- $\gamma$ ativado pelo proliferador de peroxissomo (PGC1- $\alpha$ ) no TAM e em músculo esquelético (Puigserver et al., 1998). O PGC1- $\alpha$ é um poderoso co-ativador transcricional de vários receptores nucleares (Vega et al., 2000) que parece coordenar a transcrição de genes envolvidos na termogênese, tais como aqueles que codificam enzimas mitocondriais da oxidação de ácidos graxos, subunidades da citocromo c oxidase e ATP sintase da cadeia respiratória, a UCP-1 e os envolvidos com a biogênese mitocondrial (Crowley et al., 2002).

\subsection{Inervação simpática e regulação da atividade do tecido adiposo marrom}

Além de ricamente vascularizado, o que permite a rápida oferta de oxigênio e substratos bem como o rápido transporte do calor produzido aos outros órgãos, o TAM recebe uma inervação simpática direta. O TAM interscapular de ratos consiste em dois lobos simétricos, sendo que cada um recebe cinco nervos intercostais e um nervo que percorre ao longo dos vasos sanguíneos (Himms-Hagen, 1989a).

Com técnicas refinadas de histoquímica de fluorescência, Wirsén \& Hamberger (1967) mostraram que praticamente todas as células adiposas marrons são envolvidas por uma rede delicada de terminais adrenérgicos. Este achado está de acordo com a afirmação de que a norepinefrina liberada pelos terminais simpáticos é o mais potente estimulador funcional do TAM, embora a sua atividade possa também ser regulada por hormônios, tais como insulina, glicocorticóides e hormônios tiroidianos (Himms-Hagen, 1989a).

A origem central dos nervos simpáticos do TAM é difusa e a via neuronal tem sido investigada por meio de estudos com vírus neurotrópicos retrógrados e anterógrados, 
úteis para a análise anatômica e funcional, respectivamente, dos núcleos e tratos suspeitos de participarem desta via (Cannon \& Nedergaard, 2004). Em uma análise temporal da infecção central de PRV (vírus pseudorabies) injetado no TAM e da imunorreatividade a cFos em ratos, Cano et al. (2003) demonstraram que os primeiros substratos neurais infectados ( 72 horas após a injeção) e ativados pela exposição ao frio ( 4 horas a $4{ }^{\circ} \mathrm{C}$ ) foram o núcleo paraventricular do hipotálamo (PVN) e a rafe pálida (RPa). Este resultado indica que o PVN (especialmente as porções dorsal e ventromedial) e a RPa enviam projeções diretas aos neurônios da coluna intermediolateral (IML) na medula espinal e daí para o TAM, sendo, portanto, importantes efetores da termogênese. $\mathrm{Na}$ análise realizada no tempo intermediário (78 a 84 horas após a injeção) foram marcados o PVN (anterior e posterior), a área retroquiasmática, a área hipotalâmica lateral, dentre outras áreas. Já a análise mais tardia (90 a 96 horas) revelou o envolvimento da área pré-óptica lateral e mediana (APO), PVN lateral, núcleo arqueado (Arc), núcleo dorsomedial do hipotálamo (DMH) e núcleo do trato solitário (NTS; Cano et al., 2003). Em outro estudo demonstrou-se que após 6 dias da injeção do vírus no TAM de hamsters, houve colocalização da infecção pelo PRV com neurônios que expressavam o RNAm do receptor-4 de melanocortina (MC4-R) em diversas áreas centrais, tais como o PVN ( 80\%), POA, Arc, DMH, ventromedial do hipotálamo (VMH), locus coeruleus (LC), RPa e NTS, inferindo, assim, a participação do sistema melanocortina na ativação do TAM. Neste mesmo trabalho, o agonista do MC4-R injetado no PVN aumentou a temperatura no TAM interscapular após 1, 2, 3 e 4 horas, ressaltando a importância do PVN na regulação central da termogênese (Song et al., 2008).

Portanto, a regulação central da termogênese do TAM pode ser efetuada por diferentes vias neurais provenientes de diferentes áreas centrais supracitadas, as quais podem ser ativadas diferencialmente de acordo com o estímulo inicial. De uma maneira 
geral há dois tipos de estímulos: a variação da temperatura corporal e alterações do balanço energético.

A variação da temperatura corporal desencadeia a função primária da termogênese que é a produção de calor para proteção térmica durante a exposição ao frio. Nessa via de regulação da temperatura merecem destaque as seguintes regiões: APO, DMH, RPa e IML (Morrison et al., 2008). Já as flutuações no estado energético podem ativar a função secundária da termogênese que é a combustão do excesso de energia adquirido. Nesse caso, a ativação de áreas hipotalâmicas sensíveis a nutrientes como o PVN e o NTS, principalmente neurônios MC4-R, participam da via de regulação metabólica da termogênese do TAM, e determinam a ingestão alimentar e o gasto energético (Ricquier, 2010; Blouet \& Schwartz, 2009).

Além da regulação central, outros fatores nutricionais e hormonais podem regular a atividade termogênica do TAM. Estudos clássicos de nosso laboratório mostraram que ratos alimentados com dieta rica em proteínas e livre de carboidratos apresentaram menor capacidade termogênica no TAM (Brito et al., 1992) e reduzida atividade simpática para o tecido (Brito et al., 1998). Além disso, estes animais apresentaram menor concentração plasmática de insulina (Brito et al., 1999), hormônio que estimula a utilização de carboidratos no TAM para a lipogênese e síntese de triacilglicerol (Himms-Hagen, 1989a).

Um fato interessante acerca do metabolismo do TAM é que o aumento da oxidação de ácidos graxos e da atividade termogênica desse tecido é acompanhado pelo aumento da lipogênese. Ratos alimentados com a dieta do tipo cafeteria, hipercalórica e rica em lipídeos, apresentaram aumento na concentração plasmática de insulina e alta capacidade termogênica associada ao aumento do conteúdo de UCP-1 e da atividade 
simpática do tecido. Esses animais também apresentaram maior quantidade de gordura devido, provavelmente, ao aumento da lipogênese (Chaves et al., 2008). Por outro lado, há redução da lipogênese em situações de reduzida atividade termogênica, como o jejum (Himms-Hagen, 1989a). Em outro estudo, Kawashita et al. (2002) observaram que rápidos ajustes da lipogênese do TAM necessitam da atividade simpática, e que o tecido consegue manter uma taxa de lipogênese, embora baixa (40\% menor), mesmo quando desnervado. Entretanto, a taxa de lipogênese não se manteve normal quando foi administrado soro antiinsulina tanto em animais inervados quanto em desnervados, mostrando a importância da insulina para a regulação metabólica no TAM.

Os glicocorticoides também agem no TAM. Há evidências de que o excesso de glicocorticoides causa supressão da termogênese do TAM e pode também induzir a atrofia do tecido. Como os glicocorticoides não afetam os $\beta$-adrenorreceptores diretamente no TAM, sugere-se que o efeito destes hormônios seja mediado pela redução da produção do CRH (hormônio liberador de corticotropina) no hipotálamo, culminando assim em perda do estímulo para a atividade do sistema nervoso simpático ao TAM (Himms-Hagen, 1989a).

Além da insulina e dos glicocorticóides, está bem estabelecido na literatura a importância funcional dos hormônios tireoidianos na regulação da termogênese facultativa. O TAM possui a enzima iodotironina $5^{\prime}$-deiodinase tipo 2 , que converte $T_{4}$ (hormônio secretado em maior quantidade pela glândula tireóide) em $T_{3}$, que é a forma ativa do hormônio. A concentração dessa enzima no tecido é controlada pela noradrenalina e pelo próprio $T_{3}$. Receptores nucleares para $T_{3}$ tornam-se virtualmente saturados com o hormônio em 4 horas de exposição ao frio (Leonard et al., 1983; Silva \& Larsen, 1983). O hormônio tiroidiano $T_{3}$ também é capaz de influenciar a resposta aguda termogênica do TAM e o início 
da resposta trófica. $\mathrm{OT}_{3}$ é essencial para sustentar a cascata de sinalização da noradrenalina para a ativação completa da termogênese, e ambos atuam de forma sinérgica estimulando a lipólise e a expressão de diferentes genes como, por exemplo, o da UCP-1 (Silva, 2006).

\section{3. $\quad$ Regulação da temperatura corporal}

Em mamíferos, a temperatura corporal interna é mantida em valores quase que constantes para permitir o funcionamento normal das células. Por essa razão, a alteração da temperatura ambiente pode desencadear mecanismos de regulação da temperatura para modular a troca de energia térmica entre o ambiente e o corpo e, então, garantir a homeostase térmica (Silva, 2006).

A temperatura é detectada por proteínas da família de canais iônicos de receptores de potencial transiente (TRPs). Os TRPs térmicos são ativados em diferentes limiares e são tipicamente expressos em neurônios sensoriais. O subtipo TRPV3 é sensível ao calor, por exemplo, e o TRPM8 ao frio. As informações térmicas da superfície da pele (receptores cutâneos), dos tecidos periféricos (receptores musculares), dos órgãos internos (receptores abdominais) e do eixo neural (receptores na medula espinal e no hipotálamo) são integradas em vários níveis, finalmente chegando ao hipotálamo, em especial à APO, considerada como a principal área controladora da regulação da temperatura em mamíferos (Sessler, 2009).

As respostas para a regulação da temperatura podem ser divididas em comportamentais e autonômicas. As defesas comportamentais são estimuladas por alterações tanto na temperatura da pele quanto na temperatura corporal interna, gerando ativação do sistema nervoso somatomotor para ações protetoras como, por exemplo, a 
mudança na postura corporal, busca de ambiente mais agradável e até formação de ninho (Nagashima, 2006; Sessler, 2009).

As defesas autonômicas contra o ganho de calor incluem o aumento da perda seca de calor pela vasodilatação periférica e da perda por evaporação com a sudorese. Já contra o frio há vasoconstrição periférica, piloereção e estímulo dos processos de termogênese por tremor e independente de tremor (Nagashima, 2006; Silva, 2006). Ambos os processos de defesa são controlados por áreas integrativas de regulação da temperatura localizadas no hipotálamo (Banet et al., 1978).

Em geral, todos os processos de termogênese implicam em aumento do gasto energético e podem ser classificados em dois principais grupos: termogênese obrigatória e termogênese facultativa. A termogênese obrigatória é composta pelos processos metabólicos necessários para a manutenção da vida. Assim, a termogênese obrigatória é resultante do efeito térmico da alimentação (ingestão, digestão, absorção e o subsequente estoque), e da utilização de energia para o crescimento, gravidez e lactação (Himms-Hagen, 1989a)

A termogênese facultativa acompanha processos metabólicos que são rapidamente iniciados e supressos pelo sistema nervoso central, dos quais fazem parte a termogênese induzida pelo exercício, a dependente de tremor e a independente de tremor. A termogênese induzida pelo exercício e a termogênese por tremor são mediadas por eferentes do sistema somatomotor ao músculo esquelético e estão sob controle voluntário e involuntário, respectivamente (Himms-Hagen, 1989a). 
A termogênese independente de tremor representa toda produção de calor facultativa que não envolve contração muscular. É desencadeada pela ativação de receptores cutâneos e hipotalâmicos via sistema nervoso simpático (Banet et al., 1978).

A rede de regulação da temperatura no sistema nervoso central pode estimular a termogênese facultativa em três tecidos: TAM, músculo esquelético e coração (Morrison et al., 2008). Em mamíferos, o TAM é considerado o principal local para a termogênese independente de tremor, responsável por, pelo menos, $60 \%$ deste processo de produção de calor (Cannon \& Nedergaard, 2004).

A termogênese no TAM (descrita no item 1.2) responde a dois principais estímulos que elevam o disparo dos nervos simpáticos ao tecido: temperatura e alimentação. O primeiro estímulo ocorre quando a temperatura ambiente está abaixo dos valores de termoneutralidade $\left(28{ }^{\circ} \mathrm{C}\right.$ em ratos, $23{ }^{\circ} \mathrm{C}$ em humanos). $\mathrm{O}$ segundo ocorre no estado alimentado (particularmente após o jejum), e na ingestão de alimentos palatáveis do tipo cafeteria (Himms-Hagen, 1989b; Silva, 2006).

Portanto, a termogênese no TAM é importante para o balanço térmico e, ao mesmo tempo, para o balaço energético, especialmente porque representa um fator de gasto de energia. A termogênese no TAM também pode modular a ingestão alimentar por meio da via de regulação da alimentação pela temperatura (thermoregulatory feeding), onde o aumento da temperatura corporal interna é reconhecido centralmente como sinal de alimentação e, assim, contribui no controle da quantidade de alimento ingerido (HimmsHagen, 1995). 


\section{4. $\quad$ Inibidores da ácido graxo sintase}

Os inibidores da enzima ácido graxo sintase, C75 (trans-4-carboxy-5-octyl-3methylenebutyrolactone) e cerulenina (2,3-epoxy-4-oxo-6-dodecadienoylamide), são apontados como drogas promissoras no combate à obesidade por reduzirem reversivelmente a ingestão alimentar e o peso corporal em camundongos sem toxicidade aparente (Loftus et al., 2000).

A administração central de C75, um composto sintético, aumentou a expressão de neuropeptídeos anorexígenos, CART e $\alpha M S H / P O M C$, e reduziu a expressão dos orexígenos, NPY e AgRP (proteína agouti-relacionada), no hipotálamo de camundongos (Shimokawa et al., 2002). Esses neuropeptídeos são expressos no Arc do hipotálamo, o qual envia projeções para outras regiões hipotalâmicas conhecidas por participarem da regulação do comportamento alimentar, como PVN, DMH, VMH e a área hipotalâmica lateral (Lane et al., 2005; Berthoud, 2002).

Os mecanismos de ação pelos quais o C75 altera a expressão dos neuropeptídeos hipotalâmicos ainda não estão bem esclarecidos. No entanto, propõe-se que o efeito anorexígeno do C75 seja resultado da modulação direta da droga sobre componentes metabólicos ou enzimáticos dos neurônios hipotalâmicos. O primeiro mecanismo proposto foi denominado "sinal malonil". De acordo com esta teoria, o acúmulo do substrato malonilCoA hipotalâmico, induzido pela inibição da enzima ácido graxo sintase pelo C75, mimetizaria o estado alimentado e com isso induziria a sensação de saciedade nos animais (Loftus et al., 2000; Hu et al., 2003). Devido à inibição da carnitina aciltransferase-1 (CAT-1) pelo malonil-CoA, acredita-se que o "sinal malonil" seja mediado pelo acúmulo citosólico de acil-CoA de cadeia longa, o qual ativa canais de potássio sensíveis a ATP e, assim, modula a 
ativação neuronal (Saggerson, 2008). O "sinal malonil" foi sugerido em estudos que utilizaram a administração central de TOFA (5-(tetradecyloxy)-2-furoic acid), um inibidor da acetil-CoA carboxilase, enzima que sintetiza malonil-CoA. Diferentes autores demonstraram que a administração prévia de TOFA, horas antes da injeção i.p. (intraperitoneal) ou i.c.v. (intracerebroventricular) de C75, reverteu parcialmente o efeito anorexígeno da droga, e reduziu as concentrações de malonil-CoA no hipotálamo (Loftus et al., 2000; Hu et al., 2003).

Outros estudos sugerem a existência de um derivado do C75 como mediador da resposta hipofágica. Demonstrou-se que, após administração i.c.v., ocorre a conversão do C75 em C75-CoA no hipotálamo, o qual inibe diretamente a CAT-1. Além disso, verificou-se que a pré-incubação de C75 não alterou a inibição da CAT-1 induzida pela incubação de C75CoA em fração mitocondrial de fungo com superexpressão de CAT-1 (Mera et al., 2009).

Em oposição à hipótese do "sinal malonil", experimentos de farmacocinética in vivo e in vitro demonstraram que o $\mathrm{C75}$, na concentração plasmática máxima alcançada após a administração i.p. de diferentes doses (10 e $30 \mathrm{mg} \cdot \mathrm{kg}^{-1}$ ), suprimiu a ingestão alimentar, mas não foi capaz de inibir a ácido graxo sintase hipotalâmica (Rohrbach et al., 2005). Além disso, a incubação de C75 com malonil-CoA aumentou a atividade da CAT-1 e a oxidação de palmitato em cultura da linhagem de células MCF-7 de câncer de mama humano. Resultados semelhantes foram encontrados em cultura primária de hepatócitos de rato e em cultura de adipócitos 3T3-L1, indicando que o C75 parece atuar como um agonista da CAT-1 (Thupari et al., 2002) e não como um inibidor como proposto pela teoria do "sinal malonil". Portanto, de acordo com estes autores, o mecanismo central que levaria à redução da ingestão alimentar pelo C75 seria a ativação da CAT-1, que por sua vez aumentaria a oxidação lipídica e as concentrações de ATP nos neurônios. Sabendo-se que todo aumento da razão ATP/AMP 
inibe a proteína quinase ativada por monofosfato de adenosina (AMPK), um membro da família quinase sensível à razão ATP/AMP, que por sua vez estimula a acetil-CoA carboxilase, cuja atividade eleva os níveis de malonil-CoA, novas teorias implicam a AMPK como possível mediadora do C75. A redução da ingestão alimentar via APMK foi correlacionada ao efeito hipofágico do C75 uma vez que a administração i.c.v. e i.p. da droga reduziu a fosforilação desta enzima e, assim, inibiu a sua atividade no hipotálamo de camundongos (Kim et al., 2004). Por outro lado, a administração i.c.v. de AICAR (5-aminoimidazole-4-carboxamide-1$\beta$-D-ribofuranoside), um composto que estimula a AMPK de forma similar ao AMP, reverteu o efeito do C75 sobre a fosforilação da AMPK e sobre o comportamento alimentar (Kim et al., 2004).

Além das hipóteses que levam em conta as alterações do metabolismo de lipídeos, há evidências de que o efeito hipofágico do C75 possa ser resultante de alterações do metabolismo de glicose cerebral. Por exemplo, verificou-se que a administração central da droga não reduziu a ingestão alimentar e nem o peso corporal em animais cetogênicos (alimentados com dieta pobre em carboidratos), e que a administração central de glutamina ou lactato, metabólitos que reduzem a necessidade para metabolizar glicose nos neurônios, atenuou o efeito do C75 sobre a ingestão alimentar (Wortman et al., 2003).

Kumar et al. (2002) mostraram que a supressão da ingestão alimentar, observada no primeiro dia após a administração intraperitoneal (i.p.) de C75 foi mais proeminente em camundongos obesos ob/ob (95\%) e induzidos por dieta (83\%) do que em camundongos magros (50\% a 60\%). Após administrações diárias, nos quatro dias subsequentes, somente os animais obesos mantiveram a ingestão alimentar reduzida, sendo esta redução de $90 \%$ e 44\%, respectivamente, nos grupos ob/ob e induzidos por dieta. Essas observações sugerem 
que o mecanismo de ação do C75 é mais complexo e pode envolver eventos adicionais à supressão da ingestão alimentar, como, por exemplo, o aumento do gasto energético (Kumar et al., 2002).

De fato, há evidências que o C75 também contribui para a perda de peso corporal por aumentar a oxidação de ácidos graxos periférica e o gasto energético total (Cha et al., 2005; Cha et al., 2004; Thupari et al., 2002; Thupari et al., 2004; Tu et al., 2005). O tratamento crônico com C75 (7 injeções i.p distribuídas em 12 dias) alterou a expressão de genes envolvidos no metabolismo de lipídeos favorecendo a oxidação de ácidos graxos no tecido adiposo branco em camundongos obesos induzidos por dieta (Tu et al., 2005). Após administração i.p. diária por 4 dias, o inibidor natural da ácido graxo sintase, cerulenina, aumentou a taxa metabólica (produção de calor) de camundongos magros e obesos ob/ob, e causou perda preferencial de massa adiposa, a qual foi fracamente relacionada com a ingestão alimentar (Makimura et al., 2001). Outros estudos mostram que a injeção i.c.v. de C75 aumentou a oxidação de ácidos graxos e a expressão da proteína desacopladora do tipo 3 (UCP-3) em músculo esquelético de camundongos magros e obesos (ob/ob). Tais efeitos periféricos da ação central do C75 parecem ser devido a um mecanismo de ativação simpática para o músculo esquelético, visto que os eventos ocorreram rapidamente, até 2 horas após a injeção de C75, e foram associados ao aumento de moléculas da sinalização $\beta$ adrenérgica, tais como o conteúdo de noradrenalina, AMPc e $\beta_{3}$-adrenorreceptores (Cha et al., 2005, 2006).

Tendo em vista as evidências da ativação simpática periférica induzida pela administração central do C75 e a importância do TAM na regulação do gasto energético, um tecido que recebe inervação simpática proveniente de áreas centrais (em especial o PVN), a 
hipótese desse trabalho foi que o C75, além de inibir a ingestão alimentar, pode também ativar a termogênese no TAM via transmissão simpática e, dessa forma, levar à perda de peso corporal. 


\section{Objetiver}




\section{Objetivos}

Este trabalho teve como objetivo principal investigar a importância da atividade termogênica do tecido adiposo marrom (TAM) interscapular nos efeitos induzidos pela administração i.c.v. de C75 em ratos com privação alimentar de 24 horas.

Os objetivos específicos abordados no desenvolvimento deste trabalho foram os seguintes:

2.1. Investigar o efeito do C75 na ingestão (alimentar e hídrica) e no ganho de peso corporal.

2.2. Avaliar o efeito da desnervação simpática do TAM no efeito anorético e na perda de peso corporal induzida pelo C75.

2.3. Quantificar as concentrações plasmáticas de metabólitos (glicose e ácidos graxos livres) e hormônios (insulina, tiroxina total e corticosterona) relacionados com a regulação do balanço energético em animais tratados com C75.

2.4. Avaliar a ativação simpática induzida pelo C75 por meio da quantificação das catecolaminas no plasma e no TAM.

2.5. Avaliar o efeito do C75 na temperatura corporal interna, na atividade locomotora espontânea e na temperatura da pele da cauda.

2.6. Avaliar o efeito da desnervação simpática do TAM no efeito térmico induzido pelo $\mathrm{C} 75$.

2.7. Verificar o efeito do C75 na termogênese do TAM, por meio da medida da temperatura do tecido, da análise da atividade enzimática de enzimas oxidativas (citrato sintase e citocromo c oxidase), da expressão gênica da UCP-1 e do conteúdo de gordura total. 
2.8. Avaliar o efeito da desnervação simpática do TAM na indução da termogênese induzida pelo C75 e no aumento da temperatura corporal e do TAM induzido pela cerulenina.

2.9. Analisar as áreas centrais ativadas pelo C75 por meio da contagem de núcleos com imunorreatividade positiva à proteína c-Fos em neurônios de regiões hipotalâmicas (APO, PVN, RCA, DMH, VMH e Arc) e do tronco encefálico (LC, RPa e NTS). 
Thaterial a Thétodos 


\section{Material e Métodos}

\subsection{Animais}

Foram utilizados ratos machos Wistar, com peso entre 200 e $240 \mathrm{~g}$, provenientes do Biotério Central da Faculdade de Medicina de Ribeirão Preto (FMRP) - USP. Os animais foram mantidos no Biotério do Departamento de Fisiologia, recebendo dieta balanceada (NUVLAB CR1 - NUVITAL; 22\% proteína, 55\% carboidrato e 4,5\% lipídeo) para roedores e água ad libitum em ambiente com ciclos claro-escuro de 12 horas e temperatura controlada de $25{ }^{\circ} \mathrm{C}$. Todos os animais permaneceram nestas condições ambientais por pelo menos 48 horas antes de qualquer procedimento. Os procedimentos experimentais foram previamente aprovados pelo Comitê de Ética em Experimentação Animal (CETEA) da FMRP/USP (protocolo $\left.n^{\circ} 157 / 2008\right)$.

\subsection{Protocolos Experimentais}

3.2.1. Investigação da ingestão (alimentar e hídrica) e ganho de peso corporal em animais inervados e desnervados.

Neste protocolo, os animais foram mantidos individualmente em gaiolas metabólicas, incluindo-se os seguintes grupos:

a) grupo controle: os animais deste grupo receberam 50 gramas de ração e água ad libitum após a microinjeção do veículo (meio RMPI 1640);

b) grupo C75/cerulenina: os animais deste grupo receberam 50 gramas de ração e água ad libitum após a microinjeção de C75 ou cerulenina; 
c) grupo C75/cerulenina desnervado: os animais deste grupo receberam 50 gramas de ração e água ad libitum após a microinjeção de C75 ou cerulenina.

Os procedimentos cirúrgicos foram realizados e, após a recuperação (4 dias), os animais foram mantidos em gaiolas metabólicas individuais com livre acesso à ração e água por um período de 48 horas de adaptação antes do experimento. Em seguida, os animais foram mantidos em jejum por 24 horas. No dia seguinte, imediatamente após a microinjeção das drogas ou veículo (entre 8 e 9 horas da manhã), a dieta foi reapresentada e a ingestão alimentar foi registrada no período de 1, 3, 12 e 24, 48 e 72 horas após a realimentação. A ingestão hídrica e o peso corporal foram registrados 24, 48 e 72 horas após a realimentação.

\subsubsection{Avaliação das concentrações plasmáticas de metabólitos (glicose e ácidos graxos}

livres) em animais acordados.

Os animais foram mantidos em caixas individuais, foram feitos os seguintes grupos:

a) grupo controle: os animais deste grupo, previamente canulados na veia jugular, foram mantidos em jejum de 24 horas e foram microinjetados com o veículo (meio RMPI 1640);

b) grupo C75: os animais deste grupo, previamente canulados na veia jugular, foram mantidos em jejum de 24 horas e foram microinjetados com C75.

Antes e após a microinjeção do C75 ou veículo (entre 8 e 9 horas da manhã), foram realizadas coletas seriadas de sangue $(0,15,30,45,60,120$ e $180 \mathrm{~min})$ para a dosagem plasmática da glicose e dos ácidos graxos livres. 


\subsubsection{Avaliação das concentrações plasmáticas de hormônios e de marcadores da}

atividade simpática e da termogênese em animais inervados e desnervados.

Para este protocolo, foram utilizados 3 grupos de animais mantidos em jejum por 24 horas: controle, C75 e C75 desnervado. No dia do experimento, após 1 e 4 horas da microinjeção, os animais foram sacrificados por decapitação para a coleta do sangue e remoção do TAM. O plasma foi separado e utilizado para a dosagem de insulina, corticosterona, tiroxina total $\left(T_{4}\right)$, adrenalina e noradrenalina, enquanto que o TAM foi removido para a quantificação do conteúdo de noradrenalina, gordura total, atividades enzimáticas (citrato sintase e citocromo c-oxidase) e RNAm da UCP-1.

\subsubsection{Análise da temperatura corporal interna, do TAM, da pele da cauda e da atividade} locomotora.

Os mesmos grupos experimentais do protocolo descrito no item 3.2.1 foram incluídos e mantidos em jejum por 24 horas em caixas individuais. No dia do experimento, imediatamente após a microinjeção das drogas ou veículo, procedeu-se a análise da temperatura interna e atividade locomotora por 24 horas. Grupos de animais separados foram utilizados para a avaliação da temperatura do TAM e da pele da cauda, os quais foram estudados durante 8 e 4 horas, respectivamente. Durante todos os períodos de registro, os animais permaneceram sem acesso ao alimento.

\subsubsection{Análise das áreas centrais ativadas pelo C75.}

Para este protocolo, foram utilizados 2 grupos de animais jejuados por 24 horas: controle e C75. No dia do experimento, após 90 min da microinjeção, os animais foram 
anestesiados e, em seguida perfundidos, para posterior contagem de núcleos com imunorreatividade positiva à proteína c-Fos em neurônios de regiões hipotalâmicas (APO, PVN, DMH, VMH e Arc) e do tronco encefálico (LC, RPa e NTS).

\subsection{Procedimentos Cirúrgicos e de Registro}

\subsubsection{Desnervação simpática bilateral do TAM}

Sete dias antes do experimento, os animais foram anestesiados com xilazina $2 \%$ e cetamina $10 \%\left(3,5: 5 ; 1,0 \mathrm{~mL} . \mathrm{kg}^{-1}\right.$, i.p.) e, após assepsia, foi feita uma pequena incisão (cerca de $1 \mathrm{~cm}$ ) na região interscapular dos animais. Com a localização dos nervos simpáticos que chegam ao TAM, estes foram pinçados para a retirada de 2 a $3 \mathrm{~mm}$ de cada nervo. Depois de ser feita a desnervação nos dois lados do TAM, a pele foi suturada e limpa com álcool 70\% iodado $1 \%$.

\subsubsection{Cirurgia estereotáxica e microinjeção intracerebroventricular (i.c.v.).}

Seis dias antes do experimento, os animais foram anestesiados com xilazina $2 \%$ e cetamina $10 \%\left(3,5: 5 ; 1,0 \mathrm{~mL} . \mathrm{kg}^{-1}\right.$, i.p.) e fixados a um aparelho estereotáxico (David-Kopff). A cânula-guia $(10 \mathrm{~mm})$ foi dirigida ao ventrículo lateral com coordenadas adaptadas (ânteroposterior: $-1.5 \mathrm{~mm}$ do bregma, dorso-ventral $-3.4 \mathrm{~mm}$ da superfície do crânio e mediallateral $+2.5 \mathrm{~mm}$ ) àquelas pré-estabelecidas pelo Atlas de Paxinos \& Watson (1982), fixada ao osso com cimento acrílico e um mandril foi inserido em seu interior para prevenir obstrução. Foi administrado pentabiótico veterinário $48.000 \mathrm{U}$ via intramuscular $\left(0,5 \mathrm{~mL} \cdot \mathrm{kg}^{-1}\right)$. No dia do experimento, foi realizada a microinjeção i.c.v. dos inibidores da ácido graxo sintase (150 
$\mu \mathrm{g}$ de $\mathrm{C} 75$ ou cerulenina dissolvidos em $7,5 \mu \mathrm{L}$ de meio RPMI) ou RPMI aos controles, a qual foi feita por meio de uma seringa Hamilton de $50 \mu \mathrm{L}$ conectada à cânula-guia, na velocidade de $2 \mu$ L.minuto ${ }^{-1}$.

3.3.3. Implante do sensor para registro da temperatura interna e da atividade $\underline{\text { locomotora dos animais }}$

Os animais foram anestesiados com xilazina $2 \%$ e cetamina $10 \%\left(3,5: 5 ; 1,0 \mathrm{~mL} . \mathrm{kg}^{-1}\right.$, i.p.) e, imediatamente antes da cirurgia estereotáxica, foram submetidos à assepsia e incisão de aproximadamente $2 \mathrm{~cm}$ da pele da região ventral, seguida de outra incisão na linha alba do músculo reto abdominal, possibilitando o acesso à cavidade peritoneal. Após a inserção do sensor E-mitter, o qual foi preso ao músculo abdominal por um ponto, a musculatura abdominal e a pele do animal foram suturados, e a pele limpa com álcool $70 \%$ iodado $1 \%$.

\subsubsection{Implante do sensor para obtenção da temperatura no TAM}

Os animais foram anestesiados com xilazina $2 \%$ e cetamina $10 \%\left(3,5: 5 ; 1,0 \mathrm{~mL} . \mathrm{kg}^{-1}\right.$, i.p.) e, imediatamente antes da cirurgia estereotáxica, foi feita a assepsia e uma pequena incisão (cerca de $1 \mathrm{~cm}$ ) na região interscapular dos animais. O TAM foi divulsionado na região central no sentido ântero-posterior para inserção do sensor, o qual foi preso na musculatura subjacente por um ponto. A pele foi suturada e limpa com álcool $70 \%$ iodado $1 \%$. 


\subsubsection{Registro da temperatura corporal interna e da atividade locomotora}

Para o registro da temperatura corporal interna e a atividade locomotora por telemetria, foram utilizados sensores de temperatura e locomoção (Mini-Mitter, Sunriver, OR, modelo PDT-4000 E-Mitter). O sensor para registro de temperatura interna e atividade locomotora, inserido intraperitonealmente, é um capacitor oscilatório de resistência simples cujo valor é dependente de temperatura. A frequência de saída dos pulsos digitais provenientes dos sensores está entre $297-713 \mathrm{kHz}$. Os pulsos foram captados por uma placa receptora AM (modelo ER-4000 Energizer/Receiver, Mini Mitter Co.) posicionada sob a caixa que acondiciona o animal, e enviados para um decodificador. Mudanças na intensidade (movimento vertical) e no ponto de recepção dos pulsos na placa (movimento horizontal) também são captadas e enviadas ao decodificador, refletindo a atividade locomotora espontânea. As informações foram repassadas para um software (Vital View, Mini Mitter), onde os dados foram armazenados e processados. Os registros foram feitos de 5 em 5 segundos durante 20 horas (C75) ou 8 horas (cerulenina), com a temperatura ambiente mantida a $23^{\circ} \mathrm{C}$.

Depois de cerca de 30 minutos para estabilização e registro dos valores basais, foi feita a microinjeção de RPMI, C75 ou de cerulenina (150 $\mu \mathrm{g}$ ) cuidadosamente sem tocar no animal para minimizar o estresse e o aumento da temperatura por manipulação.

\subsubsection{Registro da temperatura no TAM}

Para verificar a temperatura no TAM, foi utilizado o sistema de aquisição de dados Bio Medic Data System DAS-6002 por meio de frequências de rádio emitidas pelos sensores (IPTT-3000, BMDS Co.), sem bateria, com cerca de $1 \mathrm{~cm}$ de comprimento, implantados sob o 
TAM dos animais. Tais frequências são lidas pela sonda receptora (SP-6005) móvel e a identificação e a temperatura do sensor lidas aparecem no monitor do DAS-6002 na unidade grau Celsius $\left({ }^{\circ} \mathrm{C}\right)$. A mobilidade da sonda receptora permitiu que os animais fossem mantidos em caixas individuais sem a necessidade de manipulação para leitura da temperatura, a qual foi realizada antes ( 2 tomadas de leitura para o basal) e a cada 20 minutos após a microinjeção de RPMI, C75 ou cerulenina i.c.v. até 8 horas da administração.

\subsubsection{Registro da temperatura da pele da cauda}

A temperatura da cauda foi mensurada na superfície lateral da pele a cerca de $2 \mathrm{~cm}$ da base da cauda (Young \& Dawson, 1982) a cada 5 minutos por meio de termômetro clínico (modelo AG2000, Braile Biomédica, São Paulo, BR) durante 4 horas após a injeção i.c.v. de RPMI ou C75.

\subsection{Procedimentos Laboratoriais}

\subsubsection{Determinação das concentrações plasmáticas de glicose e ácidos graxos livres em} $\underline{\text { ratos acordados }}$

Na manhã do dia anterior ao experimento, um cateter de silicone foi implantado na veia jugular direita de animais anestesiados com xilazina $2 \%$ e cetamina $10 \%(3,5: 5 ; 1,0$ $\mathrm{mL} . \mathrm{kg}^{-1}$, i.p.). No dia do experimento, amostras de sangue foram coletadas e o volume $(0,08$ $\mathrm{mL}$ ) reposto por salina 0,9\% imediatamente antes (tempo 0) e 15, 30, 45, 60, 120 e 180 minutos após a administração i.c.v. de RPMI ou C75. O plasma obtido foi utilizado para determinar a concentração de glicose por método enzimático colorimético de kit comercial 
da Labtest (Lagoa Santa, BR), e o soro foi utilizado para determinar a concentração de ácidos graxos livres por método enzimático colorimétrico de kit comercial da Randox (Crumlin, UK).

\subsubsection{Determinação da concentração de insulina plasmática}

Para este procedimento, o sangue foi coletado em tubos heparinizados. Após centrifugação sob refrigeração a $4{ }^{\circ} \mathrm{C}$, o plasma foi armazenado a $-80{ }^{\circ} \mathrm{C}$. Amostras de plasma (10 $\mu \mathrm{L})$ foram utilizadas para detecção da insulina por método de ELISA sanduiche pelo kit comercial de ensaio para insulina de rato/camundongo (EXRMI-13K) da Millipore (St. Charles, USA). A leitura foi realizada em leitora de placas Brotek Power Wave X52 (Winooski, USA) a 450 e $590 \mathrm{~nm}$.

\subsubsection{Determinação da concentração de corticosterona plasmática}

O sangue coletado em tubos heparinizados foi centrifugado sob refrigeração a $4{ }^{\circ} \mathrm{C}$ para obtenção do plasma, o qual foi armazenado a $-80{ }^{\circ} \mathrm{C}$. As amostras de plasma $(25 \mu \mathrm{L})$ foram utilizadas para extração da corticosterona em etanol gelado. Após centrifugação (2500 rpm, 15 minutos), o sobrenadante foi liofilizado para ser ressuspendido em tampão gel e utilizado para a determinação da corticosterona segundo o método de radioimunoensaio descrito por Elias et al. (2002). Para tanto, foi adicionado o anticorpo primário e, em seguida, o hormônio marcado (trício). Após 15 horas, carvão ativado foi utilizado para separação (sequestro de hormônios livres) por centrifugação (2500 rpm, 10 minutos), e o sobrenadante foi transferido para tubos contendo coquetel de cintilação para obtenção da concentração da corticosterona por meio de cálculo baseado na contagem da radiação $\beta$ emitida pelo trício em leitor de cintilação (modelo TRY CARB 2100 TR) da Packard (Boston, USA). 


\subsubsection{Determinação da concentração de tiroxina total $\left(T_{4}\right)_{\text {plasmática }}$}

Após centrifugação sob refrigeração a $4{ }^{\circ} \mathrm{C}$ do sangue coletado em tubos heparinizados, o plasma foi armazenado a $-80{ }^{\circ} \mathrm{C}$. Amostras de plasma (15 $\mu \mathrm{L}$ ) foram utilizadas para detecção da tiroxina total $\left(T_{4}\right)$ por método de imunoensaio competitivo quimiluminescente de fase sólida pelo kit comercial de ensaio para $T_{4}$ total (PIL2KT4-21, 2008) da Siemens Healthcare Diagnostics (Llanberis, UK) analisado no sistema IMMULITE $2000^{\circledR}$ (Siemens Healthcare Diagnostics, UK).

\subsubsection{Determinação das catecolaminas no plasma e no TAM}

Para a quantificação das concentrações plasmáticas de adrenalina e noradrenalina, os animais foram sacrificados por decapitação após 1 ou 4 horas da administração i.c.v. de RPMI ou C75 e o sangue coletado em tubos heparinizados. Após centrifugação sob refrigeração a $4{ }^{\circ} \mathrm{C}$, alíquotas de $500 \mu \mathrm{L}$ de plasma foram transferidas para tubos de plástico contendo $50 \mathrm{mg}$ de metabissulfito de sódio (antioxidante), tampão Tris- $\mathrm{HCl} 2 \mathrm{M}(\mathrm{pH} 8,9)$ com 0,5\% de metabissulfito de sódio e $2,5 \%$ de EDTA e $50 \mathrm{mg}$ de alumina previamente ativada em estufa a $100{ }^{\circ} \mathrm{C}$, por meia hora. Diidroxibenzilamina foi utilizada como padrão interno. As amostras foram agitadas durante 20 minutos, centrifugadas e após aspiração do sobrenadante a alumina foi lavada repetidamente. As catecolaminas foram extraídas da alumina pela adição de solução eluidora contendo ácido perclórico 0,1 N, sob agitação de 10 minutos (Krstulovic, 1982). Alíquotas de $50 \mu \mathrm{L}$ das amostras assim obtidas foram analisadas através de cromatografia líquida de alta performance (HPLC) em um cromatógrafo modelo LC-7A, equipado com uma coluna de fase reversa Spherisorb ODS II (Sigma-Aldrich), 
acoplado a um detector eletroquímico modelo L-ESD-6A e a um polígrafo modelo C-R5A, todos da marca Shimadzu.

Para a determinação do conteúdo de noradrenalina no TAM, o tecido foi rapidamente retirado, congelado em nitrogênio líquido e mantido sob refrigeração $a-80{ }^{\circ} \mathrm{C}$, para posterior análise. Posteriormente, o tecido foi homogeneizado em ácido perclórico $0,2 \mathrm{~N}$, contendo metabissulfito de sódio $1 \%$ e EDTA $1 \mathrm{mM}$. O homogeneizado foi centrifugado sob refrigeração a $10000 \mathrm{rpm}$, durante 10 minutos. O sobrenadante foi então processado e analisado como descrito anteriormente (Garófalo et al., 1996)

\subsubsection{Atividade enzimática da citocromo c oxidase mitocondrial}

Após remoção do TAM de animais sacrificados por decapitação após 1 hora da administração i.c.v. de RPMI ou C75, o tecido foi cuidadosamente dissecado em placa de Petri sob gelo. As mitocôndrias do tecido foram isoladas de acordo com a técnica de Cannon \& Lindberg (1979) e suspendidas em 0,25 M de sacarose à concentração protéica final de $100 \mu \mathrm{g} \cdot \mathrm{mL}^{-1}$. A proteína mitocondrial foi determinada pelo método de Lowry et al. (1951), com soro bovino como o padrão. A atividade da citocromo c oxidase [EC 1.9.3.1.] foi determinada por kit de ensaio colorimétrico (Sigma-Aldrich) baseado na redução da absorbância a $550 \mathrm{~nm}$ do ferrocitocromo c causada por sua oxidação pela atividade da citocromo c oxidase da amostra. 


\subsubsection{Atividade enzimática da citrato sintase}

Após homogeneização do TAM, removido do animal 1h após administração i.c.v. de RPMI ou C75 em solução de extração (Tris-HCl 50 mM, EDTA 1 mM; pH 7,4) na proporção de 1:10 (p/v), as amostras foram centrifugadas a $10.000 \mathrm{rpm}$ por 30 segundos a $4{ }^{\circ} \mathrm{C}$, e o sobrenadante diluído 5x com a solução de extração. Para o ensaio enzimático, segundo Srere et al. (1963), foram adicionados diretamente na cubeta do espectrofotômetro $15 \mu \mathrm{L}$ da amostra diluída em $935 \mu \mathrm{L}$ de mistura de ensaio, composta por solução de ensaio (Tris-Base $100 \mathrm{mM}$, DTNB 0,2 mM; pH 8,1), Acetil CoA $\left(0,1 \mathrm{mg} \cdot \mathrm{mL}^{-1}\right)$ e Triton a 0,1\%. Seguidos 3 minutos para estabilização, foram adicionados $50 \mu \mathrm{L}$ do substrato da reação (oxaloacetato 1,32 mg. $\mathrm{mL}^{-1}$ ) e as leituras foram realizadas ao longo de 10 minutos após adição do substrato a $412 \mathrm{~nm}$. A proteína do extrato foi determinada pelo método de Lowry et al. (1951), com soro bovino como o padrão.

\subsubsection{Conteúdo de gordura total do TAM}

Após remoção do TAM de animais sacrificados por decapitação após 1 hora da administração i.c.v. de RPMI ou C75, o tecido foi cuidadosamente dissecado em placa de Petri sob gelo, pesado e homogeneizado em $10 \mathrm{~mL}$ de clorofórmio-metanol (2:1) para a extração das gorduras segundo método de Folch et al. (1957). Finalmente, a quantificação da gordura total do TAM foi realizada por método gravimétrico. 


\subsubsection{RT-PCR em tempo real}

O TAM foi rapidamente removido de animais sacrificados por decapitação após 1 e 4 horas da administração i.c.v. de RPMI ou C75, pesado e estocado a $-80{ }^{\circ} \mathrm{C}$. O RNA total foi subsequentemente extraído de cada tecido individualmente usando TRIzol (Invitrogen ${ }^{\circledR}$, Carlsbad, CA). A transcrição reversa para cDNA foi feita em $2 \mu \mathrm{g}$ do RNA celular total, utilizando $20 \mathrm{pmol}$ de oligo(dT) primer (Invitrogen ${ }^{\circledR}$ ) e a transcriptase reversa Advantage ImProm-II (Promega ${ }^{\circledR}$, Madison, WI). A PCR em tempo real foi realizada no sistema de detecção de sequência $A B I 7000$ (Applied Biosystems ${ }^{\circledR}$, Foster, CA), utilizando o kit de uma etapa para RT-qPCR SuperScript III Platinum SYBR Green com ROX (Invitrogen ${ }^{\circledR}$ ), e primers dos genes de Rattus novergicus para ucp-1 (forward 5'- CCGGTGGATGTGGTAAAAAC-3' e reverse 5'-ATCCGAGTCGCAGAAAAGAA-3') e $\beta$-actin (forward 5'-TTGCTGACAGGATGCAGAAG3' e reverse 5'-CAGTGAGGCCAGGATAGAGC-3').

A quantificação relativa dos níveis de RNAm foi plotada como vezes de aumento comparado com os valores do grupo controle. Os transcritos foram normalizados aos níveis de $\beta$-actina. O nível dos transcritos-alvo foi calculado pelo método da curva-padrão (Cikos et al., 2007).

\subsubsection{Imunohistoquímica para a proteína c-Fos}

Após 90 minutos da injeção i.c.v. de RPMI ou C75, os animais foram anestesiados com tribromoetanol 2,5\% (1 mL.100 g $\mathrm{g}^{-1}$ de peso corporal) e, após o desaparecimento dos reflexos raqui-medulares, foram submetidos à perfusão do sistema nervoso central. No momento da perfusão foi palpada a região terminal do esterno onde então foi realizado um 
corte na pele e na musculatura subjacente do abdome. As regiões laterais das costelas foram seccionadas, visualizando-se o coração, que foi isolado das estruturas adjacentes, rebatendo-se o timo a fim de visualizar o ápice cardíaco e a saída do arco aórtico. A aorta torácica descendente foi visualizada e ocluída antes de sua passagem pelo hiato da aorta no diafragma. Levantando-se o coração, foi realizado um corte no ápice do ventrículo esquerdo, sendo a seguir, introduzida uma agulha romba até a saída da aorta. Um corte foi realizado no átrio direito para permitir a saída do sangue e do líquido após a perfusão cerebral. A perfusão foi realizada primeiramente com a infusão de $200 \mathrm{~mL}$ de solução salina isotônica estéril ( $\mathrm{NaCl}$ 0,9\%) com heparina (diluição 1:80), seguida pela infusão de $400 \mathrm{~mL}$ de formoldeído $4 \%$. Neste procedimento foi utilizada uma bomba peristáltica com velocidade de infusão de $15 \mathrm{~mL}$.minuto ${ }^{-1}$. O tecido foi colocado em um tubo contendo $30 \mathrm{~mL}$ de formoaldeído $4 \%$ e mantido na geladeira $\left(4^{\circ} \mathrm{C}\right)$ por 1 hora, quando foi realizada a troca para solução de sacarose $30 \%$. O tecido cerebral foi mantido nesta solução de sacarose até a realização dos cortes histológicos em criostato.

Para realização da imunohistoquímica, os tecidos cerebrais foram seccionados em cortes de $30 \mu \mathrm{m}$ de espessura utilizando-se um criostato. Imediatamente após, foi realizado o bloqueio da peroxidase endógena com solução $\mathrm{H}_{2} \mathrm{O}_{2}(0,3 \%)$ e também o bloqueio das ligações inespecíficas utilizando-se soro normal da espécie apropriada. Posteriormente, para visualização da expressão de c-Fos, os cortes foram incubados em temperatura ambiente por 12-14 horas com o anticorpo primário anti-Fos (Ab-5, Oncogene 1:10000) e a seguir, incubados com o segundo anticorpo biotinilado (1:200) por um período de 1 hora. Para a coloração, foi utilizado o complexo avidina-biotina-peroxidase (Vectastain), empregando diaminobenzidina (DAB) e cloreto de níquel como cromógenos, cuja reação conferiu ao núcleo das células neuronais uma coloração de violeta escuro a preto. 
A contagem para c-Fos foi feita com o auxílio de um sistema de imagem acoplado ao microscópio (Leica 4500B) em uma área fixa pré-determinada de cada região para todos os animais. A delimitação das áreas (APO, PVNmp, PVNpp, RCA, DMH, VMH, Arc, LC, RPa e NTS) foi realizada com base nas coordenadas descritas por Paxinos e Watson (1997). A APO foi analisada a -0,80 mm do bregma, já as porções parvocelular medial (PVNmp) e parvocelular posterior (PVNpp) do PVN foram estudadas nas coordenadas -1,8 e -2,12 mm em relação ao bregma, respectivamente. O núcleo retroquiasmático (RCA) teve como coordenada $-2,0 \mathrm{~mm}$ do bregma. O $\mathrm{DMH}$, o $\mathrm{VMH}$ e o Arc foram considerados de $-2,2$ a 3,3 $\mathrm{mm}$ do bregma. As coordenadas para contagem de núcleos dos neurônios do LC, da RPa e do NTS foram, respectivamente, a $-9,5 \mathrm{~mm}$, a $-13,3 \mathrm{~mm}$ e a $-13,7 \mathrm{~mm}$ do bregma.

\subsubsection{Localização da cânula}

Imediatamente após o sacrifício, foi microinjetado o corante azul de Evans por meio da cânula ainda fixada na cabeça do animal, a qual foi removida logo depois para retirada do cérebro, o qual foi mantido imerso em solução de formalina $10 \%$ para enrijecer o tecido, procedimento que permitiu a sua divisão em fatias e a visualização do corante no $3^{\circ}$ dia de imersão. A localização do corante no ventrículo lateral confirma o acerto da cânula.

\subsection{Análise estatística}

Os dados obtidos apresentaram homogeneidade das variâncias (analisada pelos testes de Levene e Brown-Forsythe) e distribuição normal (testes de Lilliefors e ShapiroWilk). Nestas condições, tratamentos estatísticos paramétricos para amostras independentes foram os mais adequados. Para comparações de dois grupos, foi utilizado o 
teste $t$ de Student. Para comparações múltiplas foram realizados os testes One-Way ANOVA seguido por teste de Newman-Keuls ou Two-Way ANOVA seguido por teste de Bonferroni. Os programas Statistica 6.0 e Graph Pad Prism 4.0 foram utilizados para aplicação dos testes estatísticos. O nível de significância adotado foi $\mathrm{P}<0,05$. 
Resultador 


\section{Resultados}

\subsection{Efeito do C75 na ingestão (alimentar e hídrica) e ganho de peso corporal em animais inervados e desnervados.}

O C75 induziu um forte efeito anorexígeno já nas primeiras horas após a administração (Figura 1), com redução na ingestão alimentar de $85 \%$ no intervalo de 1-3 horas e de $94 \%$ no intervalo de 3-12 horas. A Figura 2 mostra que a administração de C75 reduziu a ingestão alimentar de 24 horas em cerca de $80 \%$ (3,0 $\pm 1,3$ g.100 $\mathrm{g}^{-1}$ peso corporal vs. $18,2 \pm 1,9$ g.100 $\mathrm{g}^{-1}$ peso corporal). Observa-se também que a desnervação simpática do TAM atenuou em 34\% o efeito anorexígeno do $\mathrm{C} 75\left(9,8 \pm 1,5 \mathrm{~g} .100 \mathrm{~g}^{-1}\right.$ peso corporal), ou seja, neste grupo, o C75 provocou redução da ingestão alimentar de 24 horas de apenas $46 \%$ no primeiro dia. Embora o efeito anorexígeno do C75 tenha sido robusto nas primeiras 24 horas, a ingestão alimentar nos demais dias estudados foi restabelecida aos valores do controle $\left(15,9 \pm 1,6\right.$ g.100 $\mathrm{g}^{-1}$ peso corporal no segundo dia e $14,0 \pm 1,1 \mathrm{~g} .100 \mathrm{~g}^{-1}$ peso corporal no terceiro dia) tanto no grupo $\mathrm{C} 75\left(13,3 \pm 2,0\right.$ g.100 $\mathrm{g}^{-1}$ peso corporal e $14,3 \pm 2,2$ g.100 $\mathrm{g}^{-1}$ peso corporal) quanto no grupo $\mathrm{C} 75$ desnervado $\left(14,0 \pm 0,7 \mathrm{~g} .100 \mathrm{~g}^{-1}\right.$ peso corporal e $14,7 \pm 1,6$ g. $100 \mathrm{~g}^{-1}$ peso corporal; Figura 2).

Não houve alteração no consumo diário de água em nenhum dos grupos estudados ao longo dos 3 dias, após a administração da droga ou do veículo (Figura 3). 


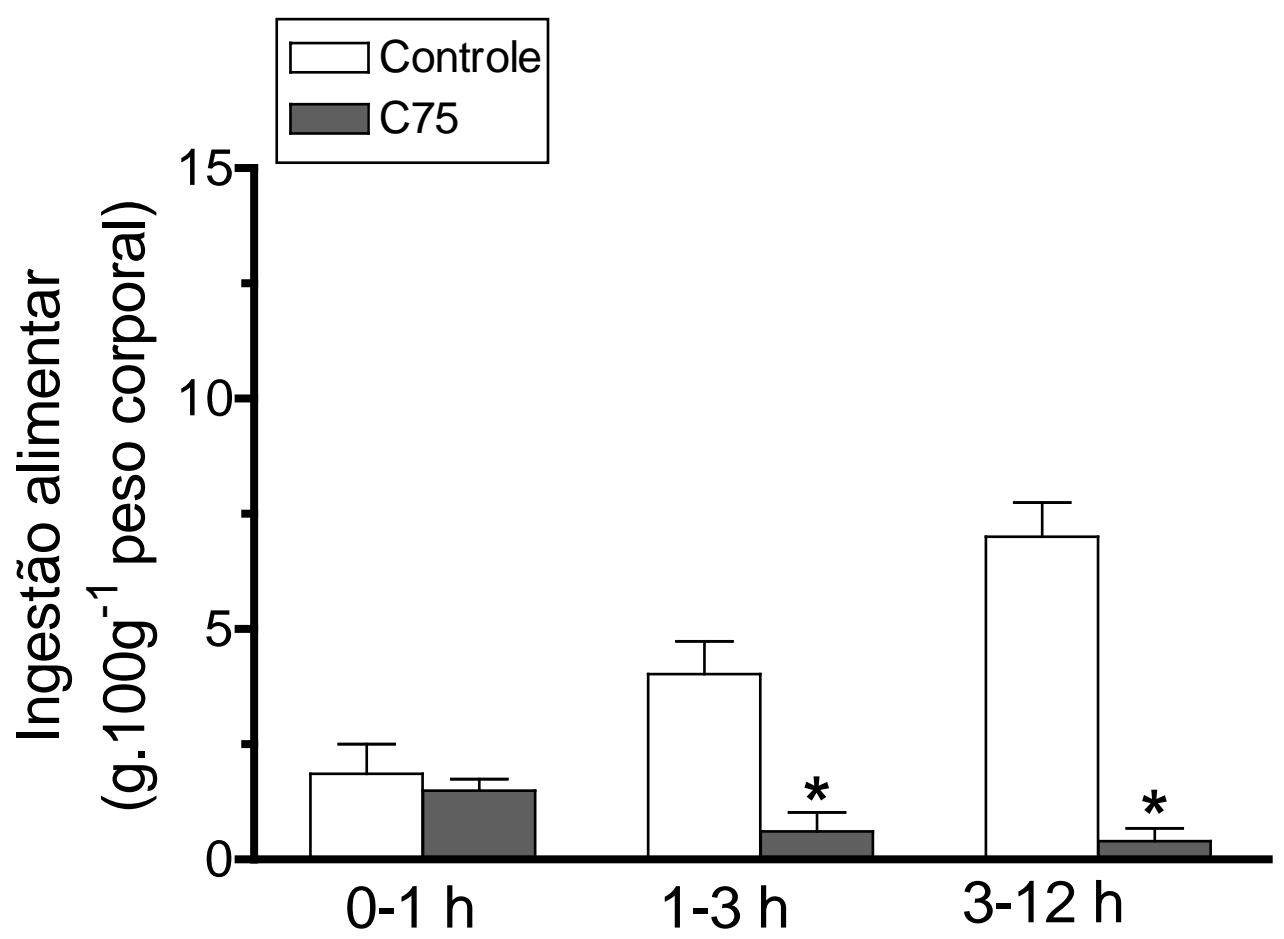

Figura 1 - Ingestão alimentar nos intervalos 0-1 hora, 1-3 horas e 3-12 horas após a administração i.c.v. de C75 ou RPMI. Os valores representam a média \pm EPM ( $n=4-7)$. $O$ teste utilizado foi $t$ de Student para amostras não-pareadas. ${ }^{*} \mathrm{P}<0,05$ em relação ao controle. 


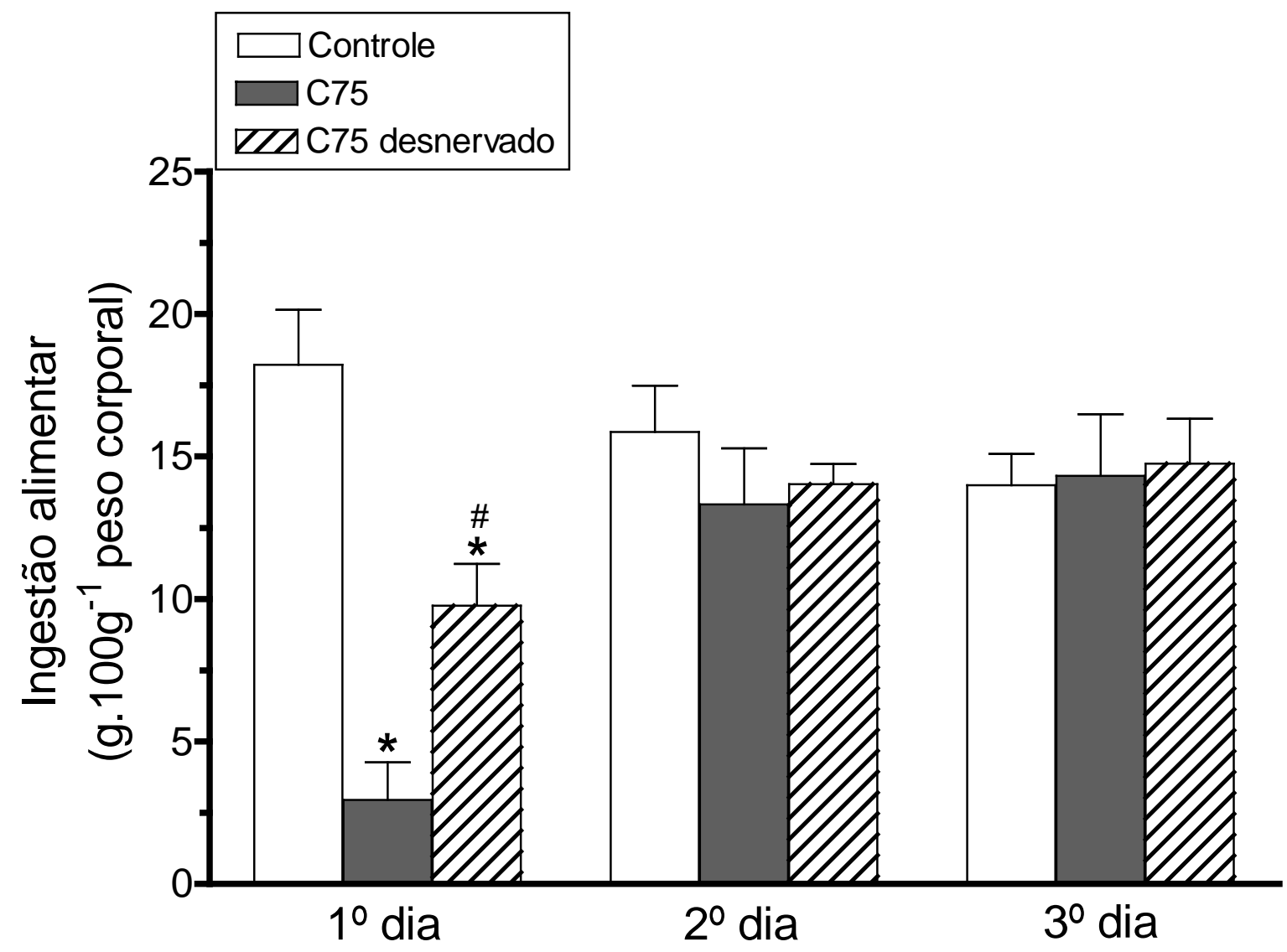

Figura 2 - Ingestão alimentar de 24 horas durante 3 dias após a administração i.c.v. de C75 ou RPMI. Os valores representam a média \pm EPM $(n=4-7)$. O teste utilizado foi Two-Way ANOVA seguido por teste de Bonferroni. ${ }^{*} \mathrm{P}<0,05$ em relação ao controle; ${ }^{\#} \mathrm{P}<0,05$ em relação ao grupo $\mathrm{C} 75$. 


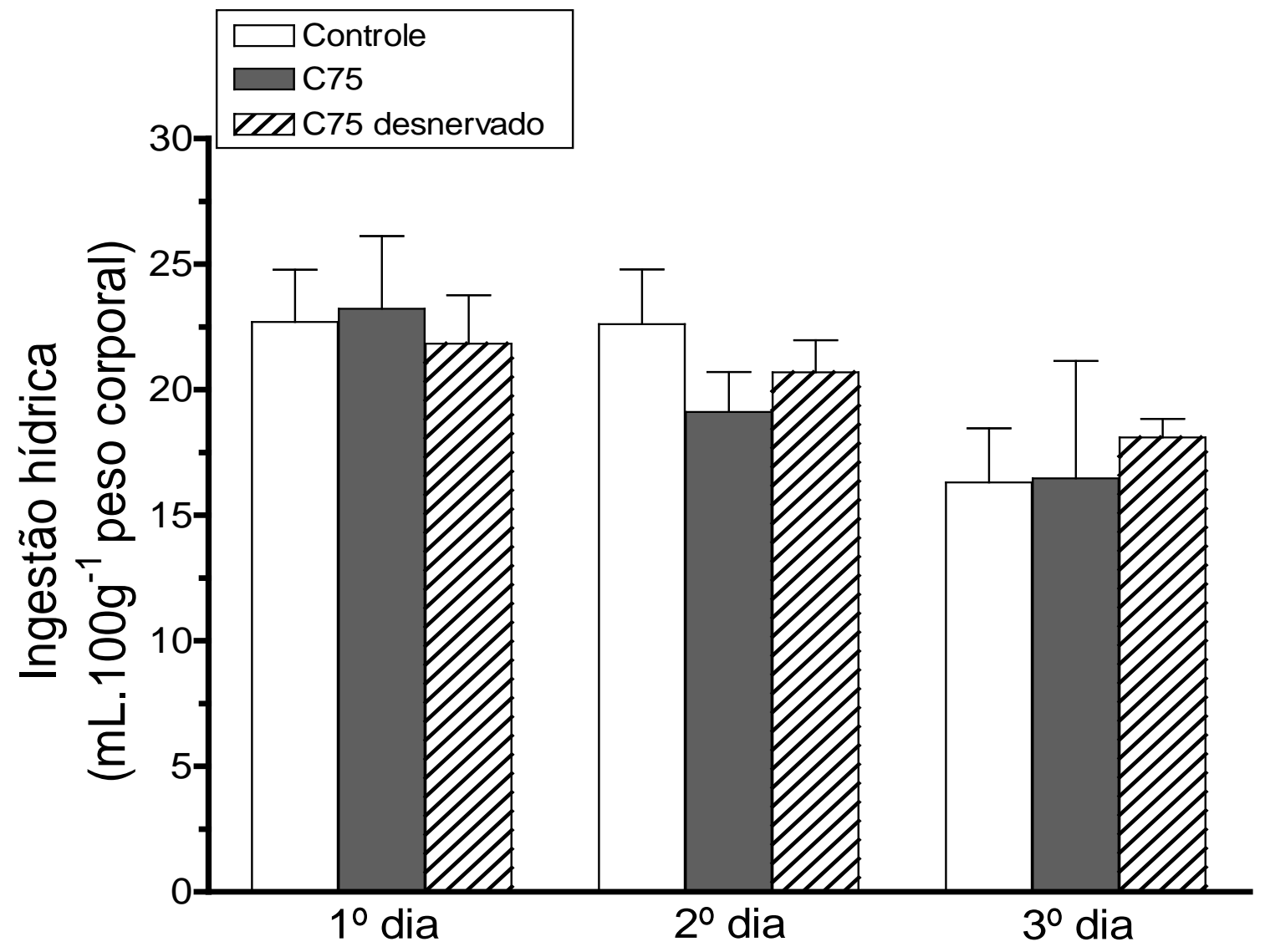

Figura 3 - Ingestão hídrica de 24 horas durante 3 dias após a administração i.c.v. de C75 ou RPMI. Os valores representam a média \pm EPM $(n=4-7)$. O teste utilizado foi Two-Way ANOVA seguido por teste de Bonferroni. 
A Figura 4 mostra que a administração de C75 induziu perda de peso de $8,5 \%(-17,7 \pm$ $2,1 \mathrm{~g})$ após 24 horas e de 1,2\% após 48 horas (-2,3 $\pm 6,0 \mathrm{~g})$, enquanto os animais do grupo controle mantiveram o ganho de peso em, respectivamente, $10 \%(22,1 \pm 2,7 \mathrm{~g})$ e $7,3 \%(16,6$ $\pm 1,2$ g) após a administração do veículo. Portanto, vale a pena ressaltar que no grupo tratado com C75 a perda de peso observada 48 horas após o tratamento com C75 não foi associada ao efeito anorexígeno da droga.

De forma semelhante à ingestão alimentar, a desnervação do TAM atenuou o efeito do C75 sobre a perda de peso corporal no primeiro dia. Após 24 horas da administração da droga, os animais do grupo C75 desnervado ganharam 2,4\% de peso $(5,4 \pm 7,4 \mathrm{~g})$ e, após 48 horas, o ganho de peso foi completamente restabelecido $(5,3 \% ; 12,0 \pm 3,0 \mathrm{~g})$. No terceiro dia, todos os grupos apresentaram ganho de peso em cerca de $5 \%$. 


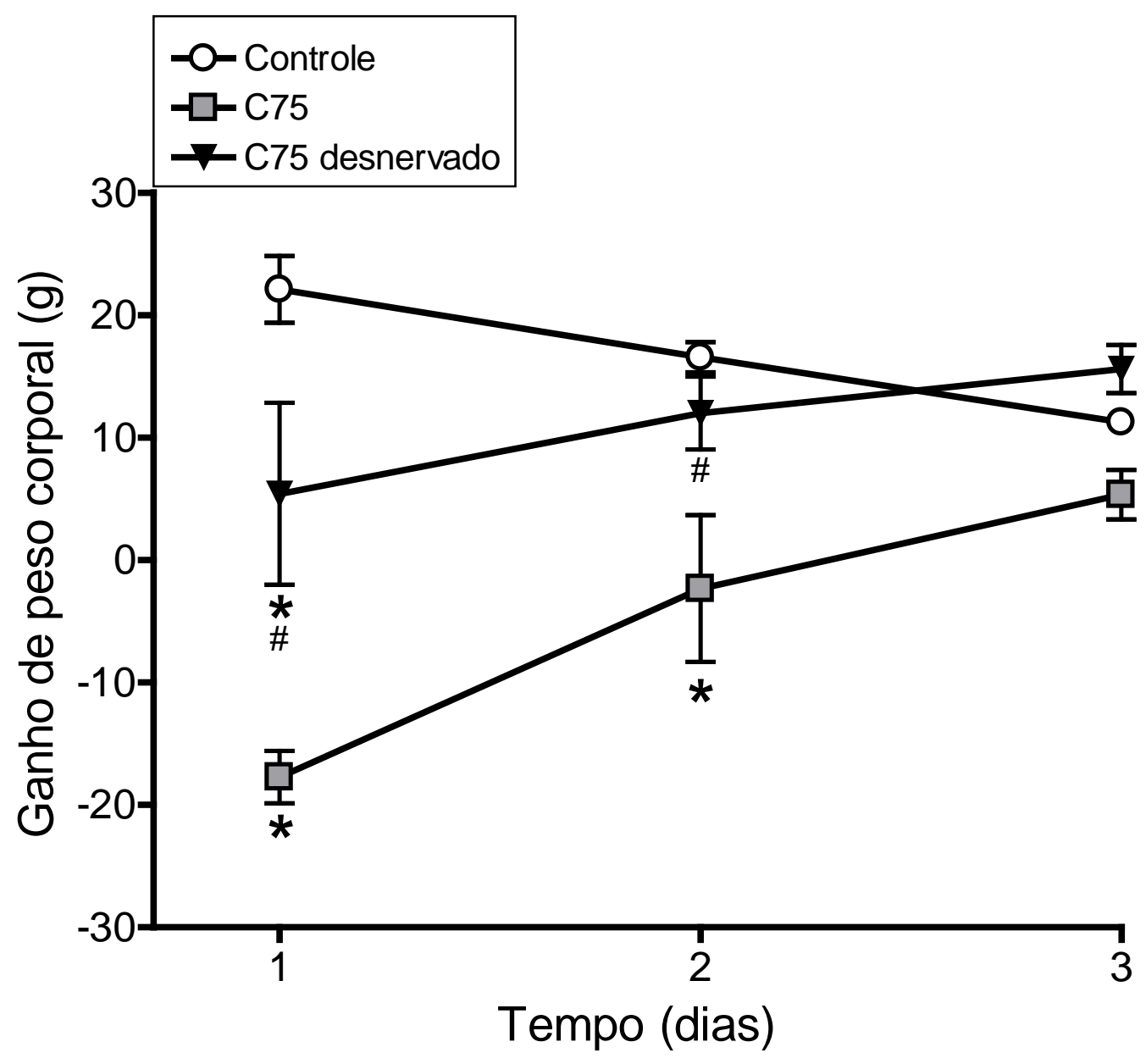

Figura 4 - Ganho de peso corporal de 24 horas durante 3 dias após a administração i.c.v. de C75 ou RPMI. Os valores representam a média \pm EPM $(n=4-7)$. O teste utilizado foi Two-Way ANOVA seguido por teste de Bonferroni. ${ }^{*} \mathrm{P}<0,05$ em relação ao controle; ${ }^{\#} \mathrm{P}<0,05$ em relação ao grupo $\mathrm{C} 75$ de seu respectivo dia. 
4.2. Efeito do C75 sobre a glicemia e a concentração plasmática de ácidos graxos livres em animais acordados.

As curvas de glicemia e da concentração plasmática de ácidos graxos livres foram obtidas em animais acordados e previamente canulados. Verificou-se que o C75 alterou a glicemia de jejum somente 1 hora após a administração (Figura 5), com aumento de 39\% em relação ao controle $(4,8 \pm 0,3 \mathrm{mM}$ vs. $3,4 \pm 0,3 \mathrm{mM})$. A droga aumentou também a concentração plasmática de ácidos graxos livres (Figura 6) nos tempos de 15 minutos $(7,5 \pm$ $1,0 \mathrm{mM}$ vs. $5,4 \pm 0,8 \mathrm{mM}), 30$ minutos $(8,6 \pm 1,0 \mathrm{mM}$ vs. $6,0 \pm 0,5 \mathrm{mM})$ e 3 horas $(7,6 \pm 0,8$ $\mathrm{mM}$ vs. 6,1 \pm 0,4 mM) após a administração em, respectivamente, $39 \%, 44 \%$ e $25 \%$ em relação ao grupo controle. 


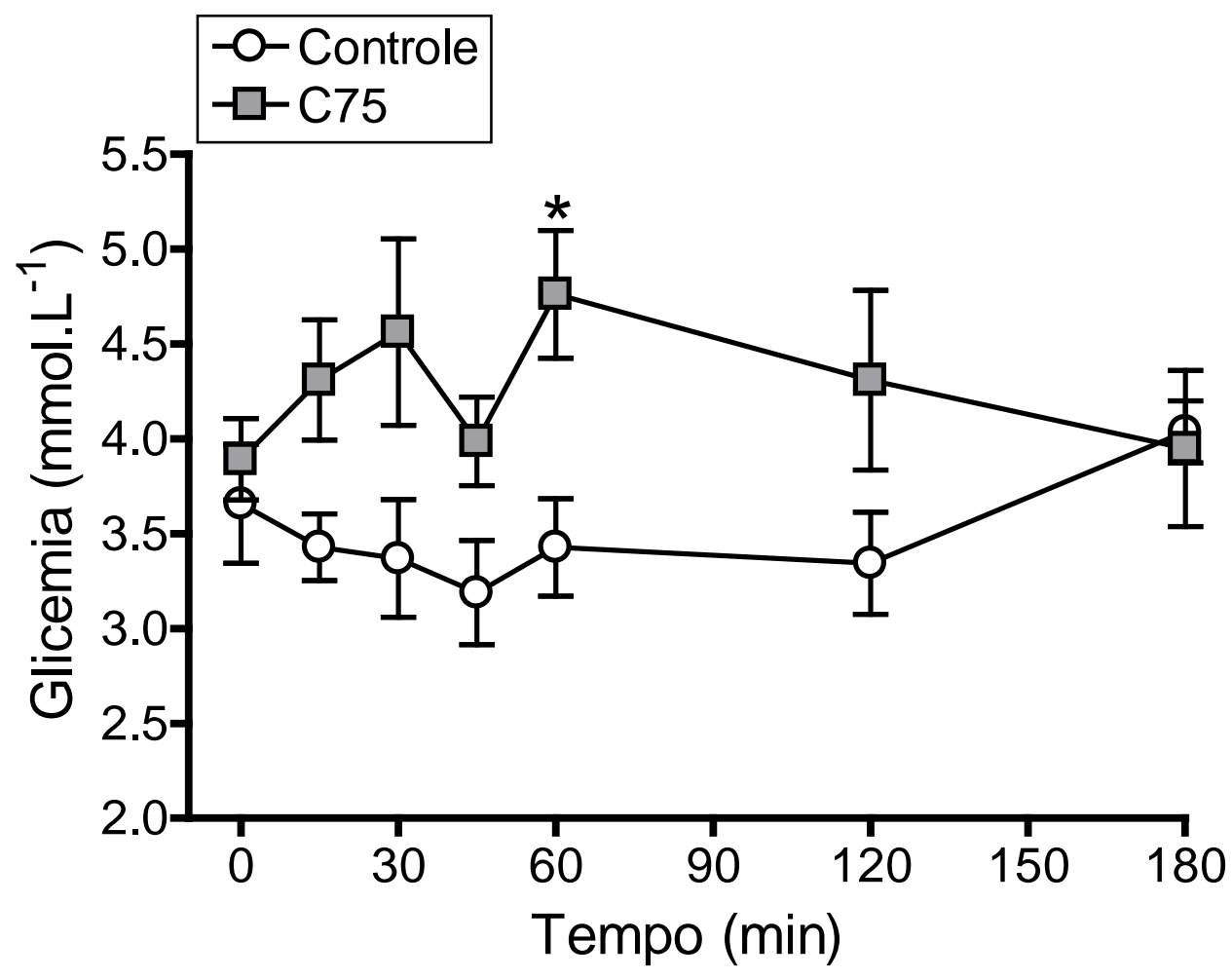

Figura 5 - Curva glicêmica ao longo de 3 horas após a administração i.c.v. de C75 ou RPMI. Os valores representam a média \pm EPM $(n=4-8)$. O teste utilizado foi Two-Way ANOVA seguido por teste de Bonferroni. ${ }^{*} \mathrm{P}<0,05$ em relação ao controle. 


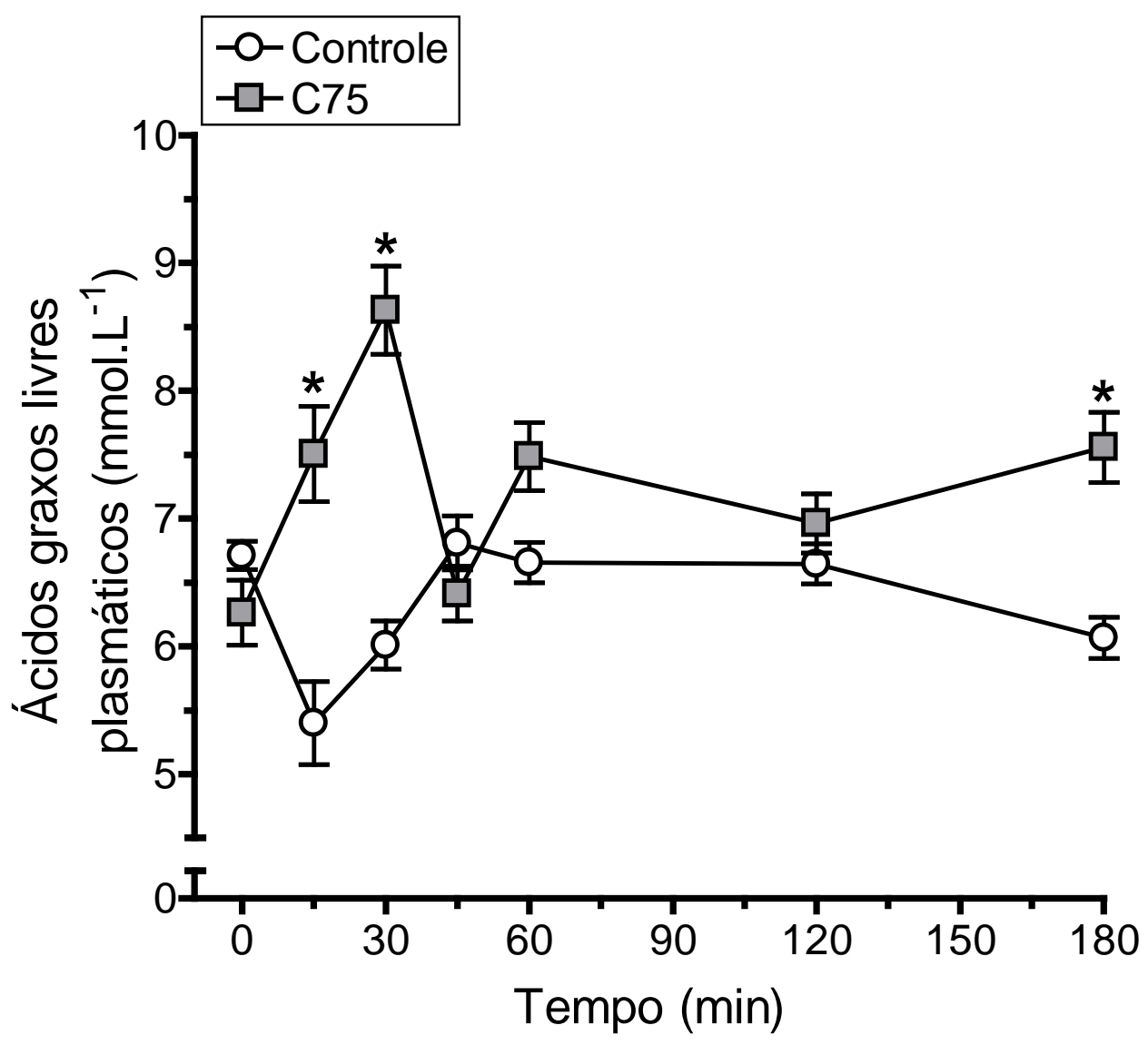

Figura 6 - Curva da concentração de ácidos graxos livres ao longo de 3 horas após a administração i.c.v. de C75 ou RPMI. Os valores representam a média \pm EPM ( $n=5-9)$. 0 teste utilizado foi Two-Way ANOVA seguido por teste de Bonferroni. ${ }^{*} \mathrm{P}<0,05$ em relação ao controle. 


\subsection{Efeito do C75 nas concentrações plasmáticas de insulina, tiroxina total $\left(T_{4}\right)$, catecolaminas e no conteúdo de noradrenalina do TAM de animais inervados e desnervados.}

Como pode ser observado na Figura 7, o C75 não alterou a concentração plasmática de insulina após 1 hora $(34,2 \pm 6,1 \mathrm{nM}$ vs. 30,3 $\pm 2,1 \mathrm{nM})$ e 4 horas $(50,4 \pm 5,2 \mathrm{nM}$ vs. 56,0 \pm $11,3 \mathrm{nM})$ da administração, em animais inervados e em desnervados $(35,9 \pm 4,5 \mathrm{nM}$ e 67,0 \pm 11,6 nM, após 1 e 4 horas, respectivamente).

Foi realizada a determinação da corticosterona plasmática após 4 horas da administração da droga. O C75 não modificou as concentrações plasmáticas de corticosterona em animais inervados $\left(27,8 \pm 5,7 \mu \mathrm{g} \cdot \mathrm{dL}^{-1} v s .27,8 \pm 2,0 \mu \mathrm{g} \cdot \mathrm{dL}^{-1}\right)$ e desnervados $\left(27,8 \pm 3,7 \mu \mathrm{g} \cdot \mathrm{dL}^{-1}\right)$.

A concentração plasmática de tiroxina total $\left(T_{4}\right)$ em animais inervados também não sofreu variação após 1 hora $\left(2,9 \pm 0,1 \mu \mathrm{g} \cdot \mathrm{dL}^{-1}\right.$ vs. $\left.2,2 \pm 0,4 \mu \mathrm{g} \cdot \mathrm{dL}^{-1}\right)$ e 4 horas $\left(2,1 \pm 0,1 \mu \mathrm{g} \cdot \mathrm{dL}^{-1}\right.$ vs. $\left.2,1 \pm 0,2 \mu \mathrm{g} \cdot \mathrm{dL}^{-1}\right)$. Resultados semelhantes foram observados em animais desnervados, após 1 hora e 4 horas da administração de $C 75\left(2,2 \pm 0,3 \mu \mathrm{g} \cdot \mathrm{dL}^{-1}\right.$ e 2,2 \pm 0,3 $\mu \mathrm{g} \cdot \mathrm{dL}^{-1}$, respectivamente; Figura 8).

A concentração de noradrenalina plasmática não foi alterada pela administração de C75 nos animais com a inervação do TAM íntegra $\left(3,9 \pm 0,3 \mathrm{ng} \cdot \mathrm{mL}^{-1}\right.$ e 3,9 $\left.\pm 0,5 \mathrm{ng} \cdot \mathrm{mL}^{-1}\right)$ e nos animais com o TAM desnervado $\left(3,4 \pm 0,6 \mathrm{ng} \cdot \mathrm{mL}^{-1}\right.$ e 3,7 $\left.\pm 0,5 \mathrm{ng} \cdot \mathrm{mL}^{-1}\right)$ após 1 hora e 4 horas, respectivamente (Figura 9). De mesmo modo, a Figura 10 mostra que o hormônio adrenalina manteve-se sem modificações após 1 hora $\left(14,8 \pm 1,7 \mathrm{ng} \cdot \mathrm{mL}^{-1}\right.$ vs. $\left.14,7 \pm 0,9 \mathrm{ng} \cdot \mathrm{mL}^{-1}\right)$ e 4 horas $\left(12,2 \pm 1,4 \mathrm{ng} \cdot \mathrm{mL}^{-1}\right.$ vs. $\left.10,4 \pm 1,4 \mathrm{ng} \cdot \mathrm{mL}^{-1}\right)$ da administração da droga, fato também 
observado no grupo com o TAM desnervado $\left(15,3 \pm 0,7 \mathrm{ng} \cdot \mathrm{mL}^{-1}\right.$ e $12,3 \pm 1,2 \mathrm{ng} \cdot \mathrm{mL}^{-1}$, respectivamente).

A administração de C75 aumentou em $21 \%$ o conteúdo de noradrenalina no TAM (Figura 11) após 1 hora em relação ao controle $\left(1302,0 \pm 92,8 \mathrm{ng} \cdot \mathrm{g}^{-1}\right.$ vs. $\left.1029,1 \pm 91,2 \mathrm{ng} \cdot \mathrm{g}^{-1}\right)$, mas não induziu qualquer alteração após 4 horas $\left(1690,7 \pm 89,1\right.$ ng.g ${ }^{-1}$ vs. $1682,7 \pm 89,6$ ng.g $g^{-}$ $\left.{ }^{1}\right)$. A Figura 11 também mostra que a desnervação simpática do TAM depletou completamente o conteúdo de noradrenalina no TAM, após 1 hora e 4 horas, respectivamente, da administração da droga $\left(37,0 \pm 18,0 \mathrm{ng} \cdot \mathrm{g}^{-1}\right.$ e $\left.71,0 \pm 26,3 \mathrm{ng} \cdot \mathrm{g}^{-1}\right)$. 


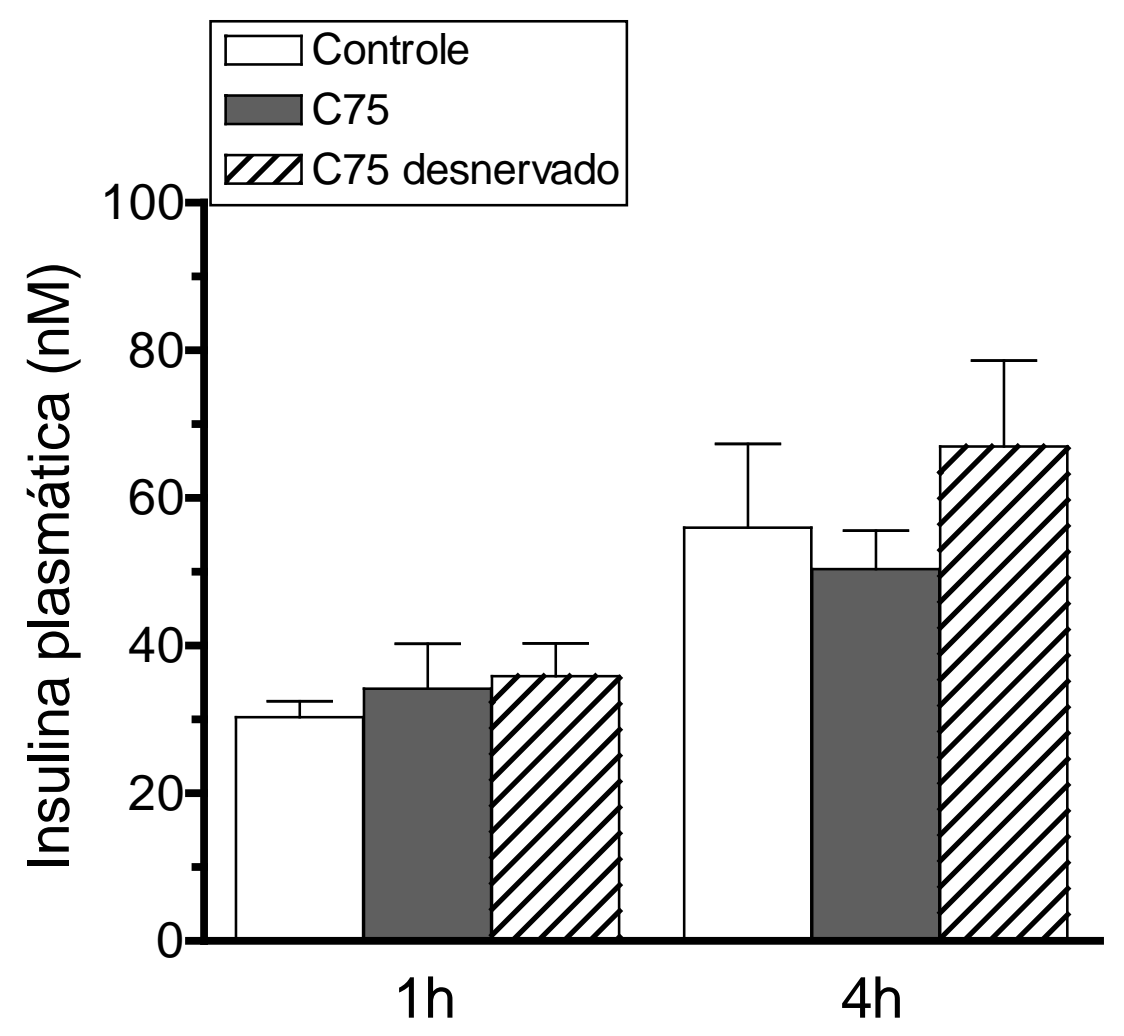

Figura 7 - Concentração plasmática de insulina após 1 hora e 4 horas da administração i.c.v. de C75 ou RPMI. Os valores representam a média \pm EPM $(n=4-5)$. O teste utilizado foi One-Way ANOVA seguido por teste de Newman-Keuls. 


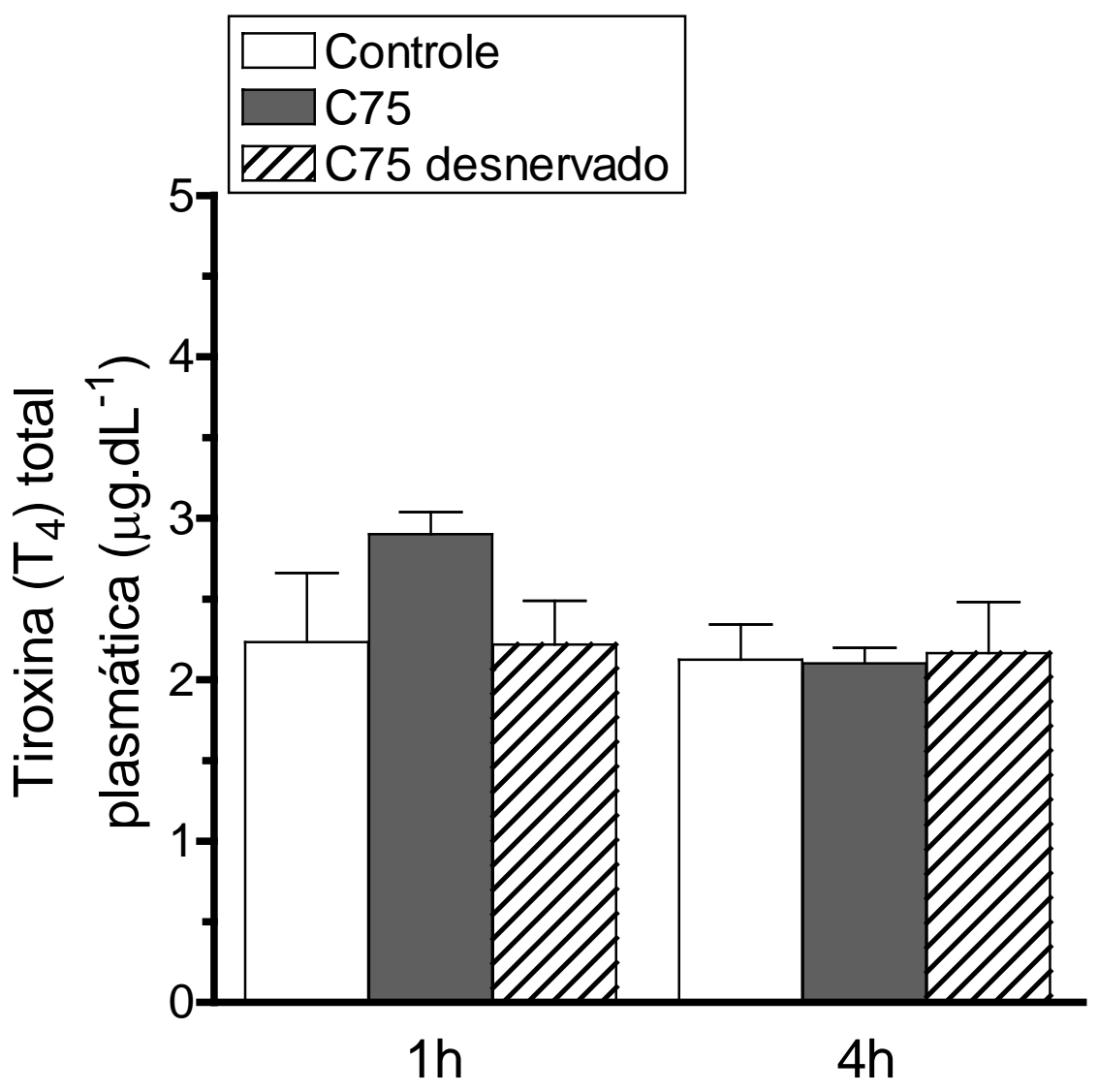

Figura 8 - Concentração plasmática de tiroxina $\left(T_{4}\right)$ total após 1 hora e 4 horas da administração i.c.v. de C75 ou RPMI. Os valores representam a média \pm EPM $(n=6)$. 0 teste utilizado foi One-Way ANOVA seguido por teste de Newman-Keuls. 


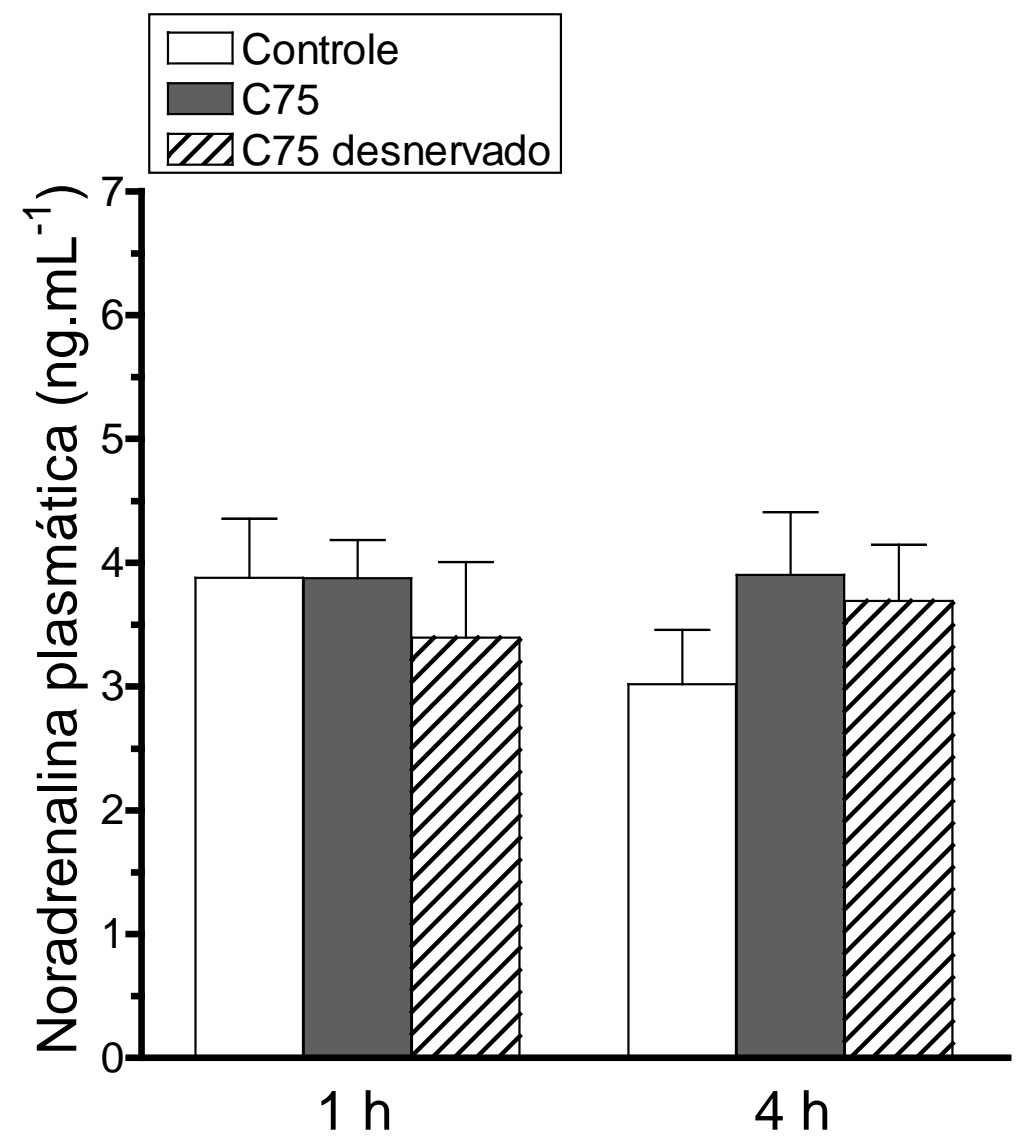

Figura 9 - Concentração plasmática de noradrenalina após 1 hora e 4 horas da administração i.c.v. de C75 ou RPMI. Os valores representam a média \pm EPM $(n=4-8)$. O teste utilizado foi One-Way ANOVA seguido por teste de Newman-Keuls. 


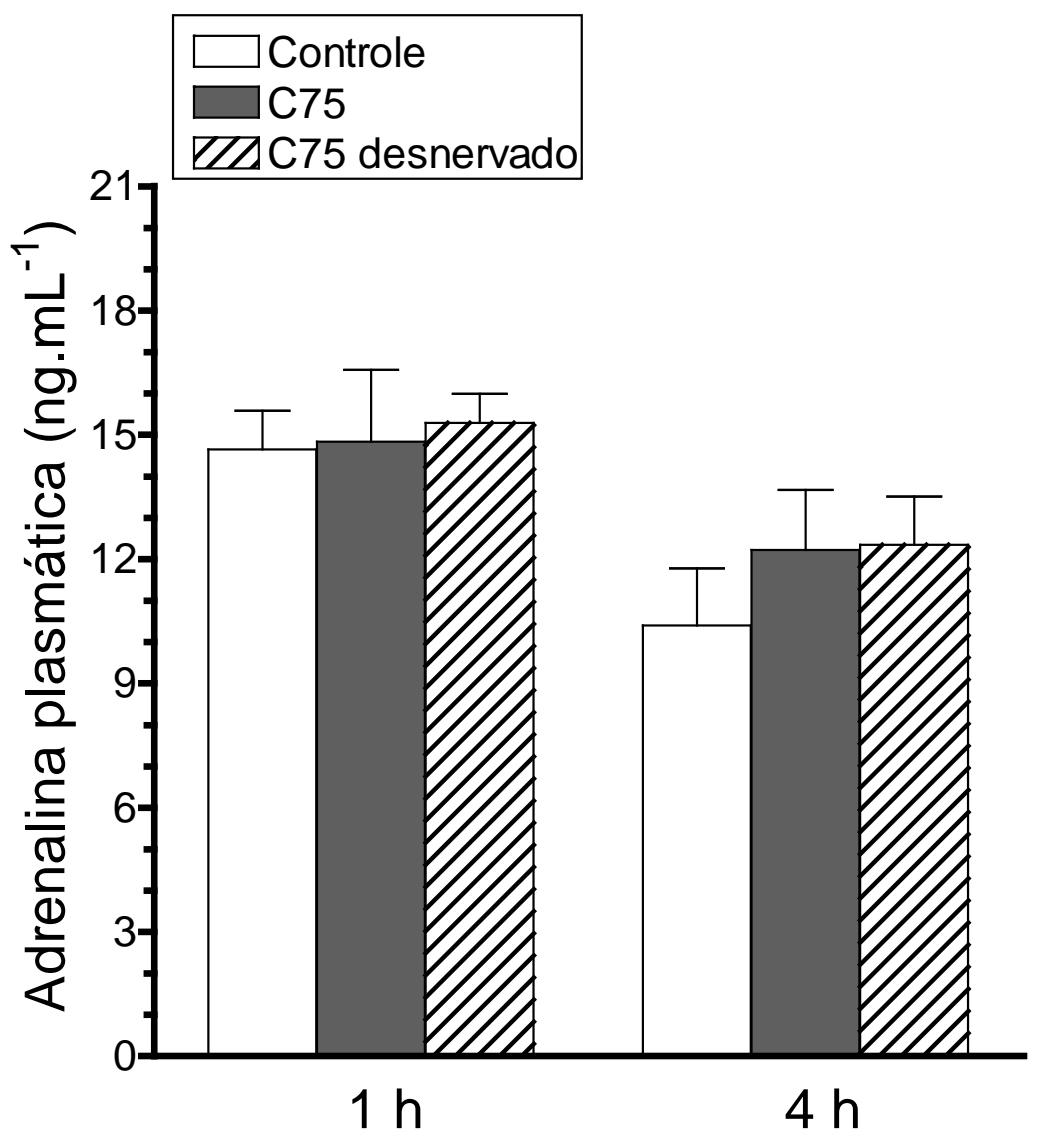

Figura 10 - Concentração plasmática de adrenalina após 1 hora e 4 horas da administração i.c.v. de C75 ou RPMI. Os valores representam a média \pm EPM $(n=4-8)$. O teste utilizado foi One-Way ANOVA seguido por teste de Newman-Keuls. 


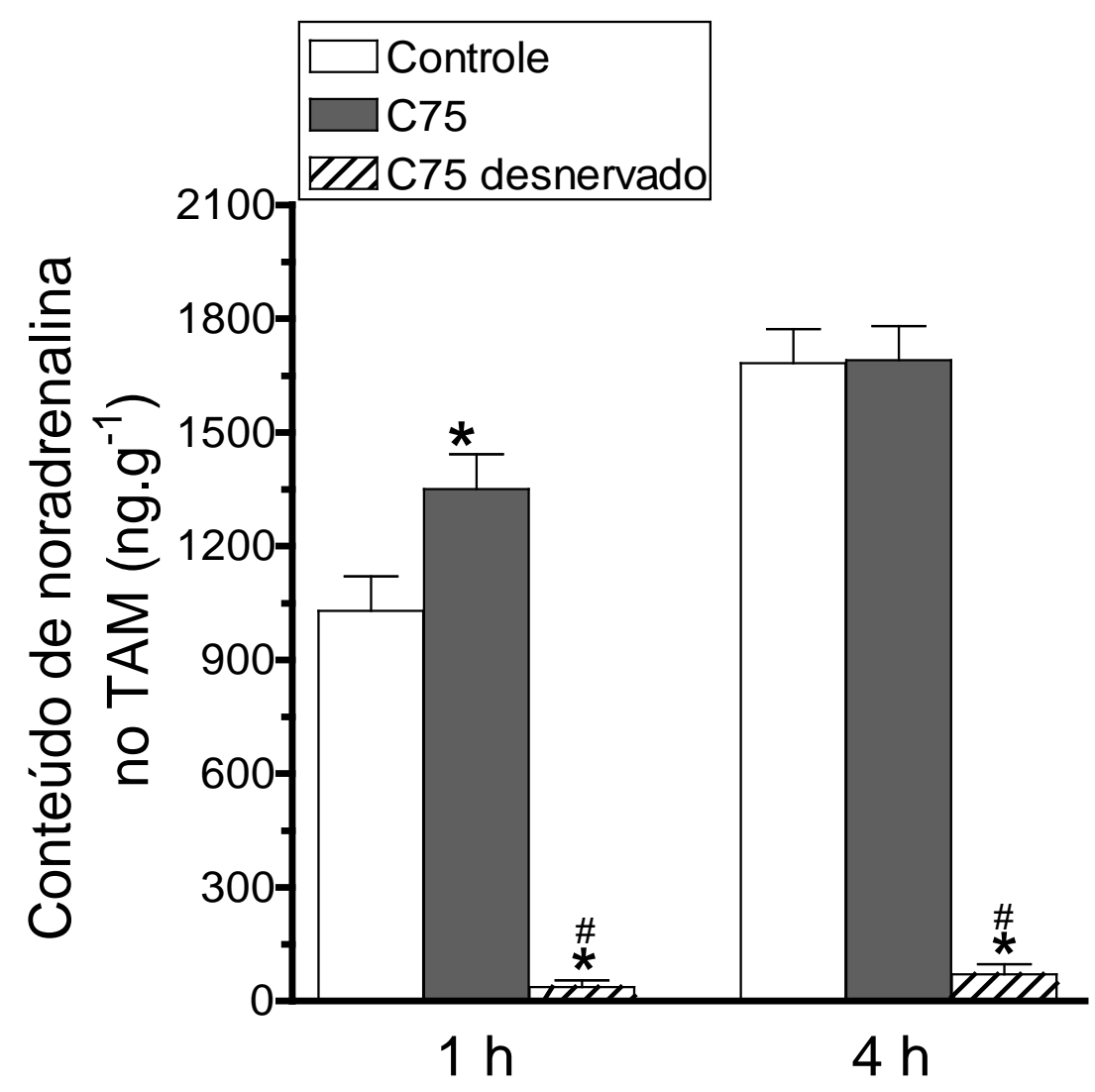

Figura 11 - Conteúdo de noradrenalina no TAM após 1 hora e 4 horas da administração i.c.v. de C75 ou RPMI. Os valores representam a média \pm EPM $(n=5-10)$. O teste utilizado foi OneWay ANOVA seguido por teste de Newman-Keuls. ${ }^{*} \mathrm{P}<0,05$ em relação ao controle; ${ }^{*} \mathrm{P}<0,05$ em relação ao grupo $\mathrm{C} 75$ de seu respectivo tempo. 


\subsection{Efeito do C75 na temperatura corporal interna e atividade locomotora espontânea em animais inervados e desnervados.}

A administração i.c.v. do C75 promoveu aumento consistente na temperatura corporal interna (Figura 12), com início já nos primeiros 30 minutos $\left(38,0 \pm 0,2{ }^{\circ} \mathrm{C}\right.$ vs. $37,6 \pm$ $\left.0,2^{\circ} \mathrm{C}\right)$ e com duração de até 9 horas $\left(39,3 \pm 0,2^{\circ} \mathrm{C}\right.$ vs. $\left.37,7 \pm 0,1^{\circ} \mathrm{C}\right)$. Após este período, observa-se uma fase de retorno da temperatura para os valores basais. A área sob a curva da temperatura corporal interna representa o índice térmico, o qual indica a razão entre a produção e a perda de calor do animal. Como se pode observar na Figura 13, o índice térmico total (análise de 20 horas) no grupo $\mathrm{C} 75$ foi $82 \%$ superior ao grupo controle $(23,8 \pm$ 2,4 U.A. vs. $13,1 \pm 2,0$ U.A.).

A taxa de estoque de calor, representada na Figura 14, mostra que a ação estimulatória do C75 sobre os mecanismos de regulação da temperatura ocorreu a partir dos 30 minutos, ou seja, teve início concomitantemente ao aumento da temperatura corporal interna, e manteve-se extremamente alta após 1 hora da administração $(6,3 \pm 2,5$ vs. $-0,5 \pm$ $0,3)$, quando a variação da temperatura foi de cerca de $0,7 \pm 0,2{ }^{\circ} \mathrm{C}$. Observa-se ainda que o aumento da taxa de estoque de calor provocado pelo C75 manteve-se por até 6 horas após a administração da droga (Figura 14) isto é, em um tempo inferior ao da hipertermia (Figura 12).

A desnervação simpática do TAM atenuou o aumento da temperatura corporal interna nas primeiras 4 horas da administração do C75, porém não modificou a elevação da temperatura corporal induzida pelo C75 durante o período de 6 a 8 horas (Figura 12). Após 1 hora da administração da droga, a desnervação do TAM bloqueou em $92 \%\left(37,6 \pm 0,1^{\circ} \mathrm{C}\right)$ o aumento da temperatura interna (Figura 12) e em 100\% o aumento da taxa de estoque de 
calor (Figura 14). Além disso, pode ser observado que a desnervação simpática do TAM aboliu completamente o efeito térmico de 20 horas do C75 (Figura 13).

Os animais apresentaram um perfil de atividade locomotora espontânea semelhante ao longo de 20 horas nos três grupos avaliados (Figura 15). As áreas sob as curvas da atividade locomotora espontânea do período de 0 a 20 horas (Figura 16) mostram que, de fato, não houve alteração da livre movimentação dos animais dentro da caixa após a administração da droga, tanto no grupo inervado (18,6 $\pm 1,6$ U.A. vs. $18,7 \pm 1,9$ U.A.) como no desnervado $(20,8 \pm 1,9$ U.A.). 


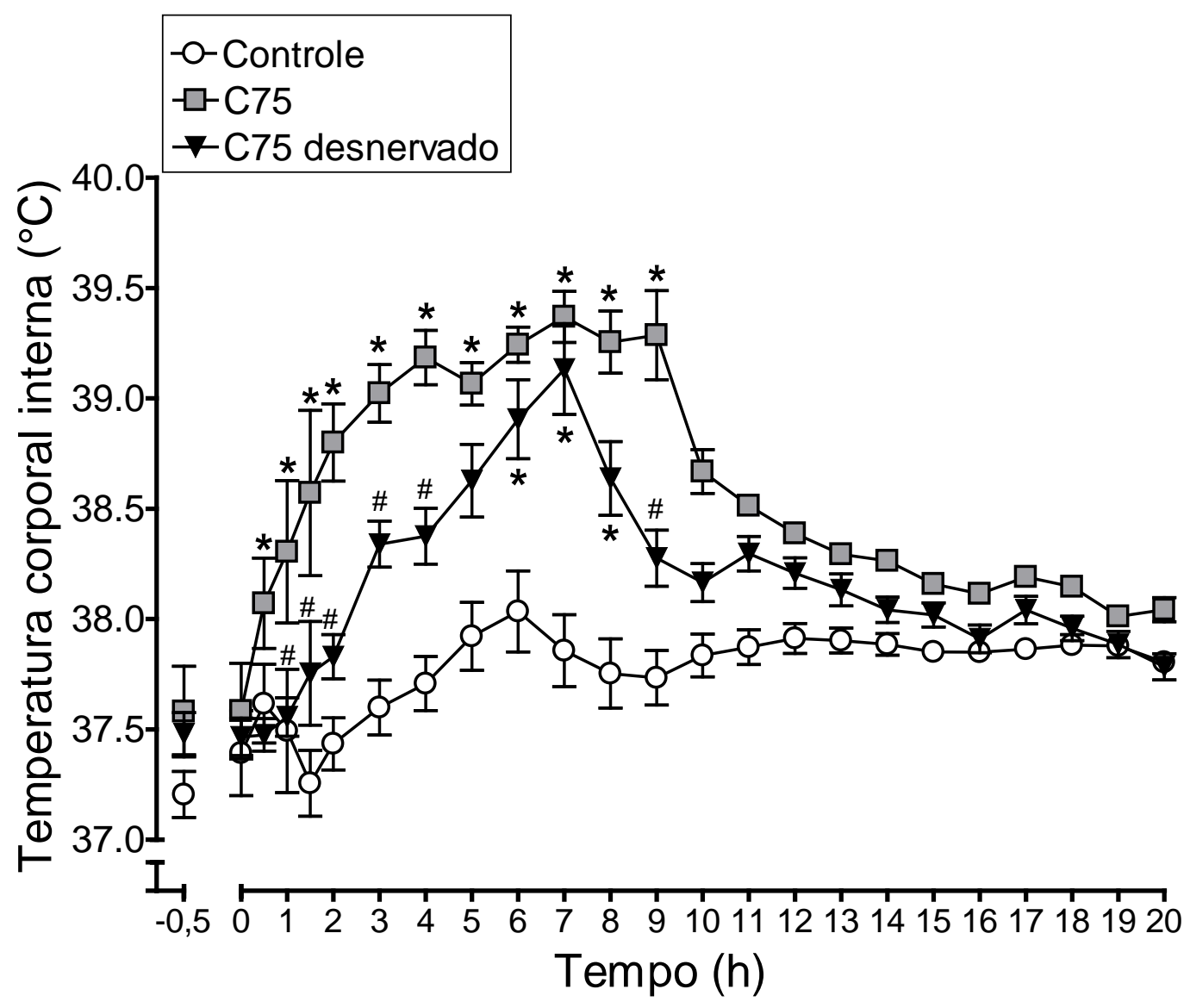

Figura 12 - Temperatura corporal interna ao longo de 20 horas após a administração i.c.v. de C75 ou RPMI. Os valores representam a média \pm EPM $(n=7-11)$. O teste utilizado foi Two-Way ANOVA seguido por teste de Bonferroni. ${ }^{*} \mathrm{P}<0,05$ em relação ao controle; $\# \mathrm{P}<0,05$ em relação ao grupo $\mathrm{C} 75$ de seu respectivo tempo. 


\section{$\square$ Controle \\ $\square \mathrm{C} 75$ \\ घ7/ 75 desnervado}

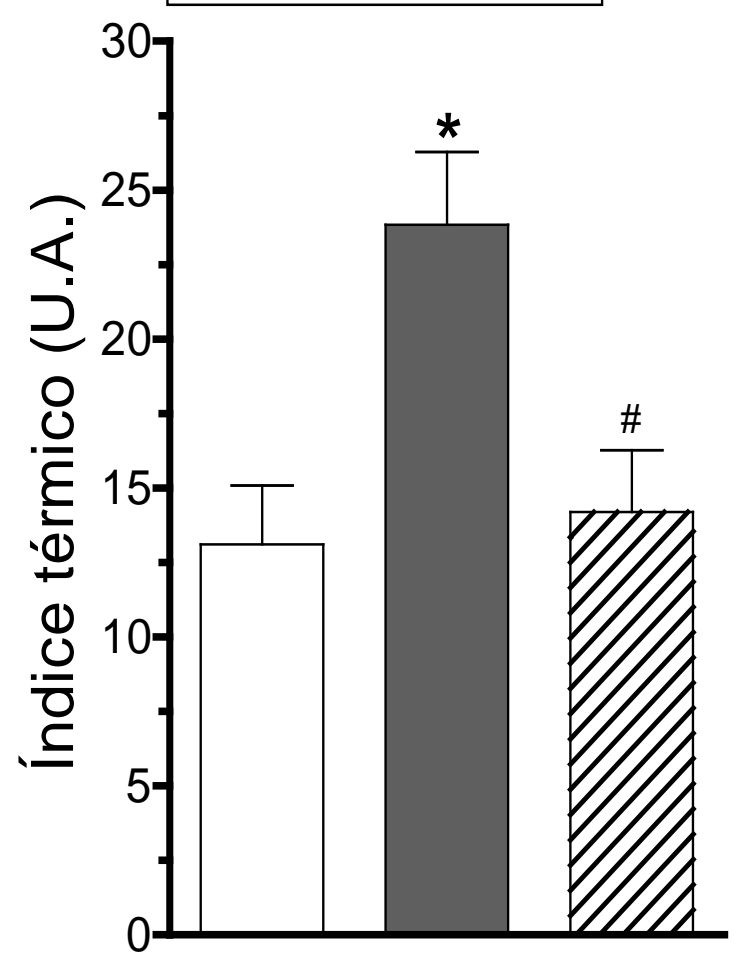

Figura 13 - Índice térmico do período de 0 a 20 horas após a administração i.c.v. de C75 ou RPMI. Os valores representam a média \pm EPM das áreas sob as curvas de temperatura corporal interna $(n=7-11)$. O teste utilizado foi One-Way ANOVA seguido por teste de Newman-Keuls. ${ }^{*} \mathrm{P}<0,05$ em relação ao controle; ${ }^{*} \mathrm{P}<0,05$ em relação ao grupo $\mathrm{C} 75$. 


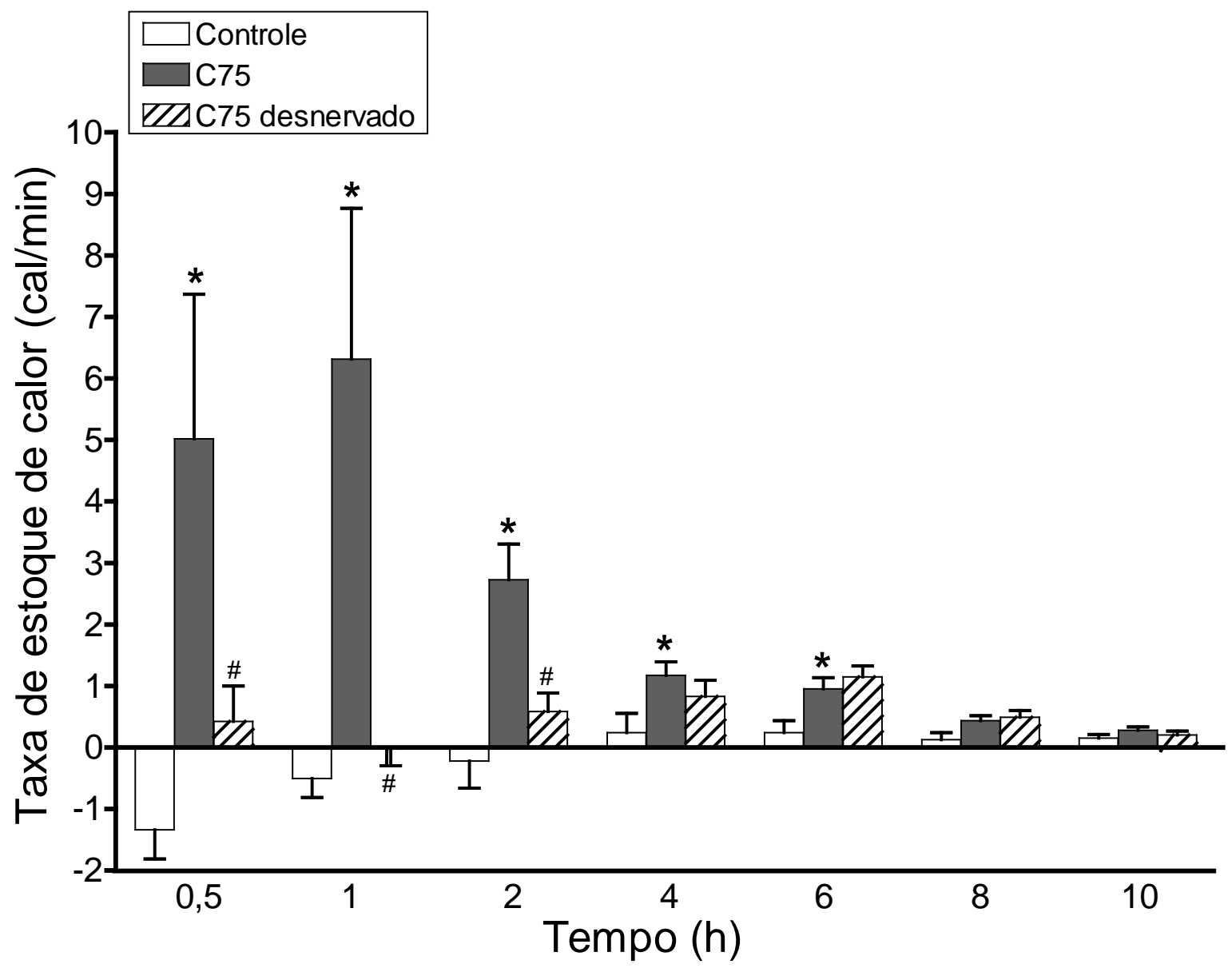

Figura 14 - Taxa de estoque de calor após a administração i.c.v. de C75 ou RPMI. Os valores representam a média \pm EPM $(n=5-10)$. O teste utilizado foi Two-Way ANOVA seguido por teste de Bonferroni. ${ }^{*} \mathrm{P}<0,05$ em relação ao controle; ${ }^{*} \mathrm{P}<0,05$ em relação ao grupo $\mathrm{C} 75$ de seu respectivo tempo. 


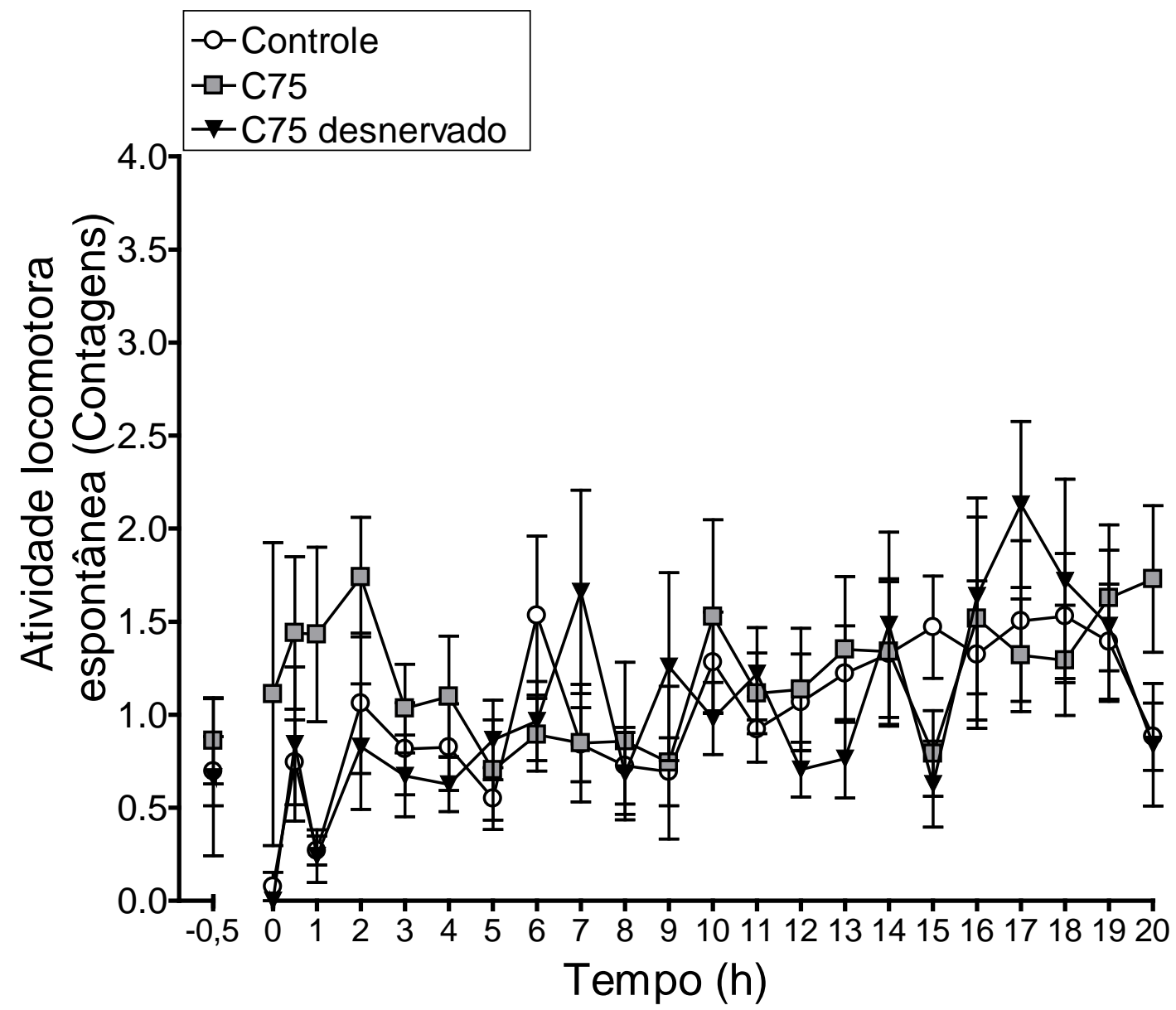

Figura 15 - Atividade locomotora espontânea ao longo de 20 horas após a administração i.c.v. de C75 ou RPMI. Os valores representam a média \pm EPM $(n=7-13)$. $O$ teste utilizado foi Two-Way ANOVA seguido por teste de Bonferroni. 


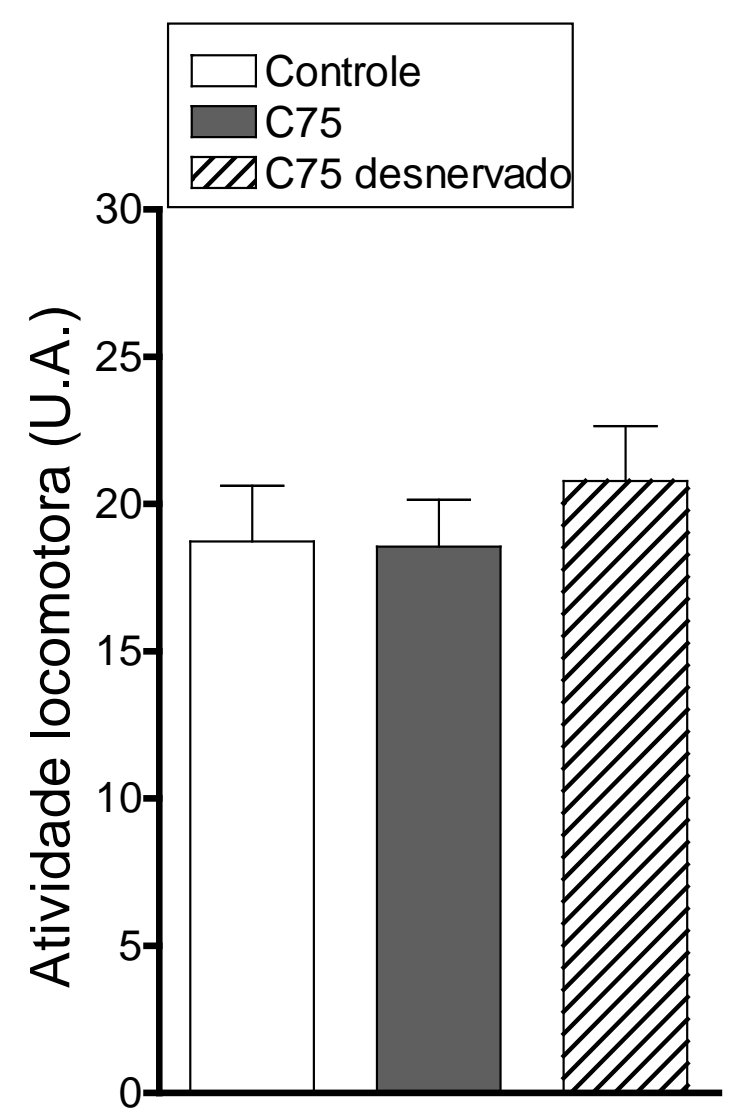

Figura 16 - Atividade locomotora espontânea, representada pela área sob a curva dos valores obtidos, durante o período de 0 a 20 horas após a administração i.c.v. de C75 ou RPMI. Os valores representam a média \pm EPM das áreas sob as curvas de temperatura corporal interna $(n=8-12)$. O teste utilizado foi One-Way ANOVA seguido por teste de Newman-Keuls. 


\subsection{Efeito do C75 na temperatura do TAM em animais inervados e desnervados}

O C75 teve um efeito bastante expressivo na estimulação da temperatura do TAM, sendo este efeito completamente dependente da inervação simpática do tecido (Figura 17). A temperatura do tecido foi elevada após 1 hora $\left(\sim 1,4 \pm 0,3^{\circ} \mathrm{C}\right)$, alcançou variação maior que $2{ }^{\circ} \mathrm{C}$ às 2 horas, e manteve-se alta até 8 horas após a administração da droga. A desnervação simpática do TAM aboliu completamente o efeito do C75 sobre a temperatura do TAM ao longo de todo o período estudado, como pode ser observado na Figura 17, e na Figura 18 que mostra a área sob a curva da temperatura do tecido. 


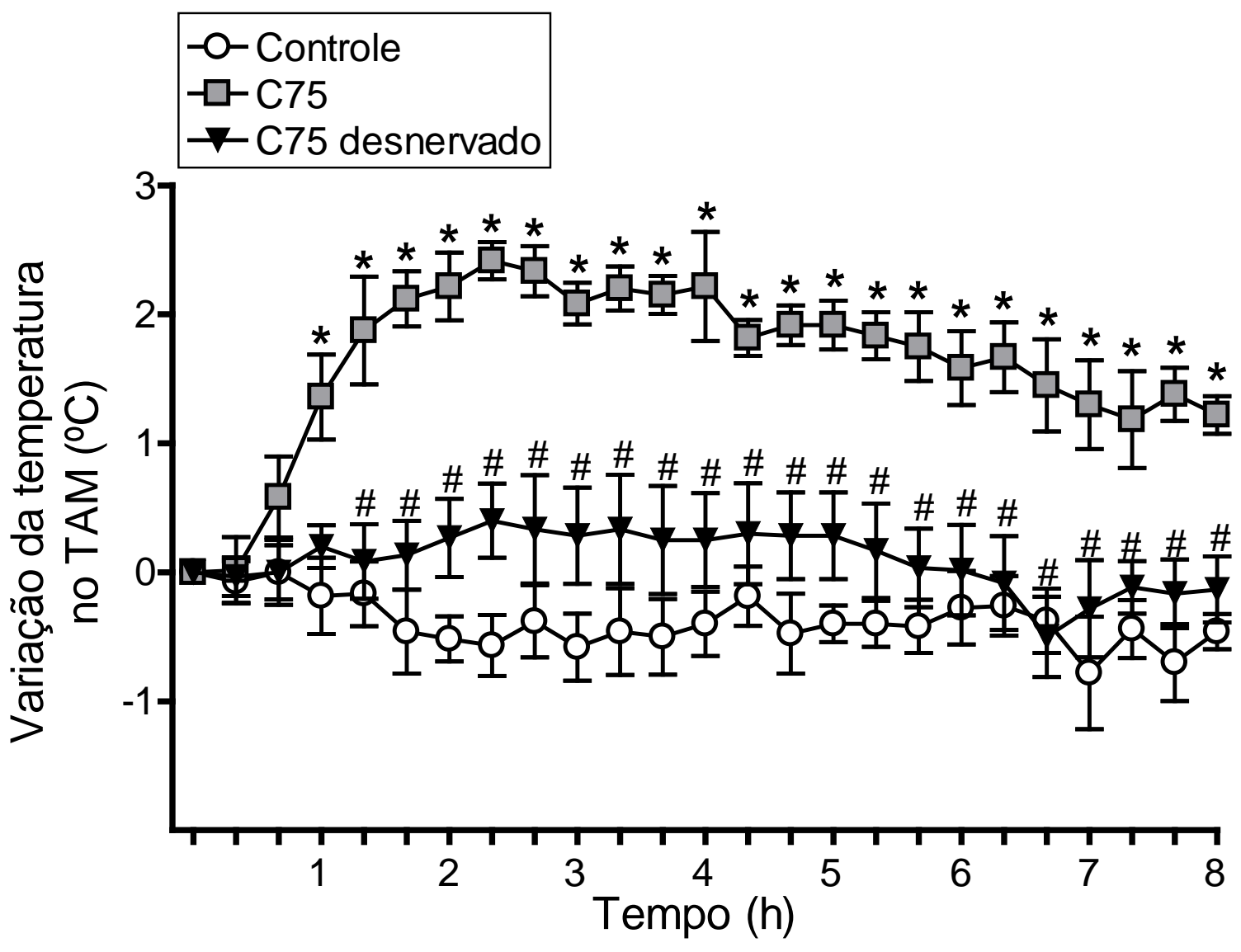

Figura 17 - Variação da temperatura no TAM ao longo de 8 horas após a administração i.c.v. de C75 ou RPMI. Os valores representam a média \pm EPM $(n=4-7)$. $O$ teste utilizado foi TwoWay ANOVA seguido por teste de Bonferroni. ${ }^{*} \mathrm{P}<0,05$ em relação ao controle; ${ }^{\#} \mathrm{P}<0,05$ em relação ao grupo $\mathrm{C} 75$ de seu respectivo tempo. 


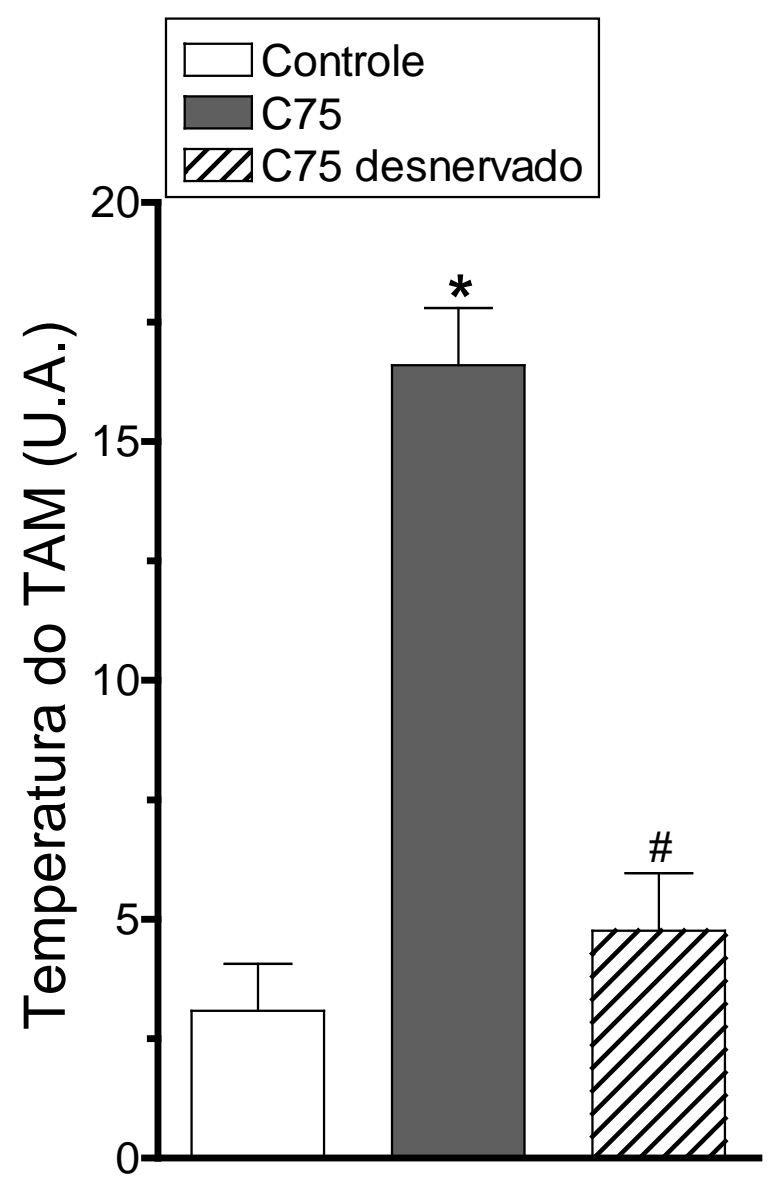

Figura 18 - Temperatura do TAM, representada como área sob a curva dos valores obtidos, durante o período de 0 a 8 horas após a administração i.c.v. de C75 ou RPMI. Os valores representam a média \pm EPM das áreas sob as curvas de temperatura corporal interna $(n=6$ 8). $O$ teste utilizado foi One-Way ANOVA seguido por teste de Newman-Keuls. ${ }^{*} P<0,05$ em relação ao controle; ${ }^{*} \mathrm{P}<0,05$ em relação ao grupo $\mathrm{C} 75$. 


\subsection{Efeito do C75 sobre a perda de calor em animais inervados e desnervados}

A perda de calor foi estimada pela variação da temperatura da pele da cauda dos animais inervados e desnervados (Figura 19). A Figura 20 apresenta a área sob a curva no período de 0 a 4 horas da temperatura da pele da cauda, onde se pode observar que a perda de calor foi $107 \%$ maior no grupo $\mathrm{C} 75$ (461,2 \pm 69,3 U.A. vs. $222,8 \pm 25,2$ U.A.) em relação ao controle. A desnervação simpática do TAM atenuou em $91 \%$ (244,3 \pm 50,0 U.A.) o efeito da droga sobre este parâmetro. 


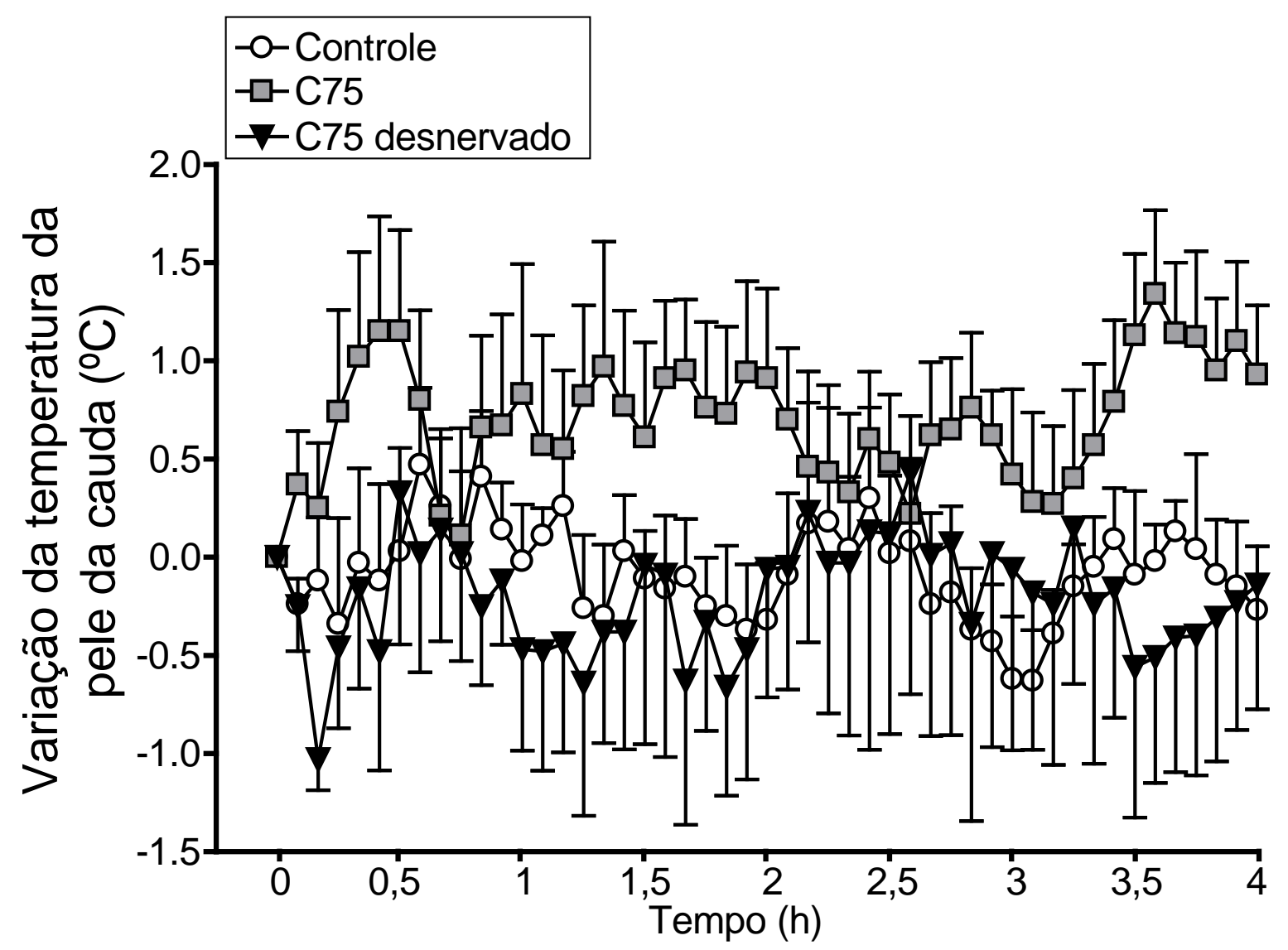

Figura 19 - Variação da temperatura da pele da cauda ao longo de 4 horas após a administração i.c.v. de C75 ou RPMI. Os valores representam a média \pm EPM $(n=4-6)$. 0 teste utilizado foi Two-Way ANOVA seguido por teste de Bonferroni. 


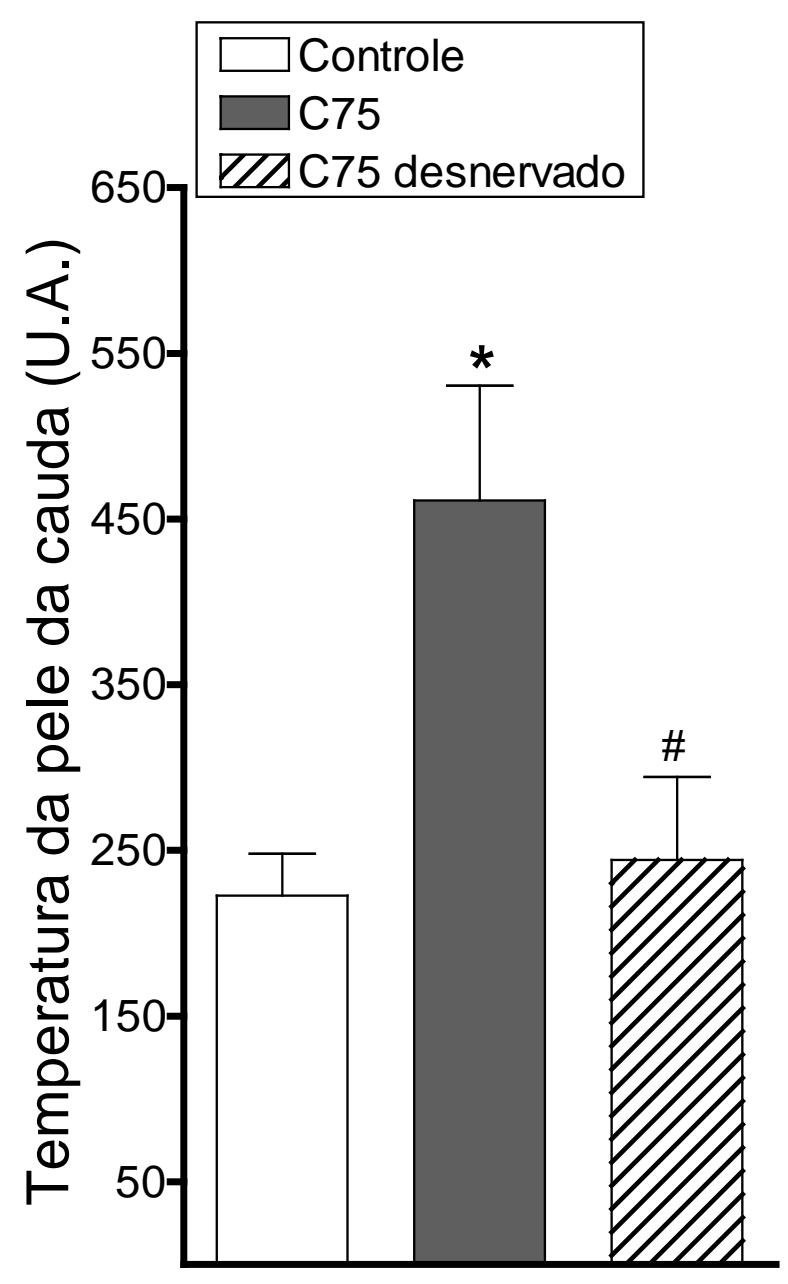

Figura 20 - Temperatura da pele da cauda, representada pela área sob a curva dos valores obtidos, durante o período de 0 a 4 horas após a administração i.c.v. de C75 ou RPMI. Os valores representam a média \pm EPM $(n=4-8)$. O teste utilizado foi One-Way ANOVA seguido por teste de Newman-Keuls. ${ }^{*} \mathrm{P}<0,05$ em relação ao controle; ${ }^{\#} \mathrm{P}<0,05$ em relação ao grupo C75. 


\subsection{Efeito do C75 no conteúdo de gordura total, atividade de enzimas oxidativas e expressão gênica da UCP-1 do TAM em animais inervados e desnervados}

A administração do C75, após 1 hora, reduziu em 13\% o conteúdo de gordura total do TAM $\left(570,4 \pm 28,7 \mathrm{mg} \cdot \mathrm{g}^{-1}\right.$ vs. $652,4 \pm 15,5 \mathrm{mg} \cdot \mathrm{g}^{-1}$ nos controles) indicando indiretamente ativação da lipólise neste tecido (Figura 21). No mesmo período de tempo, a administração desta droga também aumentou em cerca de 3 vezes a atividade da enzima mitocondrial citocromo c oxidase do $\operatorname{TAM}\left(2,7 \pm 0,4\right.$ unidades.100 $\mu$ g proteína mitocondrial ${ }^{-1} v s .0,7 \pm 0,3$ unidades.100 $\mu$ g proteína mitocondrial ${ }^{-1}$ ), mas não alterou a atividade enzimática da citrato sintase $\left(1,3 \pm 0,1 \mathrm{nmol} . \mathrm{seg}^{-1} \cdot \mathrm{mg}\right.$ proteína ${ }^{-1}$ vs. $1,3 \pm 0,0 \mathrm{nmol} \cdot \mathrm{seg}^{-1} \cdot \mathrm{mg}_{\text {proteína }}{ }^{-1}$ nos controles) e nem a expressão do gene da UCP-1 (Figuras 22 a 24). Entretanto, após 4 horas, a administração do $\mathrm{C75}$ aumentou em 2,5 vezes a transcrição do gene da UCP-1 em relação ao grupo controle (Figura 24).

A desnervação simpática do TAM preveniu completamente a depleção dos estoques de gordura total $\left(626,7 \pm 60,5 \mathrm{mg} \cdot \mathrm{g}^{-1}\right.$; Figura 21$)$, a modulação da atividade da citocromo c oxidase $\left(0,6 \pm 0,1\right.$ unidades.100 $\mu$ g proteína mitocondrial ${ }^{-1}$ ) (Figura 22), assim como o aumento da expressão da UCP-1 induzido pelo C75, a qual foi reduzida para valores abaixo dos níveis controles (Figura 24). 


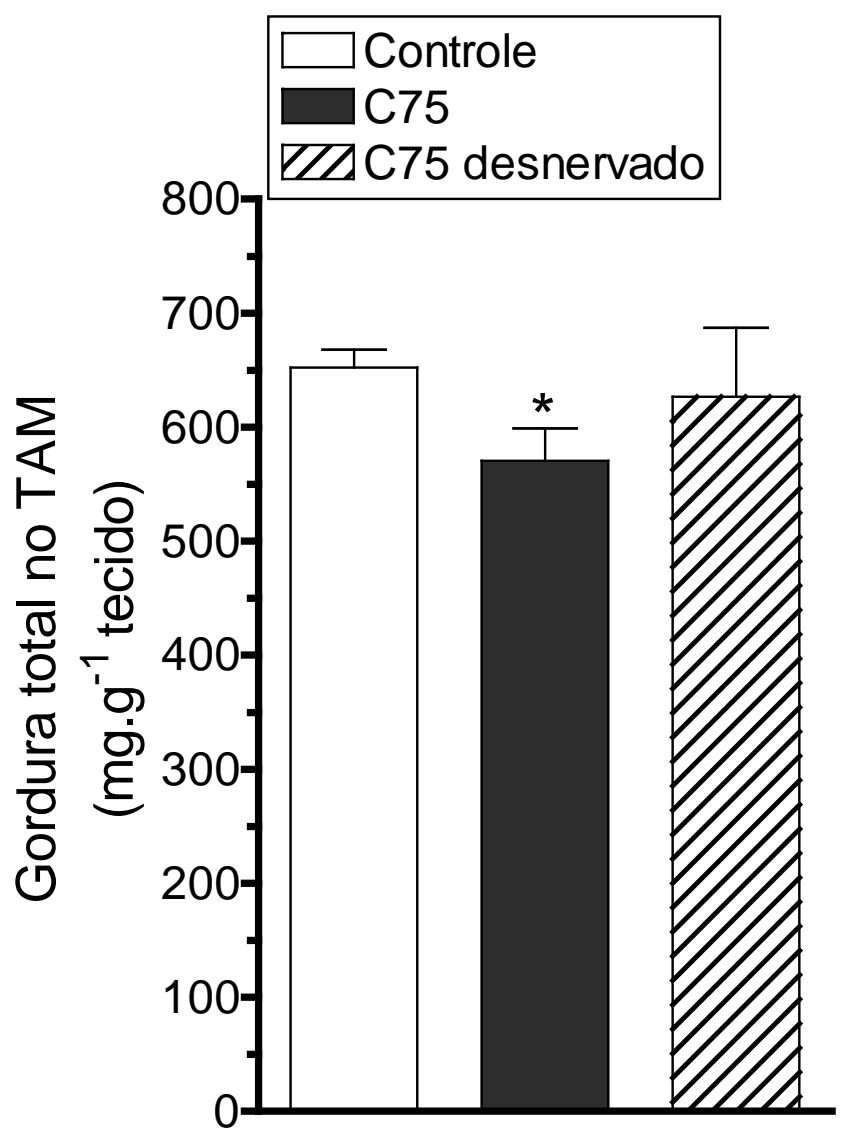

Figura 21 - Conteúdo de gordura total no TAM após 1 hora da administração i.c.v. de C75 ou RPMI. Os valores representam a média \pm EPM $(n=5-10)$. O teste utilizado foi One-Way ANOVA seguido por teste de Newman-Keuls. ${ }^{*} \mathrm{P}<0,05$ em relação ao controle. 


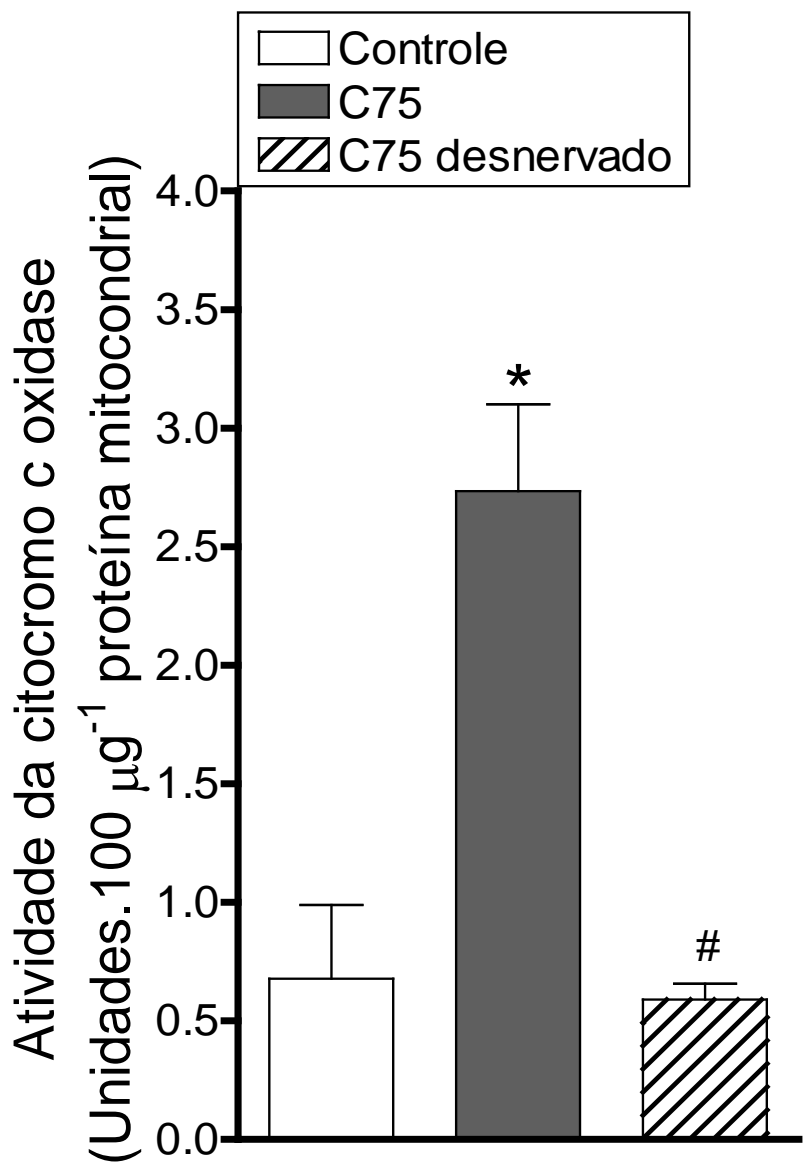

Figura 22 - Atividade enzimática da citocromo c oxidase em mitocôndrias isoladas do TAM após 1 hora da administração i.c.v. de C75 ou RPMI. Os valores representam a média \pm EPM ( $n=$ 5-6). O teste utilizado foi One-Way ANOVA seguido por teste de Newman-Keuls. ${ }^{*} \mathrm{P}<0,05$ em relação ao controle; ${ }^{\#} \mathrm{P}<0,05$ em relação ao grupo $\mathrm{C75}$. 


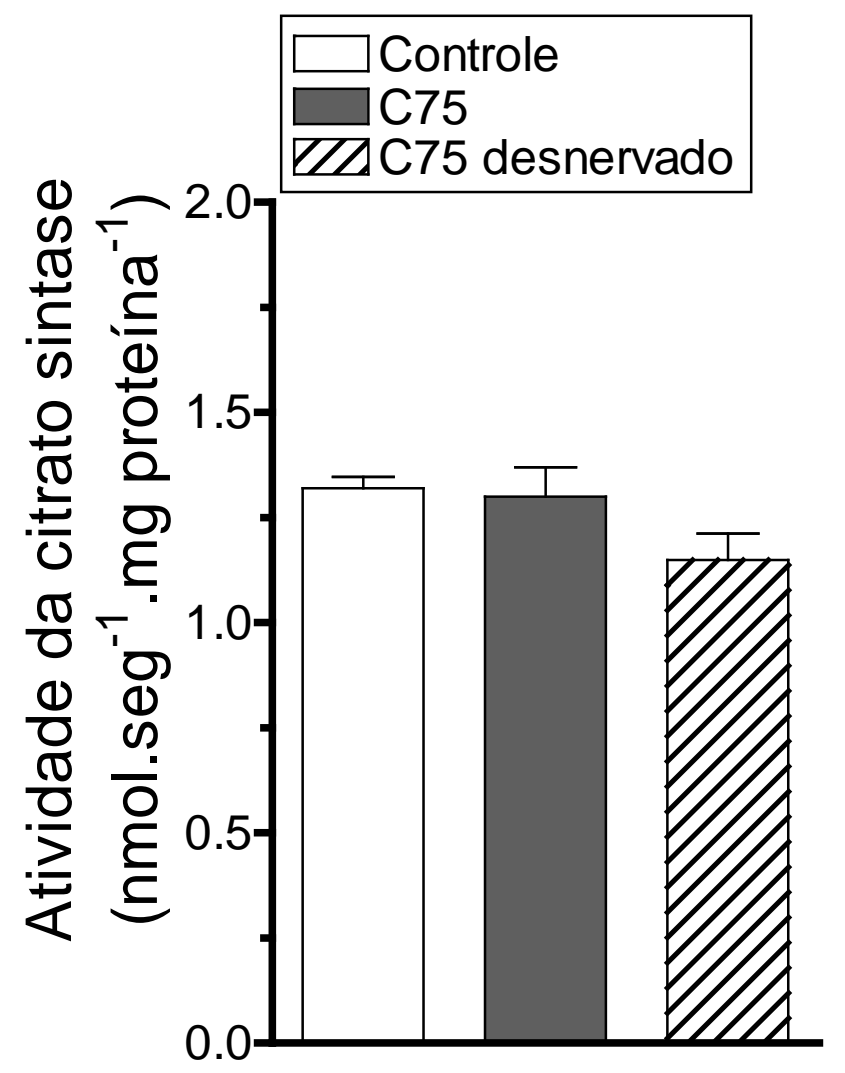

Figura 23 - Atividade enzimática da citrato sintase em extratos de TAM após 1 hora da administração i.c.v. de C75 ou RPMI. Os valores representam a média \pm EPM $(n=4-9)$. $O$ teste utilizado foi One-Way ANOVA seguido por teste de Newman-Keuls. 


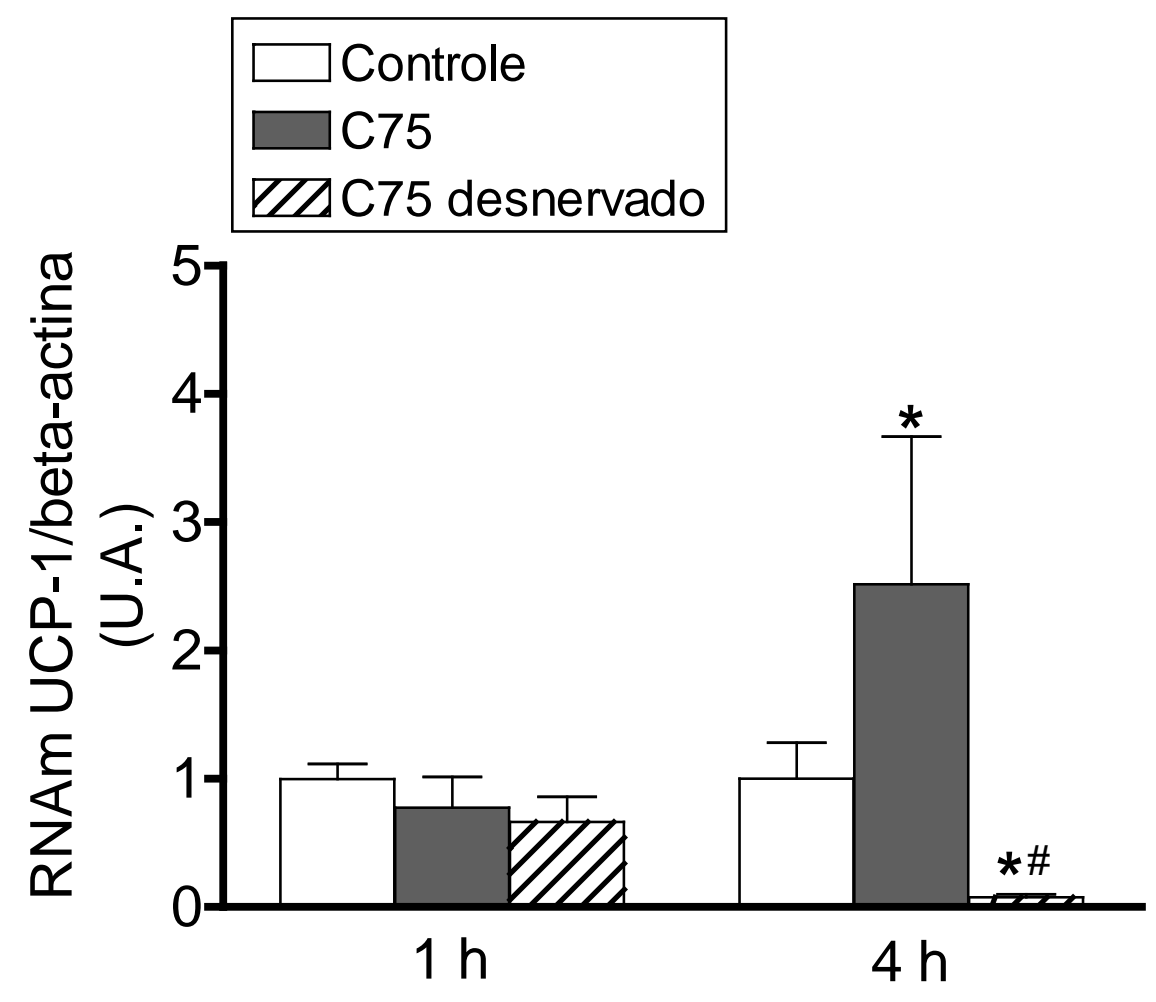

Figura 24 - Expressão gênica da UCP-1 após 1 hora e 4 horas da administração i.c.v. de C75 ou RPMI. Os valores representam a média \pm EPM $(n=6-10)$. O teste utilizado foi One-Way ANOVA seguido por teste de Newman-Keuls. ${ }^{*} \mathrm{P}<0,05$ em relação ao controle; ${ }^{\#} \mathrm{P}<0,05$ em relação ao grupo $\mathrm{C} 75$ de seu respectivo tempo. 
4.8. Efeito da cerulenina na ingestão (alimentar e hídrica) e no ganho de peso corporal em animais inervados e desnervados.

A administração i.c.v. do inibidor natural da ácido graxo sintase, cerulenina, não afetou a ingestão alimentar de 24 horas nos animais inervados $\left(13,8 \pm 1,3 \mathrm{~g} .100 \mathrm{~g}^{-1}\right.$ peso corporal) e desnervados (12,6 $\pm 1,5 \mathrm{~g} .100 \mathrm{~g}^{-1}$ peso corporal) quando comparados ao grupo controle (12,8 \pm 0,3 g.100 $\mathrm{g}^{-1}$ peso corporal). O mesmo foi observado após 48 e 72 horas após a administração da droga (Figura 25). O ganho de peso corporal assim como a ingestão hídrica também não foram alterados em nenhum grupo estudado ao longo dos 3 dias após a administração de cerulenina ou veículo (Figura 26 e 27). 


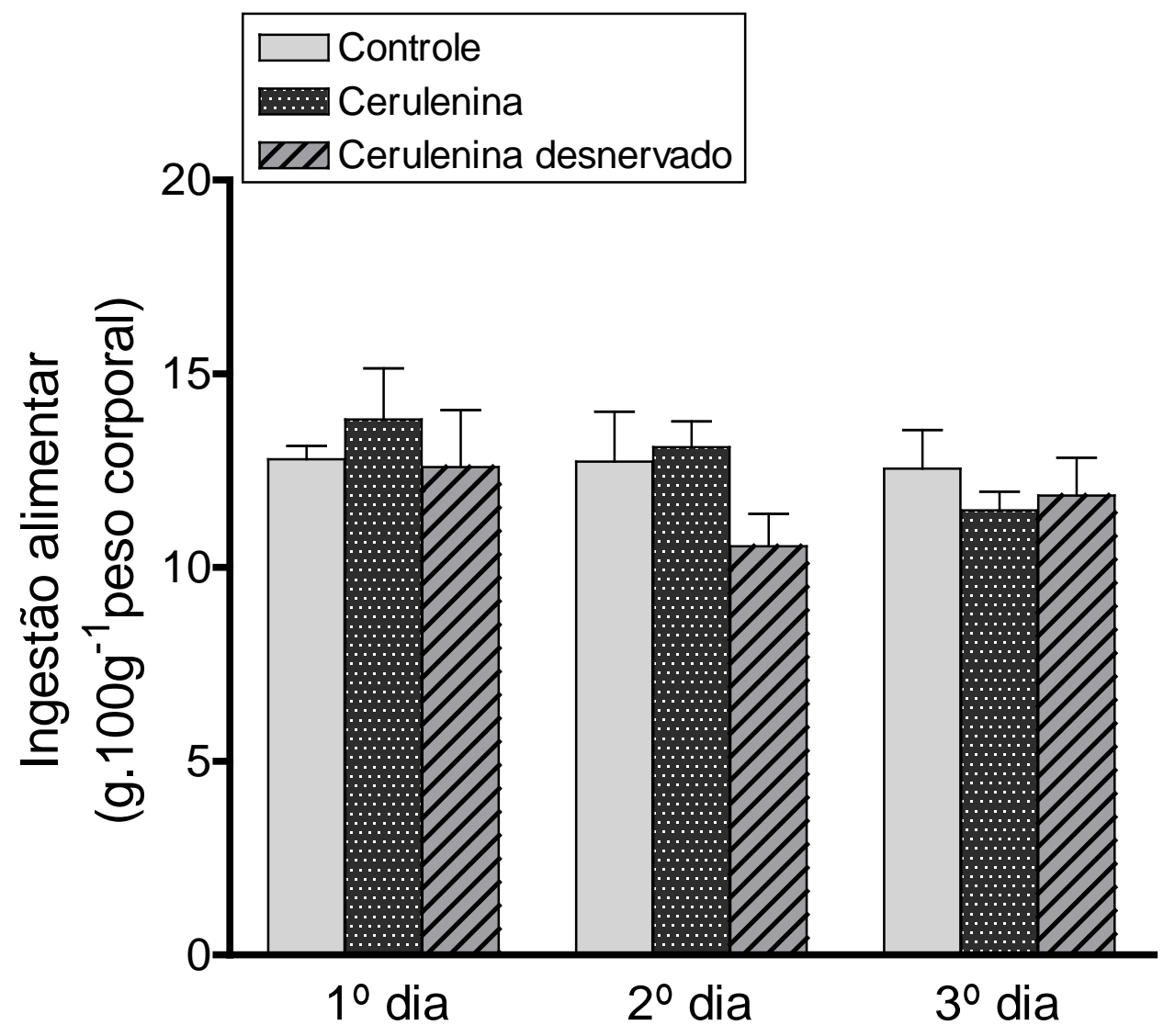

Figura 25 - Ingestão alimentar de 24 horas durante 3 dias após a administração i.c.v. de cerulenina ou RPMI. Os valores representam a média \pm EPM $(n=5-8)$. O teste utilizado foi Two-Way ANOVA seguido por teste de Bonferroni. 


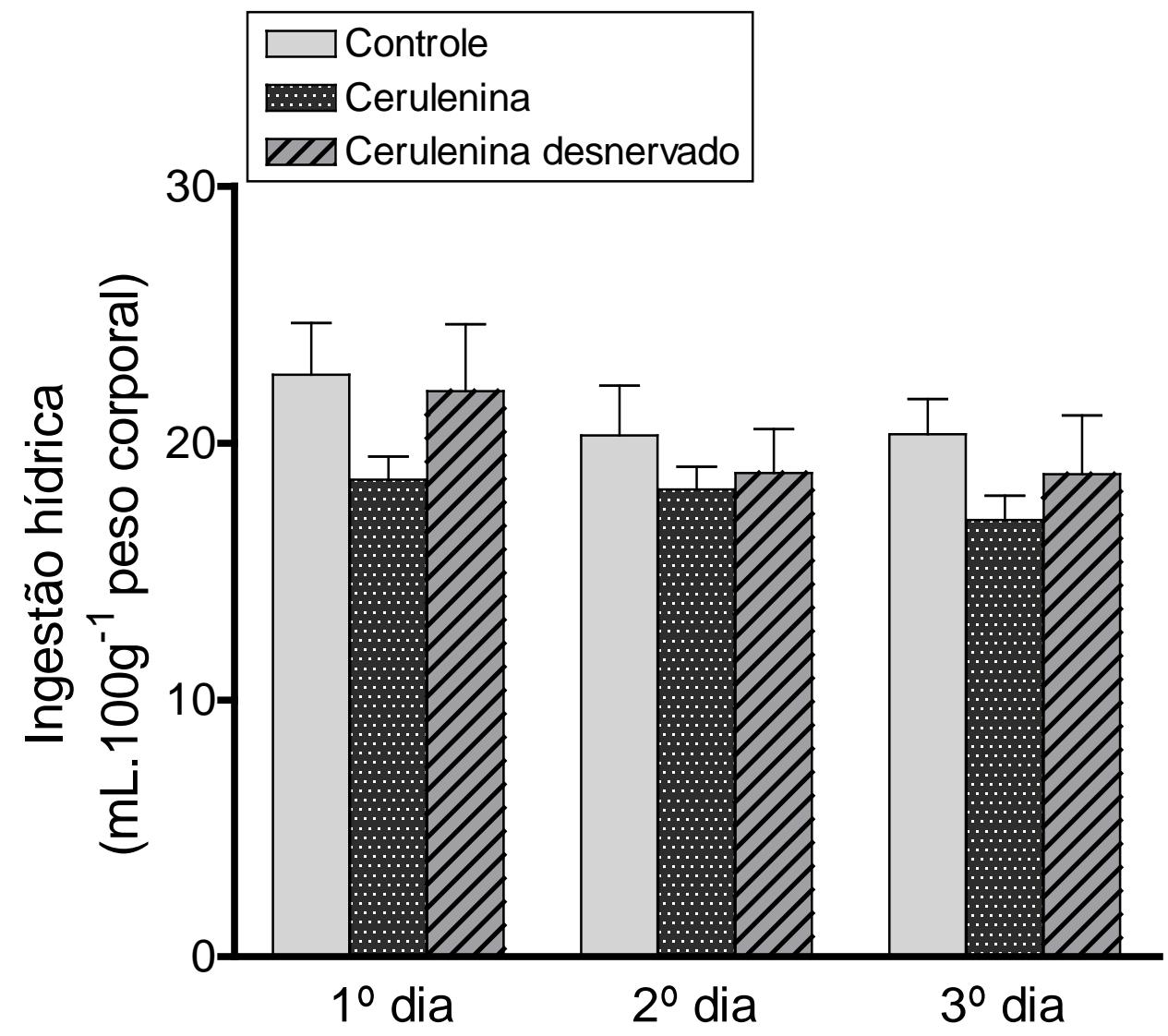

Figura 26 - Ingestão hídrica de 24 horas durante 3 dias após a administração i.c.v. de cerulenina ou RPMI. Os valores representam a média \pm EPM $(n=5-8)$. O teste utilizado foi Two-Way ANOVA seguido por teste de Bonferroni. 


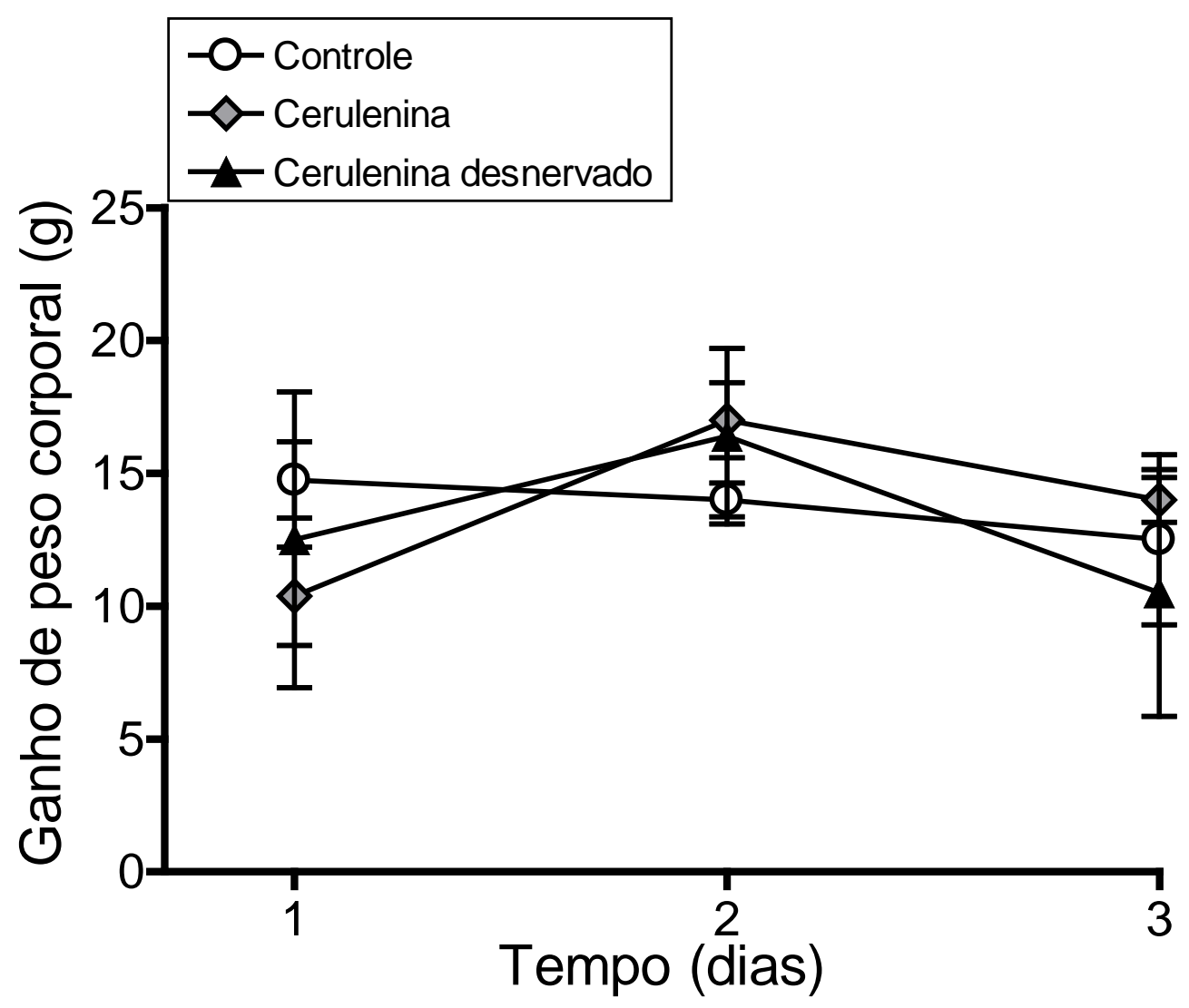

Figura 27 - Ganho de peso corporal de 24 horas durante 3 dias após a administração i.c.v. de cerulenina ou RPMI. Os valores representam a média \pm EPM $(n=4-8)$. $O$ teste utilizado foi TwoWay ANOVA seguido por teste de Bonferroni. 


\subsection{Efeito da cerulenina na temperatura corporal interna e atividade locomotora espontânea em animais inervados e desnervados.}

Após 3 horas da administração da cerulenina, observou-se um sutil aumento da temperatura corporal interna de aproximadamente $5 \%\left(38,4 \pm 0,2{ }^{\circ} \mathrm{C} v s .36,7 \pm 0,2{ }^{\circ} \mathrm{C}\right.$ nos controles). Este efeito térmico foi mantido durante 4 horas e foi completamente abolido no grupo de animais desnervados (Figura 28).

O índice térmico das primeiras 8 horas após a administração de cerulenina foi maior em relação ao controle em cerca de 2,5 vezes, e o grupo desnervado não apresentou alterações estatisticamente significativas nesse parâmetro (Figura 29).

O aumento da temperatura corporal induzido pela cerulenina não foi acompanhado pela maior atividade locomotora espontânea dos animais (Figura 30). 


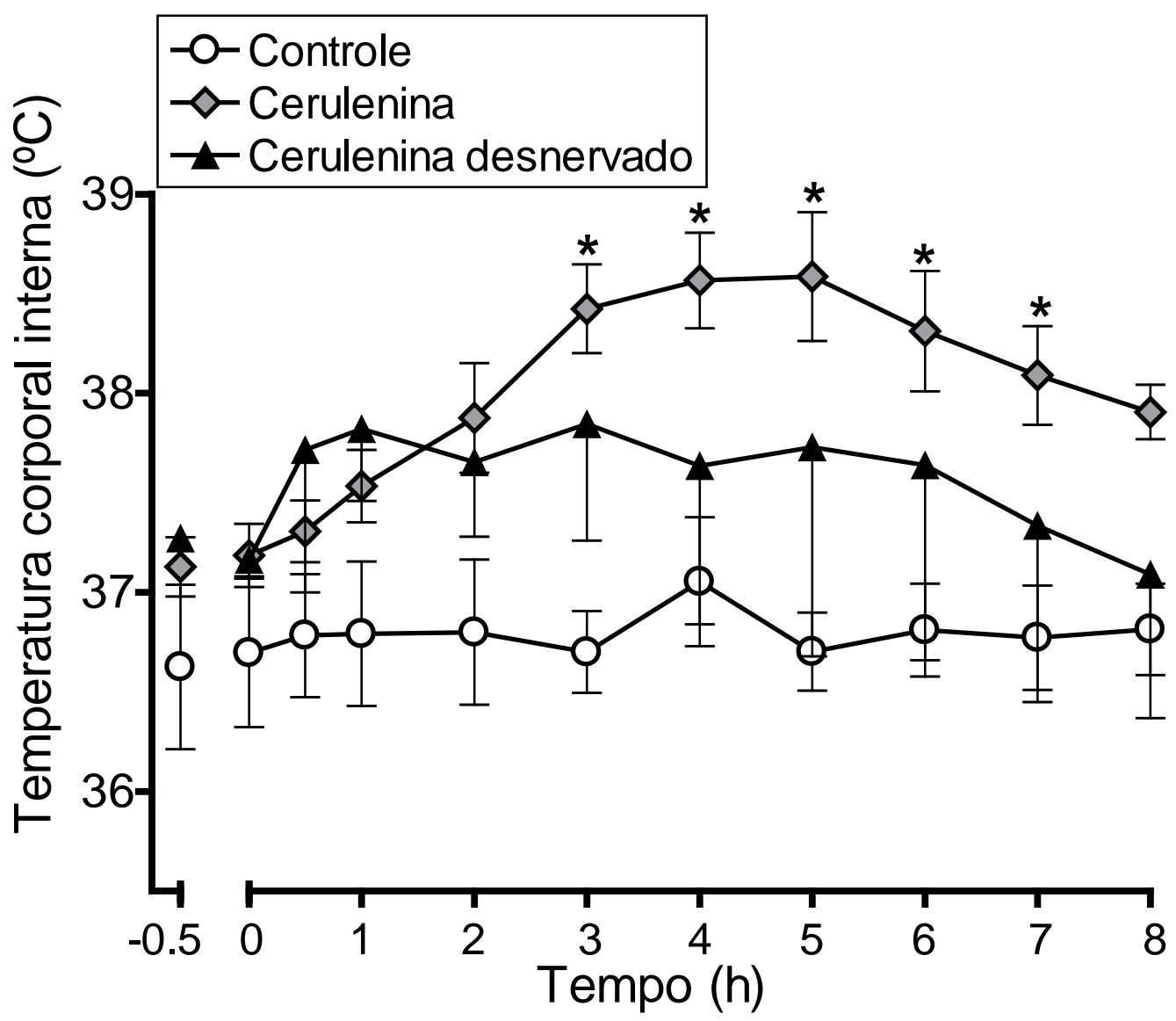

Figura 28 - Temperatura corporal interna ao longo de 8 horas após a administração i.c.v. de cerulenina ou RPMI. Os valores representam a média \pm EPM $(n=2-5)$. O teste utilizado foi Two-Way ANOVA seguido por teste de Bonferroni. ${ }^{*} \mathrm{P}<0,05$ em relação ao controle de seu respectivo tempo. 


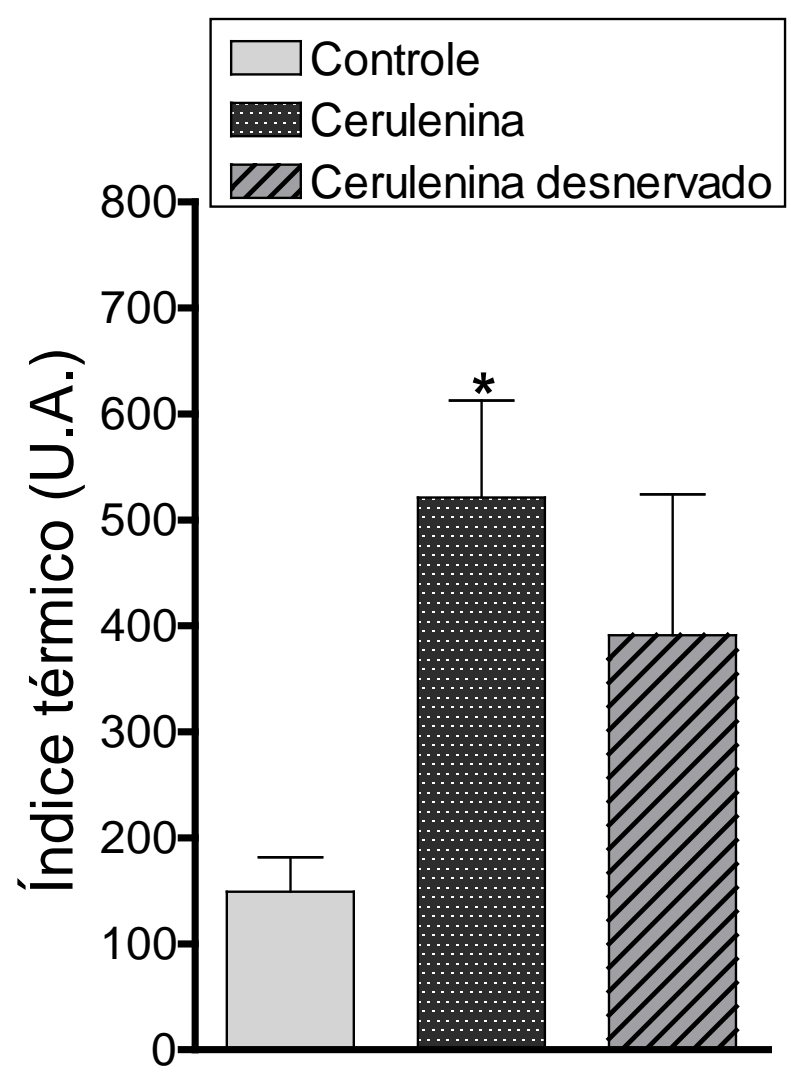

Figura 29 - Índice térmico do período de 0 a 8 horas após a administração i.c.v. de cerulenina ou RPMI. Os valores representam a média \pm EPM das áreas sob as curvas de temperatura corporal interna $(n=2-5)$. O teste utilizado foi One-Way ANOVA seguido por teste de Newman-Keuls. ${ }^{*} \mathrm{P}<0,05$ em relação ao controle. 


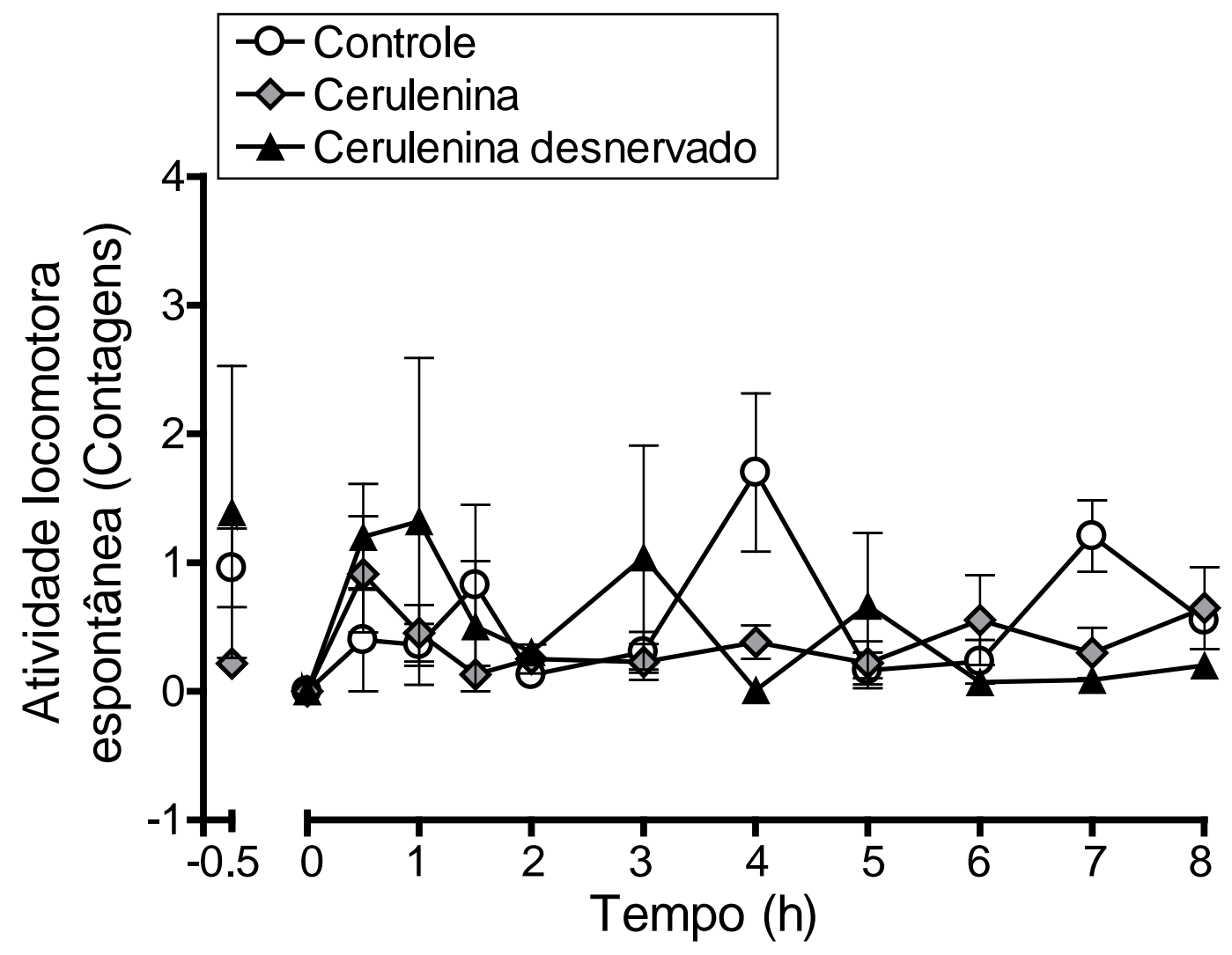

Figura 30 - Atividade locomotora espontânea ao longo de 8 horas após a administração i.c.v. de cerulenina ou RPMI. Os valores representam a média \pm EPM $(n=2-5)$. O teste utilizado foi Two-Way ANOVA seguido por teste de Bonferroni. 


\subsection{Efeito da cerulenina na temperatura do TAM em animais inervados e desnervados.}

A Figura 31.mostra que houve aumento na variação da temperatura do TAM no período de 3 a 5 horas após a administração de cerulenina, sendo este efeito abolido pela desnervação do TAM. Às 3 horas da administração, a temperatura do TAM aumentou em aproximadamente $4,5 \%$. Esta variação foi de $-0,2 \pm 0,2{ }^{\circ} \mathrm{C}$ no grupo controle e de $1,05 \pm 0,3$ ${ }^{\circ} \mathrm{C}$ no grupo com a droga, enquanto o grupo cerulenina desnervado apresentou variação de $0,2 \pm 0,4{ }^{\circ} \mathrm{C}$ no mesmo período.

A análise das áreas sob a curva da temperatura do TAM dos três grupos revelou que a desnervação do TAM bloqueou (203,4 \ 33,5 U.A.) o efeito térmico induzido pela cerulenina sobre o TAM (393,3 \pm 54,5 U.A. vs. 206,1 \pm 21,3 U.A.) no período de 0 a 8 horas (Figura 32). 


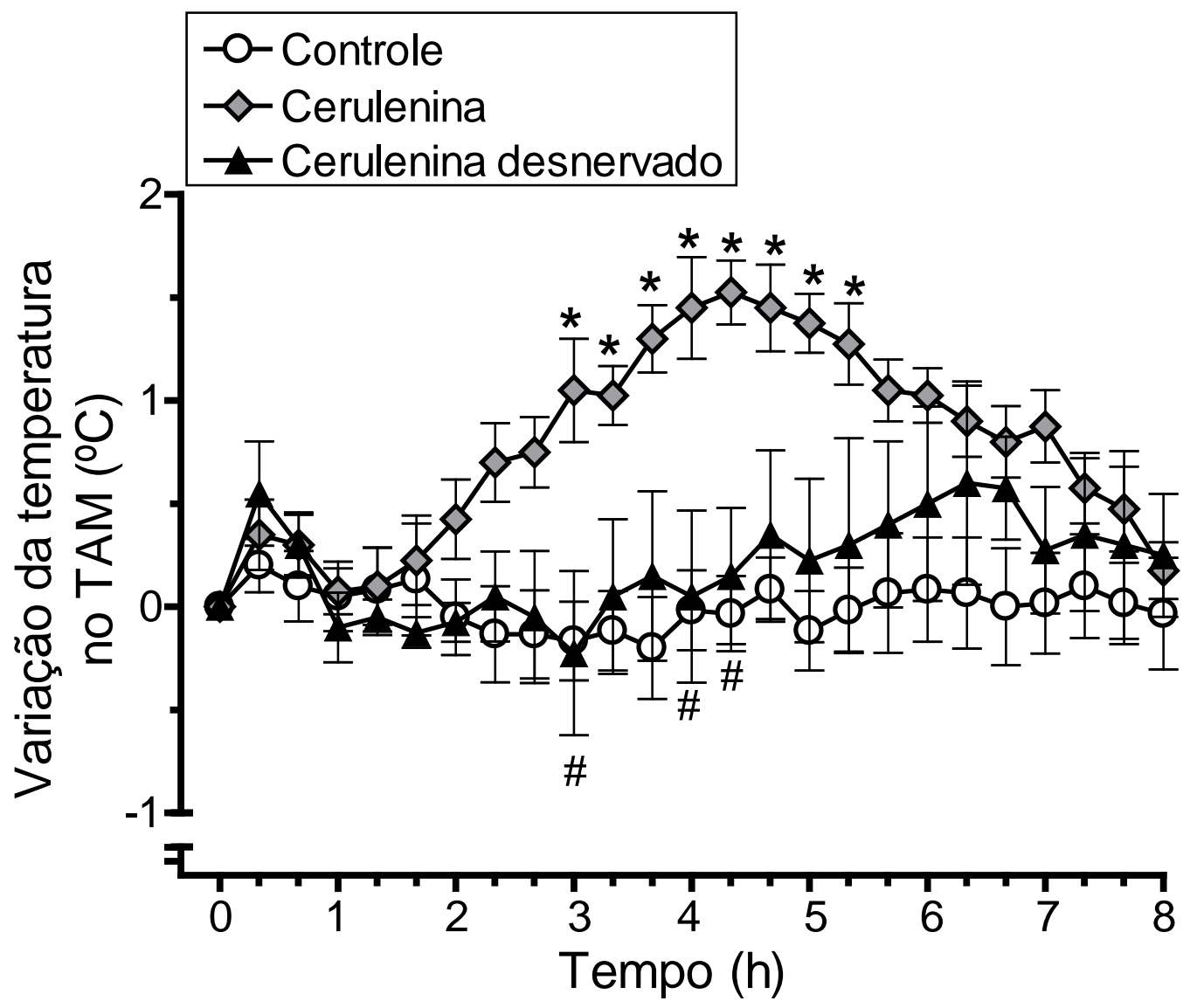

Figura 31 - Variação da temperatura no TAM ao longo de 8 horas após a administração i.c.v. de C75 ou RPMI. Os valores representam a média \pm EPM ( $n=4-7)$. O teste utilizado foi TwoWay ANOVA seguido por teste de Bonferroni. ${ }^{*} \mathrm{P}<0,05$ em relação ao controle; ${ }^{\#} \mathrm{P}<0,05$ em relação ao grupo $\mathrm{C} 75$ de seu respectivo tempo. 


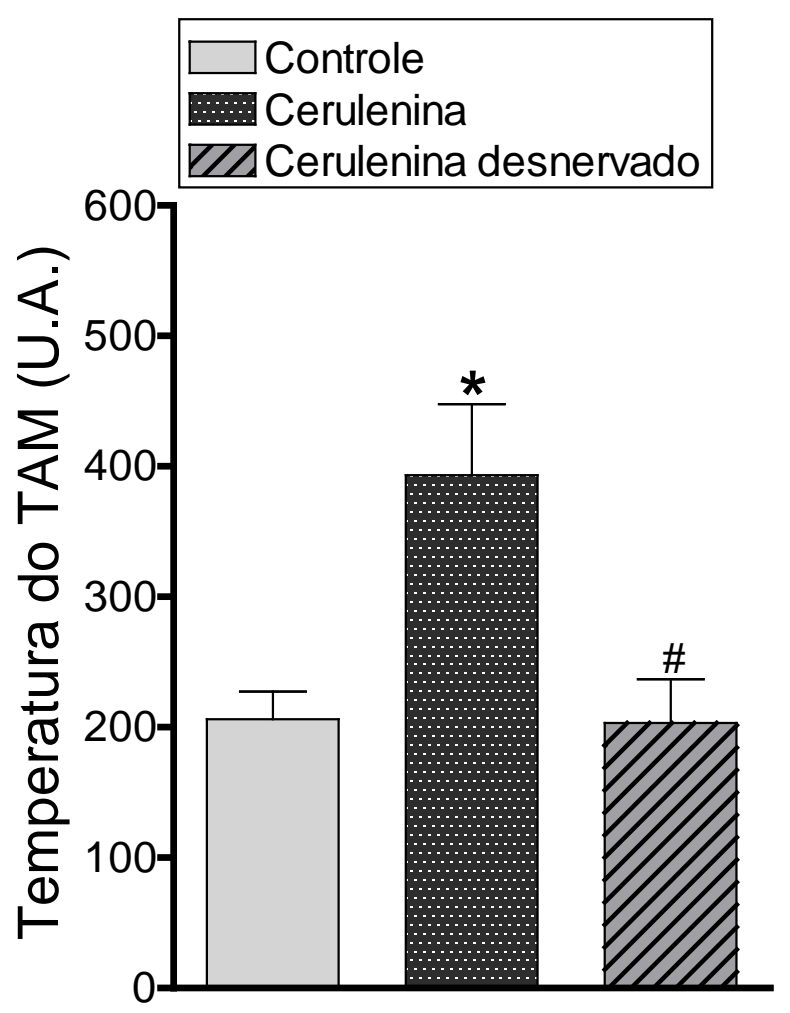

Figura 32 - Temperatura do TAM, representada como área sob a curva dos valores obtidos, durante o período de 0 a 8 horas após a administração i.c.v. de cerulenina ou RPMI. Os valores representam a média \pm EPM das áreas sob as curvas de temperatura corporal interna $(n=3-6)$. O teste utilizado foi One-Way ANOVA seguido por teste de Newman-Keuls. ${ }^{*} \mathrm{P}<0,05$ em relação ao controle; ${ }^{\#} \mathrm{P}<0,05$ em relação ao grupo cerulenina. 


\subsection{Efeito do C75 na atividade neuronal - análise da proteína c-Fos.}

Como pode ser observado na Figura 33, houve aumento significativo do número de neurônios com imunorreatividade à proteína c-Fos em várias áreas hipotalâmicas e do tronco cerebral nos animais que receberam C75. No hipotálamo, as áreas estimuladas foram a APO (aumento de 1,1 x em relação ao controle), a porção parvocelular do PVN medial $(3,7$ $x)$ e do PVN posterior (3 x), DMH (1,6 x) e VMH (2,1 x). Nas regiões do tronco encefálico, o LC (aumento de $8 \times$ em relação ao controle) e a Rpa $(1,8$ x) também apresentaram maior atividade neuronal em resposta à microinjeção de C75. As Figuras 34 e 35 mostram as fotomicrografias representativas de algumas das secções coronais analisadas após a injeção central do C75. 


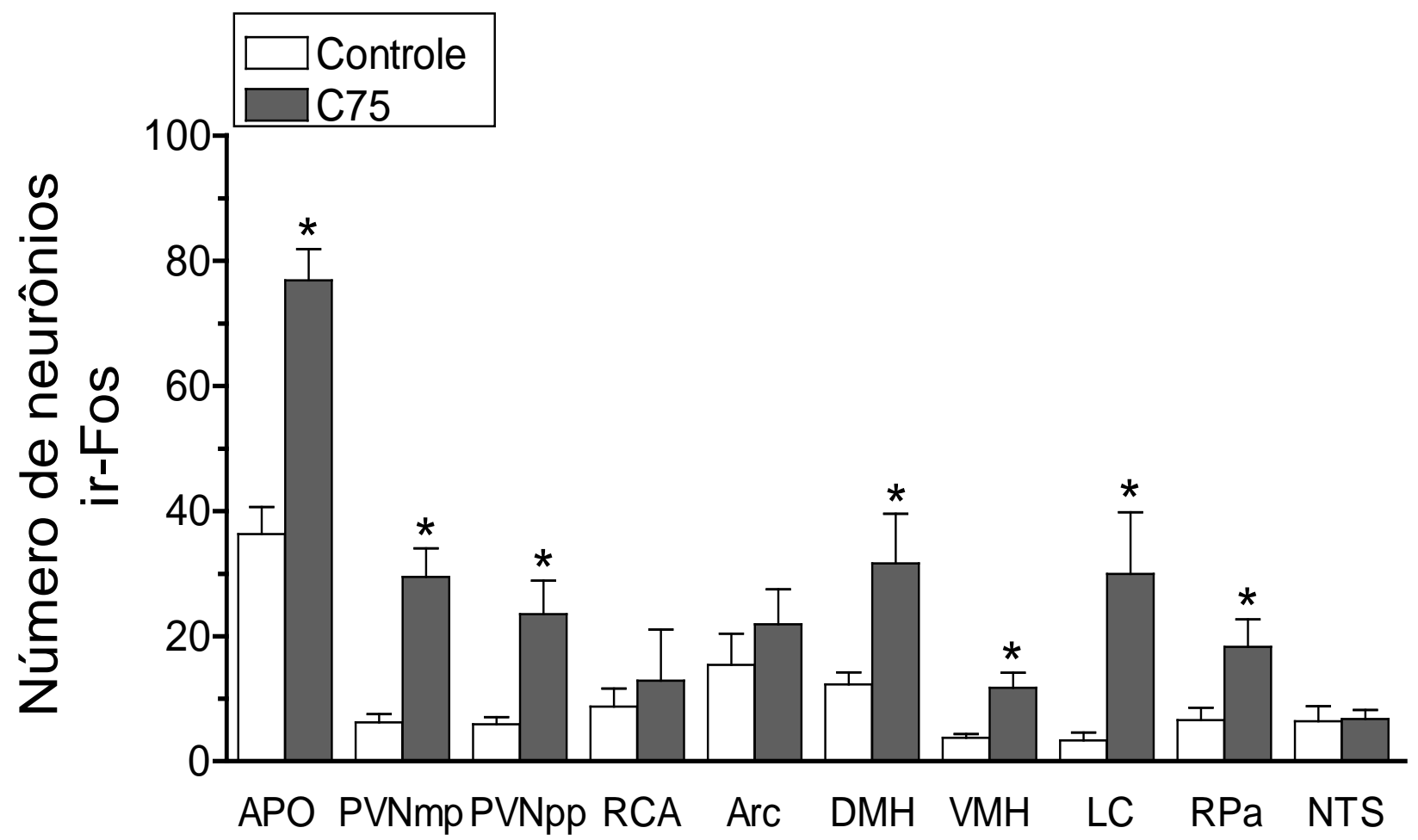

Figura 33 - Contagem dos neurônios imunorreativos à proteína c-Fos em áreas hipotalâmicas e do tronco encefálico após a administração i.c.v. de C75 ou RPMI. APO (área pré-óptica), PVNmp (porção parvocelular do PVN medial), PVNpp (porção parvocelular do PVN posterior), RCA (núcleo retroquiasmático), Arc (núcleo arqueado), DMH (dorsomedial do hipotálamo), VMH (ventromedial do hipotálamo), LC (locus coeruleus), RPa (rafe pálida) e NTS (núcleo do trato solitário). Os valores representam a média \pm EPM ( $n=5-6)$. O teste utilizado foi o $t$ de Student para amostras não-pareadas. ${ }^{*} P<0,05$ em relação ao controle. 


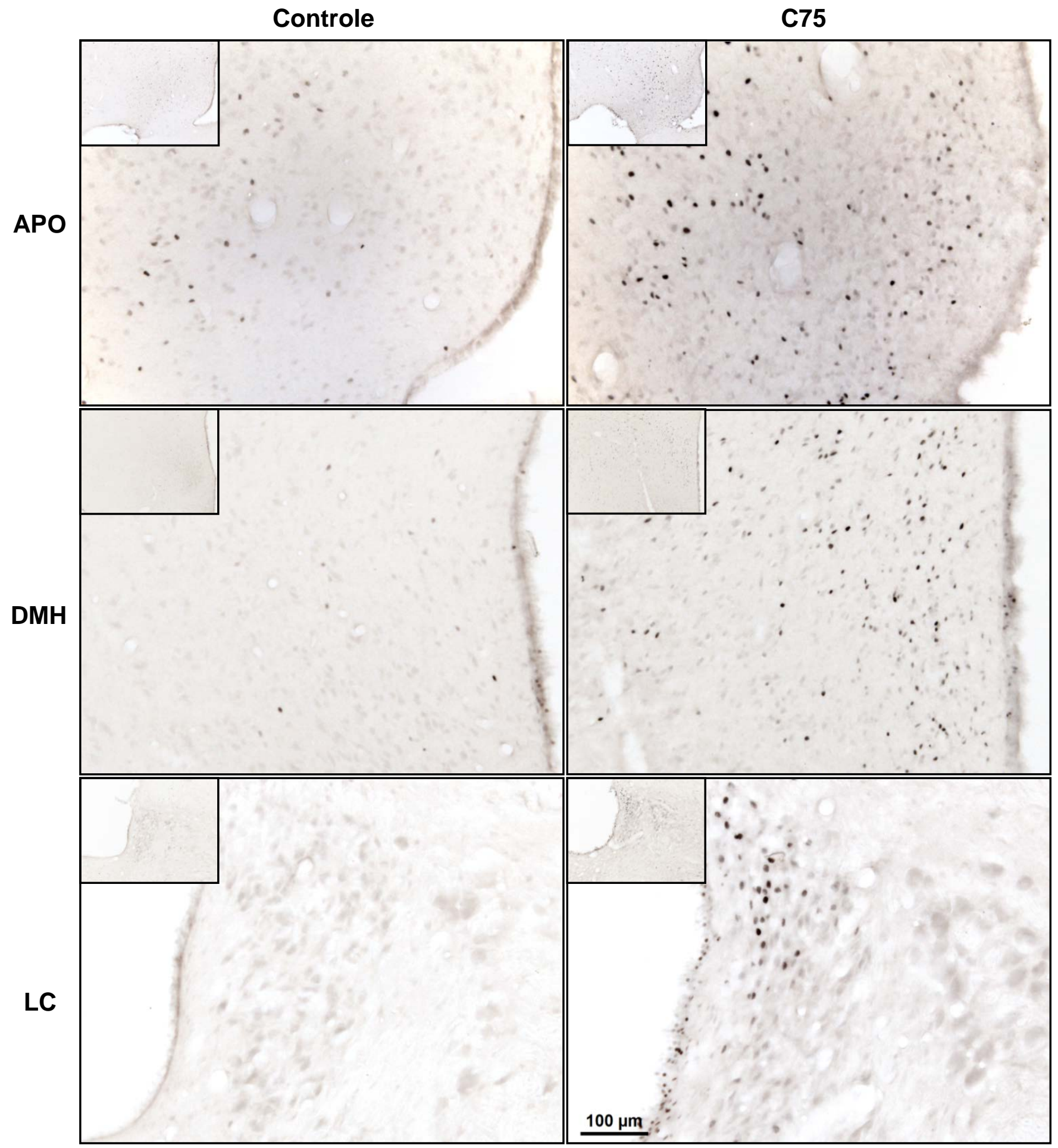

Figura 34 - Fotomicrografias representativas de secções coronais mostrando a imunorreatividade à proteína c-Fos na APO (área pré-óptica), DMH (dorsomedial do hipotálamo) e LC (locus coeruleus) dos grupos Controle e C75. As fotomicrografias estão apresentadas em aumento de $20 \mathrm{x}$ e a área onde as fotomicrografias foram capturadas está apresentada no canto superior esquerdo no aumento de 10x. Barra de escala: $100 \mu \mathrm{m}$. 


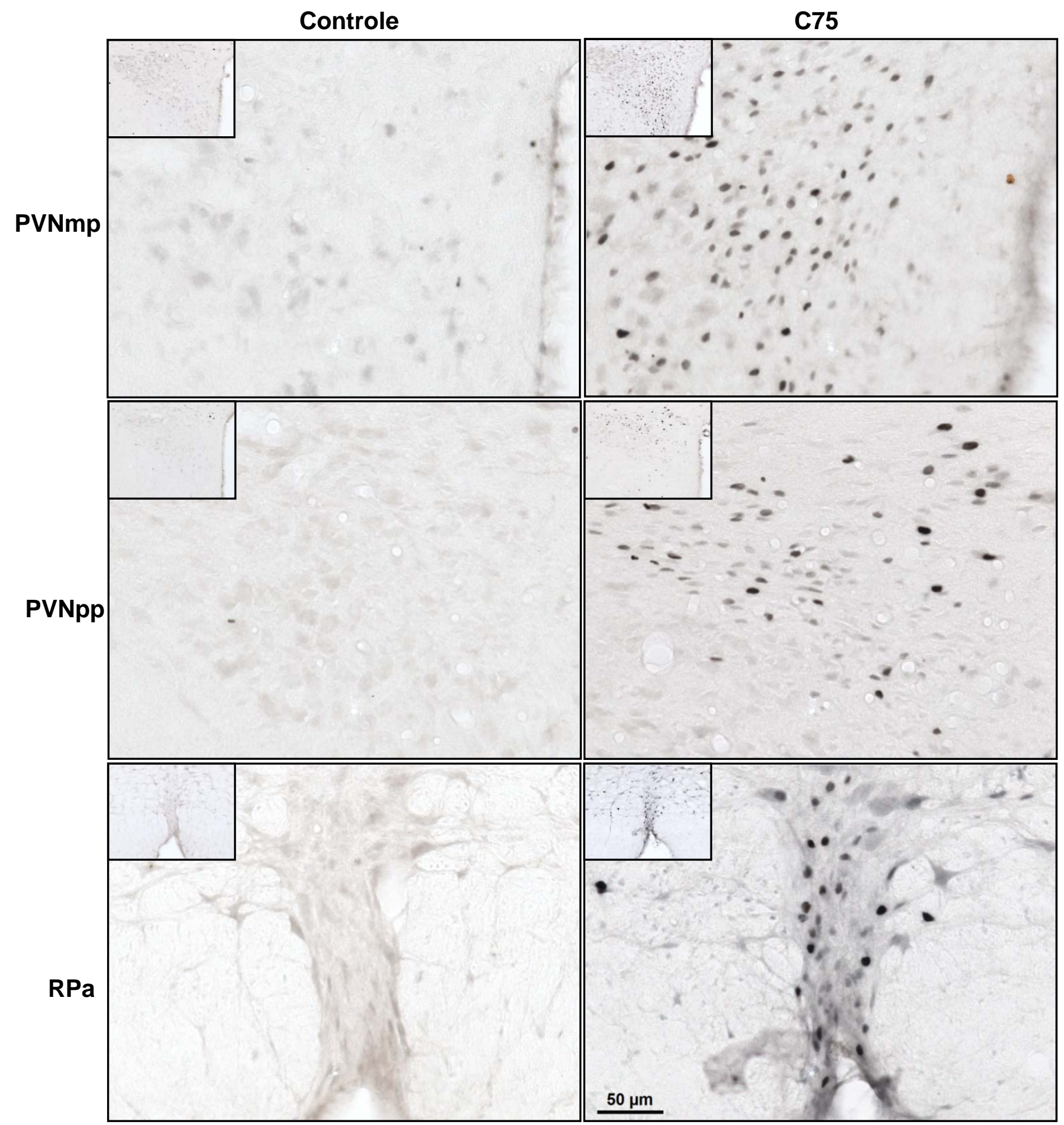

Figura 35 - Fotomicrografias representativas de seç̧ões coronais mostrando a imunorreatividade à proteína c-Fos na PVNmp (porção parvocelular do PVN medial), PVNpp (porção parvocelular do PVN posterior) e RPa (rafe pálida) dos grupos Controle e C75. As fotomicrografias estão apresentadas em aumento de 40x e a área onde as fotomicrografias foram capturadas está apresentada no canto superior esquerdo no aumento de 20x. Barra de escala: $50 \mu \mathrm{m}$. 


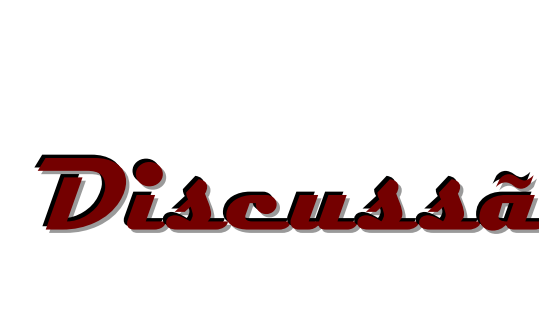




\section{Discussão}

O principal achado do presente estudo é que a administração central de uma única injeção do C75, um inibidor da ácido graxo sintase, em ratos mantido em jejum por 24 horas, induz hipofagia associada à hipertermia e aumento da termogênese facultativa, sendo estes efeitos bloqueados pela desnervação simpática do TAM. Nossas observações sugerem um novo mecanismo pelo qual o C75 contribui para a perda de peso corporal.

Sabendo-se que as ações centrais do C75 são classicamente relacionadas com hipofagia, tornou-se necessário, inicialmente, conhecer as alterações da ingestão alimentar induzidas pelo C75 em nossos animais. Como esperado, logo após as primeiras 3 horas da administração da droga, observou-se redução da ingestão alimentar. Este efeito hipofágico se manteve durante as primeiras 24 horas (Figuras 1 e 2). 0 mesmo perfil de resposta foi encontrado por outros autores, após administração i.c.v. e i.p. desta droga em ratos (Mansouri et al., 2008; Proulx et al., 2008; Mera et al., 2009) e camundongos (Kim et al., 2004; Cha et al., 2005).

Apesar do potente efeito hipofágico do C75 no primeiro dia de sua administração, a ingestão alimentar foi restabelecida no segundo dia (Figura 2), enquanto que a ingestão hídrica não foi afetada pela droga (Figura 3). Trabalhos anteriores mostram que, mesmo com administrações repetidas, a ação do C75 sobre a ingestão alimentar é transitória. Kumar et al. (2002) utilizaram um esquema de tratamento de 4 injeções/dia (i.p.) de C75, durante 4 dias, em camundongos e observaram a resposta hipofágica somente no primeiro dia. Além disso, foi demonstrado que camundongos magros e obesos (induzidos por dieta) tornaramse resistentes ao efeito anorexígeno da droga, após o 20 ํ e 16 dia de tratamento (i.p.), respectivamente (Thupari et al., 2004). 
É bem estabelecido na literatura que a redução da ingestão alimentar promovida pelo C75 é um reflexo da modulação da expressão de diferentes neuropeptídeos hipotalâmicos. Foi demonstrado que a administração i.c.v. de C75, após 3 horas, aumenta a expressão de neuropeptídeos anorexígenos (CART e POMC) e reduz a dos orexígenos (NPY e AgRP) em hipotálamo de camundongos magros (Hu et al., 2005). Em outros estudos, demonstrou-se que o C75, após 24 horas da administração i.p. em camundongos magros e obesos (ob/ob), preveniu o aumento dos neuropeptídeos NPY e AgRP induzido pelo jejum, em ambos animais, e promoveu um pequeno aumento na expressão de CART e POMC somente nos animais magros (Shimokawa et al., 2002).

Além de reduzir a ingestão alimentar nas primeiras 24 horas após a administração, observou-se no presente estudo que o C75 promoveu perda de peso corporal nesse mesmo período de tempo. Vale a pena ressaltar que o peso corporal dos animais tratados com C75 ainda permanecia abaixo dos valores controles após 48 horas da injeção, momento este em que a ingestão alimentar já estava normalizada (Figura 4). Resultados semelhantes foram relatados em estudos com camundongos magros e obesos (ob/ob e induzidos por dieta) submetidos ao tratamento com C75 e comparados a animais pair-fed (Kumar et al., 2002). A partir dessas evidências, pode-se sugerir que a perda de peso corporal induzida pelo tratamento central com $\mathrm{C} 75$ em roedores não é apenas o resultado da diminuição da ingestão, mas sim da ativação de mecanismos relacionados ao aumento do gasto energético. De fato, estudos de calorimetria indireta já haviam demonstrado que o C75 aumenta o consumo corporal de oxigênio (Thupari et al., 2002; Thupari et al., 2004; Tu et al., 2005), muito provavelmente por meio da ativação do sistema nervoso simpático. O presente estudo corrobora essa hipótese uma vez que o C75 induziu aumento da atividade simpática do TAM, avaliada indiretamente pelo aumento do conteúdo de noradrenalina neste tecido. 
Embora nosso estudo não tenha detectado aumento significativo das concentrações plasmáticas das catecolaminas, dados prévios da literatura mostram que a administração i.c.v. de C75 aumenta rapidamente a concentração de noradrenalina e AMPc, assim como a expressão de adrenorreceptores do sub-tipo $\beta_{3}$ no tecido muscular de camundongos, 2 horas após a injeção (Cha et al., 2006). Além disso, demonstrou-se no presente trabalho que o C75 induziu um aumento transitório nas concentrações plasmáticas de glicose e ácidos graxos livres em ratos acordados, dois efeitos clássicos de ativação simpática periférica (Nonogaki et al., 2000), que foram provavelmente resultantes do aumento da produção hepática de glicose e da maior mobilização dos estoques de triacilglicerol do tecido adiposo branco, respectivamente. Resultados semelhantes foram observados após a administração de C75 (Hu et al., 2003) ou cerulenina (Makimura et al, 2001) em camundongos, sem que houvesse alteração na concentração plasmática de insulina, leptina ou corticosterona. Como se pode observar na Figura 5, o aumento da glicemia após 1 hora da administração de C75 foi transitório. O retorno a valores normais de glicemia nos demais tempos estudados pode ter sido resultante do aumento da utilização desse substrato, como tem sido sugerido por diversos trabalhos que relatam redução da hiperglicemia de camundongos obesos ob/ob após 2 horas da administração i.c.v. ou i.p. de C75 (Cha et al., 2005; Shimokawa et al., 2002; Loftus et al., 2000). Na análise da curva temporal da concentração plasmática de ácidos graxos livres (Figura 6), pode-se observar que houve grande variação desse metabólito ao longo do tempo, com aumento aos 15, 30 e 180 minutos após a administração do C75. Estes resultados são completamente diferentes daqueles encontrados por Cha et al., (2005). Nesse estudo, realizado em camundongos, verificou-se que C75 reduziu a concentração plasmática de ácidos graxos livres logo após 2 horas da injeção. A razão destes resultados aparentemente contraditórios pode estar relacionada às diferentes espécies estudas e/ou ao 
grau de estresse dos animais no momento da coleta do sangue. Ao contrário de nosso estudo realizado em animais canulados e submetidos a 24 horas de privação alimentar, estes autores obtiveram as amostras de sangue do sino orbital de animais submetidos ao jejum de pernoite (12 horas).

Os efeitos periféricos decorrentes da administração central do C75 não foram associados a alterações hormonais aparentes, uma vez que as concentrações plasmáticas de insulina, corticosterona e dos hormônios tireoidianos não foram diferentes dos valores controles. Estes dados fortalecem a hipótese de que o sistema nervoso simpático é o principal mediador das alterações periféricas induzidas pela administração central do C75.

Em estudos anteriores, foi demonstrado que o tratamento crônico com C75 por duas semanas aumentava a expressão de genes relacionados com o gasto energético (enzimas do metabolismo oxidativo mitocondrial, UCP2, UCP-3, etc.) em diferentes tecidos periféricos como o fígado, músculo esquelético e tecido adiposo branco (Tu et al., 2005). Entretanto, foi Cha et al. (2005; 2006) que demonstraram, pela primeira vez, que administração central aguda de C75 resultava em efeitos semelhantes e que tais efeitos estavam diretamente associados ao aumento da atividade simpática muscular. De acordo com estes autores, a hiperexpressão da UCP-3 no músculo esquelético seria o mecanismo bioquímico responsável pelo aumento do gasto energético induzido pelo $\mathrm{C75}$, uma vez que este tecido pode dissipar parte da energia obtida da oxidação de ácidos graxos sob a forma de calor. No entanto, esta hipótese precisa ainda ser confirmada uma vez que o papel da UCP-3 no músculo esquelético ainda é bastante discutido.

Os dados do presente trabalho indicam que o TAM, um tecido ricamente inervado por fibras simpáticas, também pode participar do aumento do gasto energético induzido 
pelo C75. Como pode ser observado na Figura 4, a desnervação simpática do TAM atenuou a perda de peso após 24 e 48 horas da administração central da droga, indicando assim que o fluxo simpático deste tecido contribui diretamente para a perda de peso corporal induzida pelo $\mathrm{C75}$, não só por desencadear sinais periféricos de saciedade (Figura 2), mas também por promover aumento da termogênese.

O gasto energético total pode ser definido como a soma de diversos processos metabólicos que ocorrem em diferentes órgãos e são obrigatoriamente acompanhados pela produção de calor, a qual representa um dos fatores que influencia a temperatura corporal interna (Himms-Hagen, 1989a). Assim sendo, o aumento do gasto energético poderia refletir em aumento da temperatura corporal interna. Como pode ser observada nas Figuras 12,13 e 14, a administração i.c.v. de C75 aumentou a temperatura corporal interna, o índice térmico e a taxa de estoque de calor, respectivamente. Este aumento não foi devido ao aumento da produção de calor induzida pela contração (ou trabalho) muscular, uma vez que não houve alteração da atividade locomotora espontânea durante o período estudado (Figuras 15 e 16).

A análise temporal das alterações térmicas promovidas pelo C75 em nossos animais mostra que o aumento da temperatura corporal interna (Figura 12) e da taxa de estoque de calor (Figura 14) tiveram início já nos primeiros 30 minutos da administração. Verifica-se que no momento em que há aumento na concentração de noradrenalina no TAM (após 1 hora; Figura 11), a curva de registro da temperatura corporal interna está bastante ascendente, enquanto que a taxa de estoque de calor já alcançou o seu valor máximo, indicando, portanto, que o fluxo simpático ao TAM é o responsável pela geração da hipertermia induzida pelo C75. Corroborando esta ideia, foi demonstrado que a desnervação simpática 
bilateral do TAM atenuou o aumento da temperatura corporal interna durante as primeiras 4 horas (Figura 12), aboliu o aumento do índice térmico de 0 a 20 horas (Figura 13) e o aumento da taxa de estoque de calor nas primeiras 4 horas (Figura 14), sem entretanto alterar a atividade locomotora espontânea dos animais (Figuras 14 e 15).

Nossos resultados também mostram que a temperatura corporal interna e a taxa de estoque de calor apresentaram-se aumentadas até 9 e 6 horas da administração da droga, respectivamente. Esta natureza transitória dos efeitos térmicos induzidos pelo C75 indica que mecanismos contra-regulatórios de defesa do organismo contra o aumento da temperatura foram acionados pela droga. O aumento da temperatura da pele da cauda (Figuras 19 e 20) induzido pelo C75 permite inferir que a vasodilatação periférica, mecanismo que favorece a troca de calor com o ambiente, foi acionada a fim de fazer retornar a temperatura corporal interna aos seus valores basais.

A produção adicional de calor pelo TAM certamente está envolvida no aumento da temperatura corporal interna em nossos animais, visto que houve aumento da temperatura deste tecido desde 1 até 8 horas da administração da droga (Figuras 17 e 18). Como a temperatura do TAM manteve-se alta mesmo quando a taxa de estoque de calor já estava semelhante a do controle (Figura 13), é possível sugerir que a maior troca de calor para o ambiente, pela vasodilatação periférica, tenha sido um mecanismo eficiente para garantir o retorno da temperatura corporal interna aos valores basais.

Os dados do presente estudo mostram também que o fluxo simpático ao TAM deve ser o principal responsável pela termogênese promovida pelo C75. Como pode ser observado na Figura 17, a desnervação simpática aboliu completamente o aumento da temperatura do TAM em resposta ao C75. Além disso, esta droga não promoveu qualquer 
alteração na concentração plasmática da tiroxina $\left(T_{4}\right)$ total, que é um hormônio tiroidiano cuja ação é mediada pela sua conversão a $T_{3}$, e um dos principais hormônios reguladores da termogênese no TAM. É bem estabelecido na literatura que ocorre uma rápida supressão dos níveis de $T_{3}$ e $T_{4}$ para a preservação dos estoques de energia durante o jejum (Perello et al., 2010). Portanto, o fato das concentrações plasmáticas de $T_{3}$ estar abaixo do limite de detecção do método utilizado, isto é, $<40,0 \mathrm{ng} \cdot \mathrm{dL}^{-1}$ (dados não mostrados), provavelmente foi devido ao estado de privação alimentar de 24 horas a que os animais foram submetidos antes da administração da droga.

O conjunto dos dados até agora discutidos, em especial os resultados com a desnervação do TAM, sugere que, além da indução da hipofagia, a ação central do C75 induz ativação simpática para o TAM, que por sua vez promove aumento da produção de calor pelo tecido e, consequentemente, da temperatura corporal interna. Portanto, o efeito hipofágico associado ao aumento do gasto energético poderiam explicar a perda de perda corporal induzida pelo $\mathrm{C} 75$ em ratos.

Tendo em vista que a desnervação simpática do TAM também atenuou a hipofagia induzida pelo C75 (Figura 2), sugere-se que o efeito térmico da droga possa também interferir com o comportamento alimentar dos animais. Portanto, propõe-se neste trabalho a existência de um novo mecanismo de ação do C75 que envolve a temperatura corporal como um sinalizador de seu efeito hipofágico. Dessa forma, o aumento da temperatura interna promovido pelo C75 poderia atuar de maneira sinérgica aos efeitos centrais da droga, no sentido de alterar a expressão dos neuropeptídeos hipotalâmicos que controlam o comportamento alimentar. Há muito tempo se sabe que o estado de saciedade pode ser modulado pelo efeito termorregulatório dos alimentos. Segundo Himms-Hagen (1995), este 
controle se dá pela interrupção da alimentação induzida pelo aumento da temperatura corporal interna resultante do estímulo da termogênese no TAM. Portanto, o tempo entre o início e o término da alimentação é dependente do balanço entre a termogênese no TAM e a perda de calor para o ambiente. A existência desse mecanismo (thermoregulatory feeding) foi validada por um estudo realizado em humanos neonatos, onde a inibição do comportamento alimentar foi diretamente relacionada a ativação da termogênese no TAM, um tecido que corresponde a $2-5 \%$ do peso corporal nesses indivíduos (Chardon et al., 2006). Acredita-se que o sinal que dispara a termogênese no TAM em resposta à ingestão alimentar seja decorrente da distensão do estômago, que está diretamente relacionada com o volume e a qualidade do alimento. Há evidências obtidas em crianças pré-maturas, de que a distensão gástrica estimula sinais vagais ao hipotálamo, em especial ao $\mathrm{VMH}$, o qual também controla a produção de calor pelo TAM (Telliez et al., 2002; Chardon et al., 2006).

Com a finalidade de certificar a existência do estímulo da termogênese no TAM em resposta ao $\mathrm{C75}$, investigaram-se no presente estudo os marcadores da termogênese neste tecido. Primeiramente, avaliou-se a combustão de lipídeos, que é um componente específico do gasto energético pela termogênese no TAM (Himms-Hagen, 1989a), e depois verificou-se a expressão da UCP-1, proteína chave da termogênese facultativa.

A queda do conteúdo de gordura total no TAM (Figura 21) infere que o C75 promoveu a lipólise das gotículas de gordura do tecido. Além disso, o C75 aumentou a atividade enzimática da citocromo c oxidase mitocondrial (Figura 22), uma das enzimas que compõem a cadeia respiratória mitocondrial e cuja atividade reflete o nível de oxidação no tecido. Isso implica que houve aumento da fosforilação oxidativa, provavelmente, dos ácidos graxos mobilizados das gotículas lipídicas do próprio tecido. Curiosamente, a atividade da 
citrato sintase, enzima que catalisa a primeira etapa do ciclo de Krebs, não foi alterada pela administração central do C75 (Figura 23). Como a desnervação do TAM bloqueou a redução do conteúdo de gordura e o aumento na atividade da citocromo c oxidase, pode-se concluir que estes efeitos foram consequência do maior fluxo simpático ao tecido.

Esses resultados estão de acordo com trabalhos anteriores da literatura que demonstram que o principal combustível consumido durante a ativação da termogênese no TAM, em resposta à ativação da sinalização $\beta$-adrenérgica pela noradrenalina, são os ácidos graxos liberados dos estoques de triacilglicerol do próprio tecido (Smith \& Horwitz, 1969; Flatmark \& Pedersen, 1975). Os ácidos graxos, então, estimulam a respiração por servirem como substratos para a $\beta$-oxidação (dependente de carnitina) e/ou por aumentar simultaneamente o desacoplamento de prótons (Cannon et al., 1977; Nicholls, 1979; Nedergaard \& Lindberg, 1982, Bukowieck et al., 1981). Sabe-se que o desacoplamento de prótons no TAM é controlado diretamente pela atividade da UCP-1 mitocondrial, de tal forma que a capacidade máxima dos adipócitos em promover termogênese é determinada pela concentração dessa proteína (Cannon \& Nedergaard, 2004). Como ilustra a Figura 24, a administração i.c.v. de C75 aumentou a expressão da UCP-1 após 4 horas, indicando que os ácidos graxos provenientes das gotículas lipídicas do tecido foram oxidados para produzir calor (Krauss et al., 2005). Interessante é que a expressão da UCP-1 foi reduzida pela desnervação simpática do TAM em relação ao grupo controle somente após 4 horas da administração da droga, sem qualquer alteração após 1 hora. Isto indica que mecanismos adicionais à expressão gênica da UCP-1 são os responsáveis pela ativação a curto prazo da termogênese facultativa em resposta ao aumento do fluxo simpático induzido pelo C75. 
Com o objetivo de verificar se o efeito térmico induzido pelo C75 não era apenas resultante de um efeito inespecífico da droga no sistema nervoso central, investigou-se nesse trabalho os efeitos termoregulatórios induzidos pela cerulenina, um inibidor natural da ácido graxo sintase. Apesar da administração i.c.v. de cerulenina não ter afetado a ingestão alimentar, a ingestão hídrica e o ganho de peso corporal (Figuras 25 a 27), a cerulenina foi capaz de aumentar a temperatura corporal interna (Figuras 28 e 29) e a temperatura do TAM (Figuras 31 e 32), sem alterar a atividade locomotora espontânea (Figura 30). O efeito térmico da cerulenina foi de menor intensidade e duração em comparação ao efeito do C75, mas também foi prevenido pela desnervação simpática do TAM.

Em estudos anteriores, já havia sido demonstrado que a administração periférica de cerulenina em camundongos jejuados reduz o peso corporal sem alterar a ingestão alimentar ou a expressão dos neuropeptídeos anorexígenos (CART e POMC) ou orexígenos (NPY e AgRP) (Jin et al., 2004; Makimura et al., 2001). Foi também relatado que a queda da temperatura corporal interna dos camundongos em jejum foi revertida pela administração i.p. de cerulenina no período de 3 a 5 horas. Este efeito térmico da cerulenina foi bloqueado pelo pré-tratamento com AMPT ( $\alpha$-metil $p$-tirosina), que é o inibidor da enzima tirosina hidroxilase, indicando que o sistema nervoso simpático está envolvido no aumento da temperatura corporal interna promovido por esta droga (Jin et al., 2004). Nossos dados corroboram essa hipótese e demonstram que os efeitos térmicos da cerulenina são decorrentes da indução da termogênese no TAM, pois a desnervação simpática deste tecido preveniu completamente o aumento da temperatura induzido por esta droga (Figura 32). Este efeito poderia explicar o aumento da atividade metabólica (avaliada por calorimetria 
indireta) observada previamente em camundongos obesos da linhagem ob/ob tratados com cerulenina (Makimura et al., 2001).

Estudos mais recentes têm comparado os efeitos hipofágicos promovidos pelo C75 aos da leptina e sugerido que ambos os compostos ajam por mecanismos comuns. Por exemplo, de forma semelhante ao C75 (Kim et al., 2004; Landree et al., 2004; Wortman et al., 2003), tem sido demonstrado que a redução da ingestão alimentar promovida pela ação da leptina no sistema nervoso é mediada pela ativação da ACC no Arc e no PVN, via inibição da AMPK (Gao et al., 2007). Além disso, a administração intravenosa de leptina aumentou a oxidação de ácidos graxos em músculos esqueléticos ricos em fibras oxidativas de camundongos (Minokoshi et al., 2002), efeito similar ao encontrado em camundongos magros e obesos após administração i.c.v. de C75 (Cha et al., 2005). Com relação aos efeitos termoregulatórios da leptina, há evidências de que a injeção central deste hormônio promove ativação simpática do TAM em camundongos magros, obesos (ob/ob e induzidos por dieta) e ratos, com aumento da expressão da UCP-1 (Masaki et al., 2003; Enriori et al., 2011; Tajima et al., 2005). Além disso, ratos obesos (induzidos por dieta), quando comparados aos animais magros, apresentam maior concentração plasmática de leptina correlacionada com elevada temperatura corporal e expressão de UCP-1 no TAM. Estes efeitos térmicos são resultantes do aumento de $T_{3}$ e $T_{4}$ plasmáticos promovido pela ativação do eixo hipotálamo-hipófise-tireóide pela leptina que age diretamente no PVN ou, indiretamente, via Arc (Perello et al., 2010). Mas, diferentemente da leptina, nossos resultados indicam que o aumento da temperatura corporal e da expressão da UCP-1 pelo C75 é resultado exclusivamente da ativação simpática ao TAM, independentemente dos hormônios tiroidianos. 
O presente estudo também teve como finalidade investigar as áreas centrais ativadas pela administração central do C75. Para isso, quantificaram-se os neurônios imunorreativos à proteína c-Fos, localizada no núcleo da célula. O aumento de proteína c-Fos é utilizado como marcador de atividade neuronal, pois, em condições basais, os níveis de proteína c-Fos são muito baixos, e seu nível máximo é atingido entre 1 hora e 3 horas após um estímulo neuronal. A expressão da proteína c-Fos, especialmente pelo gene c-fos, pode ser deflagrada pelas vias PKA, PKC, MAPK e/ou CAMK, as quais são estimuladas por sinais externos, e estão relacionadas com a geração de potencial de ação em neurônios (Kovács, 1998).

Contrapondo a teoria de Takahashi et al. (2004) de que o C75 induz uma ativação neuronal inespecífica, a análise da atividade neuronal em nossos animais revela que muitas áreas envolvidas na regulação da ingestão alimentar e/ou da termogênese do TAM estão com maior quantidade de neurônios imunorreativos à c-Fos, após 90 minutos da administração do C75. Como ilustram as Figuras 33 a 35, estas áreas foram a APO, PVN, DMH, VMH, LC e RPa. Semelhante aos dados desse trabalho, há evidências de que a administração central de C75 em camundongos (Gao \& Lane, 2003) e periférica em ratos (Rohrback et al., 2005), após 2 horas, promove aumento de neurônios imunorreativos à cFos no PVN. Porém, diferentemente de nosso estudo (Figura 33), trabalhos encontraram aumento também no Arc (Gao \& Lane, 2003; Rohrback et al., 2005; Miller et al., 2004), e no NTS (Gao \& Lane, 2003; Miller et al.; 2004) . Diferentemente dos nossos resultados (Figuras 33 e 35), Miller et al. (2004) demonstraram que o C75, após 3 horas da administração i.p em camundongos, reduz a quantidade de neurônios imunorreativos à c-Fos no DMH. Os resultados contraditórios em relação ao NTS podem ser justificados pela via de administração da droga. Enquanto a administração i.p. de C75 é acompanhada por aversão ao paladar condicionada, aparentemente por indisposição ou irritação visceral, a via i.c.v. 
produz o mesmo grau de efeito anorexígeno sem produzir qualquer efeito aversivo (Clegg et al., 2002). Portanto, a ativação do NTS, que participa da via aferente que leva informações sobre o paladar, o trato gastrointestinal e outras informações viscerais para o córtex sensorial visceral (Berthoud, 2002) pode ser facilmente explicada após a administração periférica do C75. No entanto, o fato de não termos observado ativação do núcleo Arc em resposta ao C75 é, de fato, intrigante, uma vez que este núcleo é rico em neurônios que expressam os neuropeptídeos que sabidamente são modulados pela droga (Hu et al., 2005). Apesar dessas contradições, há uma concordância entre esses diferentes estudos de que o PVN é um núcleo de grande relevância para as respostas centrais ou periféricas induzidas pelo C75.

O PVN é um importante núcleo na integração da informação autonômica e neuroendócrina, e possui neurônios que desempenham papel essencial para o controle do metabolismo, crescimento, reprodução, estresse, resposta imune, dentre outros (Ferguson et al., 2008). Como componente da rede que controla o comportamento alimentar, o PVN recebe projeções de neurônios POMC, NPY e AgRP do Arc, núcleo denominado como centro integrativo primário, cuja atividade é modulada por hormônios e nutrientes (Blouet \& Schwartz, 2009). Além do PVN, outras regiões hipotalâmicas envolvidas com o controle da ingestão alimentar, como o $\mathrm{DMH}$ e o $\mathrm{VMH}$, também foram ativadas pela administração do C75. Como essas diferentes áreas expressam enzimas alvos da ação do C75, como, por exemplo, a ácido graxo sintase, AMPK e ACC (Kim et al., 2002; López et al., 2007), e algumas delas são ricas em neurônios sensíveis a nutrientes, como o PVN e o VMH (Blouet \& Schwartz, 2009; Dunn-Meynell et al., 1997), é possível sugerir que todas elas tenham participado da resposta hipofágica da droga. Dentre estas, o VMH é considerado, há muito tempo, como o centro da saciedade, e o $\mathrm{DMH}$ está envolvido na via final comum da 
termogênese no TAM, da secreção de CRH pelo PVN e do fluxo simpático para a glândula adrenal (Bernardis \& Bellinger, 1998). A participação do Arc como mediador dessas respostas foi excluída devido à quantidade inalterada de neurônios imunorreativos à c-Fos pelo C75 neste núcleo (Figura 35). Considerando, entretanto, que a imunorreatidade dos neurônios foi avaliada apenas em um único tempo após a administração da droga (90 minutos), é possível que esta área tenha sido ativada em períodos de tempos não investigados.

O PVN, VMH e a área hipotalâmica lateral também estão envolvidos na regulação dos níveis plasmáticos de glicose e ácidos graxos por meio das vias neurais e, indiretamente, por meio da secreção de hormônios como insulina, glucagon, noradrenalina e adrenalina (Steffens et al., 1988). Estudos anteriores de nosso laboratório demonstraram que sinapses colinérgicas no VMH participam do sistema central da regulação da glicemia. Esses neurônios, quando ativados, aumentam rapidamente a produção hepática de glicose, principalmente por meio do estímulo da secreção da adrenalina pela medula da adrenal (Brito et al., 1993). Esta função do $\mathrm{VMH}$ ajuda a compreender o aumento da glicemia promovido pelo C75 (Figura 5), apesar da concentração de adrenalina plasmática não ter sido alterada pela droga (Figura 10).

No que se refere à discussão das áreas centrais que participam da ativação da termogênese induzida pelo $\mathrm{C75}$, deve-se considerar, inicialmente, o estímulo fisiológico para a produção de calor, isto é, a temperatura e a alimentação. Quando a produção de calor é uma resposta à queda da temperatura corporal, a via da regulação central da termogênese parece ter início na APO, região que recebe sinais do núcleo supraquiasmático, cuja função relaciona-se com o ritmo circadiano. A APO é a área que recebe as aferências dos receptores 
térmicos distribuídos pelo corpo e é a integradora dos sinais para geração da resposta de regulação da temperatura (Morrison at al., 2008). A transmissão gabaérgica inibitória da APO chega ao $\mathrm{VMH}$ e ao $\mathrm{DMH}$. $\mathrm{O} \mathrm{VMH}$, por sua vez, envia sinais glutamatérgicos estimulatórios ao campo retrorubral na região pontina, de onde parte o estímulo, passando pelo bulbo (núcleos da rafe e olivar) e, finalmente, para os neurônios intermediolaterais da medula espinal (Cannon \& Nedergaard, 2004) que se projetam para o TAM (Morrison at al., 2008). Já o DMH envia projeções glutamatérgicas diretamente aos neurônios pré-motores simpáticos do TAM na RPa, os quais estimulam, via glutamato, neurônios intermediolateriais da medula espinal (Morrison at al., 2008).

Quando o objetivo da termogênese é o secundário, isto é, queimar o excesso de energia adquirida pela alimentação, a via da regulação central da termogênese é iniciada em outras regiões, as quais participam da regulação do comportamento alimentar. A sequência de eventos desta via ainda é obscura, mas estão incluídas, principalmente, as regiões com neurônios sensíveis a nutrientes e os centros de integração desses neurônios. As possíveis regiões envolvidas nesse controle são áreas hipotalâmicas - como Arc, PVN, VMH, DMH e a área hipotalâmica lateral -, o LC e o NTS (Berthoud et al, 2002; Blouet \& Schwartz, 2009).

Em nosso estudo, a ativação da APO demonstra que a via da regulação da temperatura foi estimulada pela administração central de C75 (Figuras 33 e 35). Provavelmente, os neurônios GABAérgicos da porção mediana da APO tenham sido estimulados no primeiro momento, para que os neurônios sensíveis ao calor da porção medial da APO sejam inibidos, os quais, por sua vez, deixariam de inibir o DMH. É possível, também, que neurônios glutamatérgicos da porção medial da APO tenham sido ativados para estimular o DMH (Morrison et al., 2012), tendo em vista que os neurônios da porção 
medial da APO foram fortemente marcados após 6 dias da transfecção de PRV no TAM de hamsteres siberianos (Bamshad et al., 1999).

A ativação neuronal do $\mathrm{DMH}$ e da RPa pode promover uma regulação conjunta da termogênese (Figuras 33 a 35). A desinibição de neurônios do DMH e da RPa pela injeção de bicuculina aumenta o fluxo simpático, o metabolismo e a termogênese no TAM (Cerri \& Morrison, 2005). Em ratos, a ativação de neurônios projetados do DMH para RPa modula a vasoconstrição na cauda e esta via participa da regulação da temperatura por alterar a dissipação de calor (DiMicco \& Zaretsky, 2007). Então, em nosso modelo experimental, o DMH e a RPa devem participar como ativadores da termogênese, mas também podem estar envolvidos com o aumento da temperatura na pele da cauda (Figura 19) como um mecanismo protetor contra a hipertermia.

Embora haja projeções do DMH para a RPa, o principal alvo das projeções eferentes do DMH são neurônios contendo CRH na porção parvocelular do PVN. Parte das projeções dos neurônios $\mathrm{CRH}$ entram em contato com neurônios que contem hormônio liberador de tireotropina (TRH) no próprio PVN, o qual poderia auxiliar no aumento da termogênese no TAM via aumento da liberação de $T_{3}$ e $T_{4}$ pela tireóide (Mihaly et al., 2001). Nossos resultados mostram que não houve aumento dos hormônios tiroidianos (Figura 8) e da corticosterona no plasma de animais tratados com C75. Portanto, se os neurônios que se projetam do $\mathrm{DMH}$ ao $\mathrm{PVN}$ foram ativados pelo $\mathrm{C75}$, tal ativação deve ter sido modesta para não alterar as concentrações hormonais no plasma.

Estudos funcionais mostram que o VMH é a via final comum de todas as estruturas neurais envolvidos na regulação central do TAM (Cannon \& Nedergaard, 2004), incluindo aquela relacionada com a ativação da termorregulação pela alimentação (Telliez et al., 
2002). Entretanto, um estudo anatômico das origens centrais do fluxo simpático ao TAM demonstrou pouca conexão entre VMH e o TAM interscapular (Bamshad et al., 1999). Esta divergência entre os estudos funcionais e os neuroanatômicos sobre o papel do VMH no controle do TAM pode ser justificada pelo fato da manipulação (estimulação ou destruição) do $\mathrm{VMH}$ nos estudos funcionais ter afetado, secundariamente, neurônios da porção caudal do PVN que são projetados próximos e ao redor do VMH (Hosoya et al., 1991; Luiten et al., 1985; Bamshad et al., 1999).

O LC recebe projeções de várias áreas hipotalâmicas, tais como APO, PVN, Arc e DMH, e neurônios noradrenérgicos do LC participam na inervação do PVN, particularmente da subdivisão periventricular (Cano et al., 2003). Devido à sua localização estratégica, o LC pode participar do controle da atividade das vias neuronais efetoras para a regulação da temperatura, mas parece estar mais relacionado com o aumento da temperatura por pirógenos na sinalização da febre (Almeida et al., 2004). Como o LC recebe projeções de neurônios CRH do PVN (Lehnert et al., 1998), é possível que a ativação do LC pelo C75 seja resultado do estímulo desses neurônios no PVN, os quais podem ter sido ativados por projeções de neurônios provenientes do $\mathrm{DMH}$.

Considerando o perfil de ativação dos neurônios encontrado em nossos animais e o fato de que a maioria das fibras autonômicas descendentes do hipotálamo surge do PVN, Arc, núcleo perifornical e hipotálamo dorso-lateral, com projeções menores derivadas da APO, DMH, VMH e RCA (Palkovits, 1999), é possível sugerir que o PVN tenha um papel central nos efeitos termorregulatórios induzidos pelo C75. Esta hipótese é corroborada pelos estudos que mostram que o PVN é a primeira região infectada quando o PRV é injetado no TAM, indicando a existência de projeções diretas do PVN ao TAM (Cano et al., 2003). 
Adicionalmente, Song et al. (2008) demonstraram um alto índice de colocalização de neurônios infectados com o RNAm da MC4-R no PVN, e um aumento da temperatura no TAM quando o agonista do MC4-R é administrado nesse núcleo. O MC4-R é um dos integrantes do sistema melanocortina, que é o principal mediador da sinalização anorexígena (Valassi et al., 2008). As mutações no gene do MC4-R estão associadas com 5\% dos casos de obesidade mórbida não-sindrômica, e são caracterizadas por obesidade severa, hiperfagia, aumento da massa gorda e hiperinsulinemia (Farooqi et al., 2003).

Em resumo, pode-se concluir que as áreas ativadas pela administração i.c.v. de C75 estão relacionadas com projeções descendentes autonômicas e possuem grande relevância na regulação do balanço energético. Certamente, a maioria das regiões ativadas (APO, PVN, DMH, VMH, LC e RPa) participa, ao menos em parte, da regulação da termogênese do TAM. Sendo assim, o fluxo simpático induzido pela droga para o TAM pode ter sido originado em uma ou algumas dessas regiões. Parte das áreas ativadas (PVN, DMH e VMH) também controla a ingestão alimentar e pode estar envolvida nos efeitos hipofágicos da droga. Os dados do presente estudo também permitem concluir que a ativação da termogênese do TAM induzida pelo C75 pode contribuir para a perda de peso corporal por meio da elevação do gasto energético e pela indução da hipofagia induzida pela resposta termorregulatória. Os efeitos da administração central de C75 observados neste trabalho encorajam estudos posteriores para a compreensão mais detalhada dos mecanismos de ação central da droga, com a finalidade de sua utilização terapêutica no combate à obesidade. 


\section{Referências Bablifograficas}




\section{Referências Bibliográficas}

Almeida MC, Steiner AA, Coimbra NC, Branco LGS. Thermoeffector neuronal pathways in fever: a study in rats showing a new role of locus coeruleus. J Physiol 558(1): 283-294, 2004.

Bamshad M, Song CK \& Bartness TM. CNS origins of the sympathetic nervous system outflow to brown adipose tissue. Am J Physiol Regul Integr Comp Physiol 276: R1569-R1578, 1999.

Banet $\mathbf{M}$, Hensel $\mathbf{H}$ \& Liebermann $\mathbf{H}$. The central control of shivering and non-shivering thermogenesis in the rat. J Physiol 283: 569-584, 1978.

Bernardis LL \& Bellinger LL. The dorsomedial hypothalamic nucleus revisited: 1998 update. Proc Soc Exp Biol Med 218(4): 284-306, 1998.

Berthoud, H-R. Multiple neural systems controlling food intake and body weight. Neurosc Biobeh Rev 26: 393B-394B, 2002.

Blouet C \& Schwartz GJ. Hypothalamic nutrient sensing in the control of energy homeostasis. Behav Brain Res, 2009.

Brito MN, Brito NA \& Migliorini RH. Thermogenic capacity of brown adipose tissue is reduced in rats fed a high protein, carbohydrate-free diet. J Nutr 122: 2081-2086, 1992.

Brito NA, Brito MN, Kettelhut IC \& Migliorini RH. Intra-ventramedial hypothalamic injection of cholinergic agents induces rapid hyperglycemia, hyperlactatemia and gluconeogenesis activation in fed, conscious rats. Brain Res 626: 339-342, 1993.

Brito MN, Brito NA, Garófalo MAR, Kettelhut IC \& Migliorini RH. Sympathetic activity in brown adipose tissue from rats adapted to a high protein, carbohydrate-free diet. J Auton Nerv Syst 69: 1-5, 1998.

Brito MN, Brito NA, Brito SRC, Moura MAF, Kawashita NH, Kettelhut IC \& Migliorini RH. Brown adipose tissue triacylglycerol synthesis in rats adapted to a high-protein, carbohydrate-free diet. Am J Physiol Regu Integr Comp Physiol 276: R1003-R1009, 1999. 
Bukowiecki L, Folléa N, Lupren J \& Paradis A. Metabolic relationships between lipolysis and respiration in rat brown adipocytes. The role of long chain fatty acids as regulators of mitochondrial respiration and feedback inhibitors of lipolysis. J Biol Chem 256: 12840-12848, 1981.

Bukowiecki L, Collet AJ, Follea N, Guay G \& Jahjah L. Brown adipose tissue hyperplasia: a fundamental mechanism of adaptation to cold and hyperphagia. Am J Physiol 242(5): E353E359, 1982.

Bukowiecki LJ, Geloen A \& Collet AJ. Proliferation and differentiation of brown adipocytes from interstitial cells during cold acclimation. Am J Physiol Cell Physiol 250: C880-C887, 1986.

Cannon, B \& Lindberg, O. Mitochondria from brown adipose tissue: isolation and properties. Meth Enzimol 55: 65-78, 1979.

Cannon B \& Nedergaard J. Brown adipose tissue: function and physiological significance. Physiol Rev 84: 277-359, 2004.

Cannon B, Sundin U \& Romert L. Palmitoyl coenzyme A: a possible physiological regulator of nucleotide binding to brown adipose tissue mitochondria. FEBS Lett 74: 43-46, 1977.

Cano G, Passerin AM, Schiltz JC, Card JP, Morisson SF \& Sved AF. Anatomical substrates for the central control of sympathetic outflow to interscapular adipose tissue during cold exposure. J Comp Neurol 460: 303-326, 2003.

Cerri M \& Morrison SF. Activation of lateral hypothalamic neurous stimulates brown adipose tissue thermogenesis. Neuroscience 135: 627-638, 2005.

Cha S-H, Hu Z \& Lane MD. Long-term effects of a fatty acid inhibitor on obese mice: food intake, hypothalamic neuropeptides and UCP3. Biochem Biophys Res Commun 317: 301-308, 2004.

Cha S-H, Hu Z, Lane MD \& Chohnan S. Inhibition of hypothalamic fatty acid synthase triggers rapid activation of fatty acid oxidation in skeletal muscle. Proc Natl Acad Sci USA 102(41): 14557-14562, 2005. 
Cha S-H, Rodgers JT, Puigserver P, Chohnan S \& Lane MD. Hypothalamic malonyl-CoA triggers mitochondrial biogenesis and oxidative gene expression in skeletal muscle: Role of

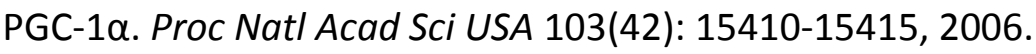

Chardon K, Cardot V, Léké A, Delanaud S, Bach V, Dewasmes G \& Telliez F. Thermoregulatory control of feeding and sleep in premature infants. Obesity 14: 1535-1542, 2006.

Chaves VE, Frasson D, Martins-Santos MES, Navegantes LCC, Galban VD, Garófalo MAR, Kettelhut IC \& Migliorini RH. Fatty acid synthesis and generation of glycerol-3-phosphate in brown adipose tissue from rats fed a cafeteria diet. Can J Physiol Pharmacol 86: 416-423, 2008.

Cikos S, Bukovska A \& Koppel J. Relative quantification of mRNA: comparison of methods currently used for real-time PCR data analysis. BMC Mol Biol 8: 113-127, 2007.

Clegg, DJ, Wortman MD, Benoit SC, McOsker CC, Seeley RJ. Comparison of central and peripheral administration of C75 on food intake, body weight, and conditioned taste aversion. Diabetes 51: 3196-201, 2002.

Collins S, Yehuda-Shnaidman E \& Wang H. Positive and negative control of Ucp1 gene transcription and the role of $\beta$-adrenergic signaling networks. Int J Obes 34: S28-S33, 2010.

Crowley VEF, Yeo GSH \& O'Rahilly S. Obesity theraphy: altering the energy intake-andexpenditure balance sheet. Nature Rev 1: 276-286, 2002.

Cypess AM, Lehman MB, Williams G, Tal I, Rodman D, Goldfine AB, Kuo FC, Palmer EL, Tseng Y-H, Doria A, Kolodny GM \& Kahn CR. Identification and importance of brown adipose tissue in adult humans. N Engl J Med 360: 1509-1517, 2009.

DiMicco JA \& Zaretsky DV. The dorsomedial hypothalamus: a new player in thermoregulation. Am J Physiol Regul Integr Comp Physiol 292: R47-R63, 2007.

Dunn-Meynell AA, Govek E \& Levin BE. Intracarotid glucose selectively increases Fos-like immunoreactivity in paraventricular, ventromedial and dorsomedial nuclei neurons. Brain Res 748(1-2): 100-106, 1997. 
Elias LL, Dorival Campos A \& Moreira AC. The opposite effects of short- and long-term salt loading on pituitary adrenal axis activity in rats. Horm Metab Res 34: 207-211, 2002.

Enriori PJ, Sinnayah P, Simonds SE, Rudaz CG \& Cowley MA. Leptin action in the dorsomedial hypothalamus increases sympathetic tone to brown adipose tissue in spite of systemic leptin resistance. J Neurosci 31(34): 12189-12197, 2011.

Farooqi IS, Keogh JM, Yeo GS, Lank EJ, Cheetham T \& O'Rahilly S. Clinical spectrum of obesity and mutations in the melanocortin 4 receptor gene. N Engl J Med 348: 1085-1095, 2003.

Ferguson AV, Latchford KJ \& Samson WK. The paraventricular nucleus of the hypothalamus a potential target for integrative treatment of autonomic dysfunction. Expert Opin Ther Targets 12(6): 717-727, 2008.

Flatmark T \& Pedersen Jl. Brown adipose tissue mitochondria. Biochim Biophys Acta 416: 53-103, 1975.

Folch J, Less M \& Stanley GA. A simple method for the isolation and purification of total lipids from animal tissues. J Biol Chem 226: 497-509, 1957.

Gao S, Kinzig KP, Aja S, Scott KA, Keung W, Kelly S, Strynadka K, Chohnan S, Smith WW, Tamashiro KLK, Ladenheim EE, Ronnett GV, Tu Y, Birnbaum MJ, Lopaschuk GD \& Moran TH. Leptin activates hypothalamic acetyl-CoA carboxylase to inhibit food intake. Proc Natl Acad Sci USA 104(44): 17358-17363, 2007.

Gao S \& Lane, MD. Effect of the anorectic fatty acid synthase inhibitor C75 on neuronal activity in the hypothalamus and brainstem. Proc Natl Acad Sci USA 100(10): 5628-5633, 2003.

Garlid KD, Jaburek M, Jezek P \& Varecha M. How do uncoupling proteins uncouple? Biochim Biophys Acta 1459: 383-389, 2000.

Garófalo MAR, Kettelhut IC, Roselino J E S, Migliorini RH. Effect of acute cold exposure on norephinephrine turnover rates in rat white adipose tissue. J Auton Nerv Syst 60: 206-8, 1996. 
Hainer V, Toplak H \& Mitrakou A. Treatment modalities of obesity. Diabetes Care 31(2): S269-S277, 2008.

Heaton J. The distribution of brown adipose tissue in the human. J Anat 112(1): 35-39, 1972.

Himms-Hagen J. Brown adipose tissue thermogenesis and obesity. Prog Lipid Res 28: 67115,1989 a.

Himms-Hagen J. Role of thermogenesis in the regulation of energy balance in relation to obesity. Can J Physiol Pharmacol 67: 394-401, 1989b.

Himms-Hagen J. Role of brown adipose tissue thermogenesis in control of thermoregulatory feeding in rats: a new hypothesis that links thermostatic and glucostatic hypotheses for control of food intake. Proc Soc Exp Biol Med 208(2): 159-169, 1995.

Hosoya Y, Sugiura Y, Okada N, Loewy AD \& Kohno K. Descending input from the hypothalamic paraventricular neurons to sympathetic preganglionic neurons in the rat.Exp Brain Res 85: 10-20, 1991.

Hu Z, Cha S-H, Chohnan S \& Lane MD. Hypothalamic malonyl-CoA as a mediator of feeding behavior. Proc Natl Acad Sci USA 100 (22): 12624-12629, 2003.

Hu Z, Cha S-H, Van Haasteren G, Wang J \& Lane MD. Effect of centrally administered, a fatty acid synthase inhibitor, on ghrelin secretion and its downstream effects. Proc Natl Acad Sci USA 102 (11): 3972-3977, 2005.

Jin Y-J, Li S-Z, Zhao Z-S, An JJ, Kim RY, Kim TM, Baik J-H \& Lim S-K. Carnitine Palmitoyltransferase-1 (CPT-1) activity stimulation by cerulenin via sympathetic nervous system activation overrides cerulenin's peripheral effect. Endocrinology 145: 3197-3204, 2004.

Kawashita NH, Moura MAF, Brito MN, Brito SMRC, Garófalo MAR, Kettelhut IC \& Migliorini RH. Relative importance of sympathetic outflow and insulin in the reactivation of brown adipose tissue lipogenesis in rats adapted to a high-protein diet. Metabolism 51(3): 343-349, 2002. 
Kim E-K, Miller I, Aja S, Landree LE, Pinn M, McFadden J, Kuhajda FP, Moran TH \& Ronnett GV. C75, a fatty acid synthase inhibitor, reduces food intake via hypothalamic AMP-activated protein kinase. J Biol Chem 279(19): 19970-19976, 2004.

Kim EK, Miller I, Landree LE, Borisy-Rudin FF, Brown P, Tihan T, Townsend CA, Witters LA, Moran TH, Kuhajda FP \& Ronnett GV. Expression of FAS within hypothalamic neurons: a model for decreased food intake after C75 treatment. Am J Physiol Endocrinol Metab 283: E867-E879, 2002.

Klingenberg M \& Huang SG. Structure and function of the uncoupling protein from brown adipose tissue. Biochem Biophys Acta 1415(2): 271-296, 1999.

Korner J \& Aronne LJ. The emerging science of body weight regulation and its impact on obesity treatment. J Clin Invest 111: 565-570, 2003.

Kovács KJ. Measurement of immediate-early gene activation - c-fos and beyond. J Neuroendocrinol 20: 665-672, 2008.

Krauss S, Zhang C-Y \& Lowell BB.The mitochondrial uncoupling-protein homologues. Nature Rev Mol Cell Biol 6: 248-261, 2005.

Krstulovic A M. Investigations of catecholamines metabolism using high performance liquid chromatography. J Chromatogr 35: 207-210, 1982.

Kumar MV, Shimokawa T, Nagy TR \& Lane D. Differential effects of centrally acting fatty acid synthase inhibitor in lean and obese mice. Proc Natl Acad Sci USA 99(4): 1921-1925, 2002.

Landree LE, Hanlon AL, Strong DW, Rumbaugh G, Miller IM, Thupari JN, Connolly EC, Huganir RL, Richardson C, Witters LA, Kuhadja FP \& Ronnett GV. C75, a fatty acid synthase inhibitor, modulates AMP-activated protein kinase to alter neuronal energy metabolism. $J$ Biol Chem 279(5): 3817-3827, 2004.

Lane DM, Hu Z, Cha S-H, Dai Y, Wolfgang M \& Sidhaye A. Role of malonyl-CoA in the hypothalamic control of food intake and energy expenditure. Biochem Soc Trans 33: 10631067, 2005. 
Lehnert H, Schukz C \& Dieterich K. Physiological and neurochemical aspects of corticotropinreleasing factor actions in the brain: the role of the locus coeruleus. Neurochem Res 23(8): 1039-1052, 1998.

Leonard JL, Mellen SA \& Larsen PR. Thyroxine 5'-deiodinase activity in brown adipose tissue. Endocrinology 112: 1153-1155, 1983.

Loftus TM, Jaworsky DE, Frehywot GL, Townsend CA, Ronnett GV, Lane MD \& Kahajda FP. Reduced food intake and body weight in mice treated with fatty acid synthase inhibitors. Science 288: 2379-2381, 2000.

López M, Lelliot CJ \& Vidal-Puig A. Hypothalamic fatty acid metabolism: a housekeeping pathways that regulates food intake. BioEssays 29: 248-261, 2007.

Lowry OH, Rosebrough NJ, Farr AL \& Randall RJ. Protein measurement with the Folin phenol reagent. J Biol Chem 193: 265-275, 1951.

Luiten PGM, ter Horst GJ, Karst H \& Steffens AB. The course of paraventricular hypothalamic efferents to autonomic structures in medulla and spinal cord. Brain Res 329: 374-378, 1985.

Makimura H, Mizuno TM, Yang X-J, Silverstein J, Beasley J \& Mobbs CV. Cerulenin mimics effects of leptin on metabolic rate, food intake, and body weight independent of the melanocortin system, but unlike leptin, cerulenin fails to block neuroendocrine effects of fasting. Diabetes 50: 733-739, 2001.

Mansouri A, Aja S, Moran TH, Ronnett G, Kuhajda FP, Arnold M, Geary N, Langhans W \& Leonhardt M. Intraperitoneal injections of low doses of C75 elicit a behaviorally specific and vagal afferent-independent inhibition of eating in rats. Am Physiol Regul Integr Comp Physiol 295: R799-R805, 2008.

Masaki T, Yoshimichi G, Chiba S, Yasuda T, Noguchi H, Kakuma T, Sakata T \& Yoshimatsu H. Corticotropin-releasing hormone-mediated pathway of leptin to regulate feeding, adiposity, and uncoupling protein expression in mice. Endocrinology 144: 3547-3554, 2003. 
Mera P, Bentebibel A, López-Viñas E, Cordente AG, Gurunathan C, Sebastián D, Vázquez I, Herrero L, Ariza X, Gómez-Puertas P, Asins G, Serra D, García J \& Hegardt FG. C75 is converted to $\mathrm{C75}-\mathrm{CoA}$ in the hypothalamus, where it inhibits carnitine palmitoyltransferase 1 and decreases food intake and body weight. Biochem Pharmacol 77: 1084-1095, 2009.

Mihaly E, Fekete C, Legradi G \& Lechan RM. Hypothalamic dorsomedial nucleus neurons innervate thyrotropin-releasing hormone-synthesizing neurons in the paraventricular nucleus. Brain Res 891: 20-31, 2001.

Miller I, Ronnett GV, Moran TH \& Aja S. Anorexigenic C75 alters c-Fos in mouse hypothalamic and hindbrain subnuclei. NeuroReport 15: 925-929, 2004.

Minokoshi Y, Kim T-B, Peroni OD, Fryer LGD, Müller C, Carling D \& Kahn BB. Leptin stimulates fatty-acid oxidation by activating AMP-activated protein kinase. Nature 415: 339343, 2002.

Morrison SF, Madden CJ Tupone D\& . Central control of brown adipose tissue thermogenesis. Front Endocrinol (Lausanne) 3(5): doi:10.3389/fendo.2012.00005, 2012.

Morrison SF, Nakamura K \& Madden CJ. Central control of thermogenesis in mammals. Exp Physiol 93(7): 773-797, 2008.

Nagashima K. Central mechanisms for thermoregulation in a hot environment. Ind Health 44: 359-367, 2006.

Nedergaard J, Golozoubova V, Matthias A, Asadi A, Jacobson A \& Cannon B. UCP: the only protein able to mediate adaptive non-shivering thermogenesis and metabolic inefficiency. Biochem Biophys Acta 1504: 82-106, 2001.

Nedergaard J \& Lindberg O. The brown fat cell. Int Rev Cytol 74: 187-286, 1982.

Nicholls DG. Brown adipose tissue mitochondria. Biochem Biophys Acta 549: 1-29, 1979.

Nonogaki K. New insights into sympathetic regulation of glucose and fat metabolism. Diabetologia 43: 533-549, 2000. 
Palkovits M, Baffi JS \& Pacak K. The role of ascending neuronal pathways in stress-induced release of norepinephrine in the hypothalamic paraventricular nucleus of rats. $J$ Neuroendocrinol 11: 529-539, 1999.

Paxinos G, Watson C. The rat brain in stereotaxic coordinates. $2^{\text {nd }}$ edn. Academic Press, Sydney, 1982.

Paxinos G, Watson C. The rat brain in stereotaxic coordinates. 3rd edn Academic, San Diego, 1997.

Perello M, Cakir I, Cyr NE, Romero A, Stuart RC, Chiappini F, Hollenberg AN \& Nillni EA. Maintenance of the thyroid axis during diet-induced obesity in rodents is controlled at central level. Am J Physiol Endocrinol Metab 299: E976-E989, 2010.

Proulx K, Cota D, Woods SC \& Seeley RJ. Fatty acid synthase inhibitors modulate energy balance via mammalian target of rapamycin complex 1 signaling in the central nervous system. Diabetes 57: 3231-3238, 2008.

Puigserver P, Wu Z, Park CW, Graves R, Wright M \& Spiegelman BM. A cold-inducible coactivador of nuclear receptors linked to adaptive thermogenesis. Cell 92: 829-839, 1998.

Rial E \& Nicholls DG. The uncoupling protein from brown adipose tissue mitochondria. Cell Biol Rev 11: 75-104, 1987.

Ricquier D. Biology of brown adipose tissue: view from the chair. Int J Obes 34: S3-S6, 2010.

Rohrbach KW, Han S, Gan J, O'Tanyi EJ, Zhang H, Chi CL, Taub R, Largent BL \& Cheng D. Disconnection between the early onset anorectic effects by $\mathrm{C} 75$ and hypothalamic fatty acid synthase inhibition in rodents. Eur J Pharmacol 511: 31-41, 2005.

Rosenbaum M \& Leibel RL. Adaptive thermogenesis in humans. Int J Obes 34: S47-S55, 2010.

Saggerson D. Malonyl-CoA, a key signaling molecule in mammalian cells. Annu Rev Nutr 28: $6.1-6.20,2008$.

Sessler DI. Thermoregulatory defense mechanisms. Crit Care Med 37(7): S203-S210, 2009. 
Shimokawa T, Kumar MV \& Lane D. Effect of a fatty acid synthase inhibitor on food intake and expression of hypothalamic neuropeptides. Proc Natl Acad Sci USA 99(1): 66-71, 2002.

Silva JE \& Larsen PR. Adrenergic activation of triiodothyronine production in brown adipose tissue. Nature 305: 712-713, 1983.

Silva JE. Thermogenic mechanisms and their hormonal regulation. Physiol Rev 86, 435-464, 2006.

Skulachev VP. Fatty acid circuit as a physiological mechanism of uncoupling of oxidative phosphorylation. FEBS Lett 294(3): 158-162, 1991.

Skulachev VP. Uncoupling: new approaches to an old problem of bioenergetics. Biochim Biophys Acta 1363(2): 100-124, 1998.

Smith RE. Thermogenic activity of the hibernating gland in the cold-acclimated rat. Physiologist 4: 113-113, 1961.

Smith RE \& Horwitz BA. Brown fat and thermogenesis. Physiol Rev 49: 330-425, 1969.

Song CK, Vaughan CH, Keen-Rhinehart E, Harris RBS, Richard D \& Bartness TJ. Melanocortin-4 receptor mRNA expressed in sympathetic outflow neurons to brown adipose tissue: neuroanatomical and functional evidence. Am J Physiol Regul Integr Comp Physiol 295: R417-R428, 2008.

Srere PA, Brazil H \& Gonen L. The citrate condensing enzyme of pigeon breast muscle and moth flight muscle. Acta Chem Scandinavica 17: 129-134, 1963.

Steffens AB, Scheurink AJW, Luiten PGM \& Bohus B. Hypothalamic food intake regulating areas are involved in the homeostasis of blood glucose and plasma FFA levels. Physiol Behav 44(4/5): 581-589, 1988.

Tajima D, Masaki T, Hidaka S, Kakuma T, Sakata T \& Yoshimatsu H. Acute central infusion of leptin modulates fatty acid mobilization by affecting lipolysis and mRNA expression for uncoupling proteins. Exp Biol Med 230: 200-206, 2005. 
Takahashi KA, Smart JL, Liu H \& Cone RD. The anorexigenic fatty acid synthase inhibitor, C75, is a nonspecific neuronal activator. Endocrinology 145: 184-193, 2004.

Telliez F, Bach V, Léké A, Chardon K \& Libert JP. Feeding behaviour in neonates whose diet contained medium-chain triacylglycerols: short term effects on thermoregulation and sleep. Am J Clin Nutr 76: 1091-1095, 2002.

Thupari JN, Kim E-K, Moran TH, Ronnett GV \& Kuhadja FP. Chronic C75 treatment of dietinduced obese mice increases fat oxidation and reduces food intake to reduce adipose mass. Am J Physiol Endocrinol Metab 287: E97-E104, 2004.

Thupari JN, Landree LE, Ronnett GV \& Kuhadja FP. C75 increases peripheral energy utilization and fatty acid oxidation in diet-induced obesity. Proc Natl Acad Sci USA 99(14): 9498-9502, 2002.

Tseng Y-H, Cypess AM \& Kahn CR. Cellular bioenergetics as a target for obesity therapy. Nature Rev 9: 465-481, 2010.

Tu Y, Thupari JN, Kim E-K, Pinn ML, Moran TH, Ronnett GV \& Kuhajda FP. C75 alters central and peripheral gene expression to reduce food intake and increase energy expenditure. Endocrinology 146(1): 486-493, 2005.

Valassi E, Scacchi M \& Cavagnini F. Neuroendocrine control of food intake. Nutr Metab Cardiovasc Dis 18: 158-168, 2008.

van Marken Lichtenbelt WD, Vanhommerig JW, Smulders NM, Drossaerts JMAFL, Kemerink GJ, Bouvy ND, Schrauwen P \& Teule GJJ. Cold-activated brown adipose tissue in healthy men. N Engl J Med 360: 1500-1508, 2009.

Vega RB, Huss JM \& Kelly DP. The coactivator PGC-1 cooperates with peroxisome proliferator-activated receptor- $\alpha$ in transcriptional control of nuclear genes encoding mitochondrial fatty acid oxidation enzymes. Mol Cell Biol 20: 1868-1876, 2000.

Virtanen KA, Lidell ME, Orava J, Heglind M, Westergren R, Niemi T, Taittonen M, Laine J, Savisto N-J, Enerbäck S \& Nuutila P. Functional brown adipose tissue in healthy adults. N Engl J Med 360: 1518-1525, 2009. 
Wirsén C \& Hamberger B. Catecholamines in brown fat. Nature 214: 625-626, 1967.

Wortman MD, Clegg DJ, D’Alessio D, Woods SC \& Seeley RJ. C75 inhibits food intake by increasing CNS glucose metabolism. Nature Med 9(5): 483-485, 2003.

Young AA \& Dawson NJ. Evidence for on-off control of heat dissipation from the tail of the rat. Can J Physiol Pharmacol 60: 392-398, 1982.

Yun JW. Possible anti-obesity therapeutics from nature - a review. Phytochem 71: 16251641, 2010. 
Anero 
Importance of brown adipose tissue to thermoregulatory and satiety-related responses induced by central administration of $\mathrm{C75}$

Priscila Cassolla ${ }^{1}$, Maria Antonieta Rissato Garófalo ${ }^{1}$, Frederico Sander Mansur Machado ${ }^{2}$, Juliana Bohnen Guimarães ${ }^{2}$, Cândido Celso Coimbra ${ }^{2}$, Nilton de Almeida Brito ${ }^{3}$, Isis do Carmo Kettelhut ${ }^{4}$, Luiz Carlos Carvalho Navegantes ${ }^{1}$

${ }^{1}$ Department of Physiology, School of Medicine of Ribeirão Preto, University of São Paulo, Ribeirão Preto, SP, Brazil; ${ }^{2}$ Department of Physiology and Biophysics, Institute of Biological Sciences, Federal University of Minas Gerais, Belo Horizonte, MG, Brazil; ${ }^{3}$ Department of Physiological Sciences, Biological Sciences Center, State University of Maringá, Maringá, PR, Brazil; ${ }^{4}$ Department of Biochemistry and Immunology, School of Medicine of Ribeirão Preto, University of São Paulo, Ribeirão Preto, SP, Brazil

Running title: FAS inhibitors and BAT thermogenesis

Keywords: brown adipose tissue, fatty acid synthase inhibitors, thermogenesis

Word count: 4,151 words

Correspondence: Luiz Carlos Carvalho Navegantes

Universidade de São Paulo

Faculdade de Medicina de Ribeirão Preto

Departamento de Fisiologia

Av. Bandeirantes, 3900 - Monte Alegre

14049-900

Ribeirão Preto - São Paulo

Brazil

E-mail: navegantes@fmrp.usp.br 


\begin{abstract}
C75, a synthetic inhibitor of fatty acid synthase (FAS), causes anorexia and weight loss in rodents, but the underlying mechanisms remain unknown. Thus, we hypothesized that brown adipose tissue (BAT), an important site for thermogenesis, could be involved in the anti-obesity effects of FAS inhibitors. We report that a single intracerebroventricular injection of $\mathrm{C} 75$ decreased the food intake on the first day, and induced weight loss for two days in fasted rats. Furthermore, C75 induced a rapid increase in core body temperature, a higher heat variation rate from $30 \mathrm{~min}$ until $6 \mathrm{~h}$ of injection, and an increase in heat dissipation for $4 \mathrm{~h}$. The sympathetic BAT denervation attenuated the thermoregulatory effects of C75 as well as its effect on weight loss and satiety. In parallel, C75 induced an increase in BAT thermogenesis, evidenced by a marked increase in BAT temperature (up to 8 $h$ of the injection), higher levels of BAT norepinephrine, and an increase in the activity of BAT cytochrome c oxidase and mRNA levels of ucp-1. All these effects were abolished by sympathetic denervation. Like C75, the central administration of cerulenin, a natural FAS inhibitor, also induced an increase in the BAT and core body temperature, which was also abolished by denervation. The spontaneous locomotor activity was not altered by any FAS inhibitor. These data implicate a role for BAT in the FAS inhibitors-evoked increase in body temperature and provide new mechanisms to explain hypophagia and increased energy expenditure observed with these compounds.
\end{abstract}

\title{
Abbreviations:
}

FAS, fatty acid synthase; NPY, neuropeptide Y; AgRP, agouti-related peptide; $\alpha M S H, \alpha-$ melanocortin stimulating protein; CART, caffeine-amphetamine-regulated transcript; i.c.v., intracerebroventricular; UCP, uncoupling protein; SNS, sympathetic nervous system; CAMP, cyclic adenosine monophosphate; BAT, brown adipose tissue; i.p., intraperitoneal; FFA, free

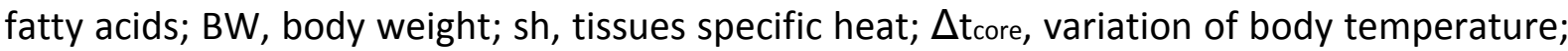
$\Delta \mathrm{t}$, time interval; AUC, area under curve; CDNA, complementary deoxyribonucleic acid; $\mathrm{NADH}$, nicotinamide adenine dinucleotide; $\mathrm{FADH}_{2}$, flavin adenine dinucleotide. 


\section{Introduction}

It has been reported that fatty acid synthase (FAS) inhibitors, such as C75 (trans-4carboxy-5-octyl-3-methylenebutyrolactone) and cerulenin (2,3-epoxy-4-oxo-6dodecadienoylamide), are promising anti-obesity drugs because reversibly reduce food intake and body weight without obvious toxicity in mice (Loftus et al., 2000). In addition to its effect on FAS, C75 has been reported to stimulate carnitine palmitoyl-transferase-1 (Bentebiel et al., 2006), that is sufficient to inhibit eating and decrease body weight (Aja et al., 2008).

The central administration of C75, a synthetic compound, suppresses the expression of orexigenic neuropeptides (e.g., NPY and AgRP), and activates expression of anorexigenic neuropeptides (e.g. $\alpha \mathrm{MSH}$ and CART) in the hypothalamus that is known to be involved in the regulation of feeding behavior (Shimokawa et al., 2002; Lane et al., 2005). On the other hand, a large body of evidences indicates that $\mathrm{C} 75$ also contributes to body weight loss by increasing peripheral fatty acid oxidation and overall energy expenditure (Cha et al., 2005; Cha et al., 2004; Thupari et al., 2002; Thupari et al., 2004; Tu et al., 2005). For example, it has been shown that chronic treatment with $\mathrm{C} 75$ alters the expression of genes involved in fatty acid metabolism to favor fatty acid oxidation in white adipose tissue from diet-induced obese mice (Tu et al., 2005). Hence, the intracerebroventricular (i.c.v.) injection of C75 increases fatty acid oxidation and thermogenic uncoupling mediated by uncoupling protein (UCP)-3 in skeletal muscle in both lean and obese (ob/ob) mice (Cha et al., 2005). Thus, it has been postulated a linkage between the anabolic pathway of FAS in the hypothalamus and energy expenditure. This signal seems to be transmitted from the brain to periphery by the sympathetic nervous system (SNS) because these events taken place rapidly, i.e., $\leq 2 \mathrm{~h}$ after 
the injection of the $\mathrm{C} 75$ and increase the muscle expression of the $\beta$-adrenergic signaling molecules (e.g., norepinephrine, $\beta_{3}$-adrenergic receptor, and cAMP). It is unknown, however, whether the central injection of $\mathrm{C} 75$ also affects other peripheral tissues to inhibit eating and stimulate energy expenditure.

The brown adipose tissue (BAT) receives a dense innervation by SNS (Cannon \& Nedergaard, 2004), and this innervation plays an important role in heat production by BAT. This process, known as adaptive non-shivering thermogenesis (Bamshad et al., 1999), occurs through the uncoupling of oxidative phosphorylation from electron transport by mitochondrial UCP-1 activity (Bartness et al., 2010). Although the main function of BAT is to generate heat for thermal protection during cold exposure (Cannon \& Nedergaard, 2004) it is well established that the BAT has also an important role in adaptive adjustments of overall body energy expenditure not only to the level of energy intake but also to the macronutrient composition of the diet (Himms-Hagen, 1989). It has been recently shown that the BAT is functional in adult humans and the amount of BAT is inversely correlated with body-mass index, suggesting a potential role of this tissue in adult human metabolism and as a new target of anti-obesity drugs (Cypess et al., 2009; van Marken Lichtenbelt et al., 2009; Virtanen et al., 2009). Thus, the present study was undertaken to test the hypothesis that FAS inhibitors stimulate the sympathetically mediated thermogenesis in BAT which could contribute to the weight loss induced by these compounds. To this end, we investigated the effects of i.c.v. administration of $\mathrm{C} 75$ or cerulenin on eating and BAT activity in fasted rats submitted to sympathetic denervation. 


\section{Methods}

\section{Ethical Approval}

All experimental protocols agree with the Ethical principles in animal research adopted by Brazilian College of Animal Experimentation (COBEA) and they were approved by the College of Medicine of Ribeirão Preto of the University of São Paulo - Ethical Commission of Ethics in Animal Research (CETEA; $n^{\circ}$ 116/2006).

\section{Animals}

Male Wistar rats $(230 \pm 20 \mathrm{~g})$ were obtained from University of São Paulo Animal Breeding Center and housed in groups of four or five in a room kept under $12 \mathrm{~h} / 12 \mathrm{~h}$ light/dark cycle (lights on at $6.00 \mathrm{am}$ ), at $25 \pm 2 \stackrel{\circ}{ }$, and given access to water and standard rodent chow ad libitum (Nuvilab CR1, Nuvital, BR; 22\% protein, 55\% carbohydrate, and 4.5\% lipid) at least 2 days before surgical procedures. All experiments were performed beginning at 8.00 am in a quiet air-conditioned $(25 \pm 1 \stackrel{\circ}{\circ}$ ) room in individually separated 24 h-fasted animals. For most experiments, animals were randomly divided into three treatment groups: C75 or cerulenin-treated (single i.c.v. injection of $150 \mu \mathrm{g}$ in RPMI medium 1640 vehicle), control (single i.c.v. injection of RPMI medium 1640), and denervated C75 or cerulenin (animals were previously submitted to bilateral BAT sympathetic denervation and treated with single i.c.v. injection of $\mathrm{C} 75$ or cerulenin). At the end of experiments, the animals were sacrificed by an overdose of anesthetic. C75, cerulenin and RPMI medium 1640 were purchased from Sigma-Aldrich (São Paulo, BR). 


\section{Stereotaxic surgical and drug injection}

For guide cannula implant into right lateral ventricle, animals were anesthetized with intraperitoneal (i.p.) injection of Ketamine/Xylazine cocktail $\left(5: 3.5 ; 1 \mathrm{~mL} . \mathrm{Kg}^{-1}\right.$ body weight) and fixed in a stereotaxic apparatus (David-Kopff). Adapted from Paxinos and Watson (1982), the coordinates were: anterior-posterior $-1.5 \mathrm{~mm}$ (from bregma), dorsal-ventral $-3.4 \mathrm{~mm}$ (from skull surface) and medial-lateral $+2.5 \mathrm{~mm}$. After the surgery, veterinarian poly-antibiotic preparation was given via intramuscular $\left(0.5 \mathrm{~mL} . \mathrm{Kg}^{-1}\right.$ body weight, Pentabiótico ${ }^{\circledR} 48,000$ U; Fort Dodge, Campinas, BR). After a recovery period of 6 days, the animals were submitted to food privation for $24 \mathrm{~h}$ before the experiments. About $1 \mathrm{~h}$ after housed in the experimental room, the injection of $\mathrm{C75} /$ cerulenin or vehicle alone was performed using a calibrated Hamilton syringe. Cannula placement was verified in the brains immersed in paraformaldehyde $10 \%$ for two days by Evans blue dye i.c.v. injected $(5 \mu \mathrm{L})$ at the end of each experiment.

\section{BAT bilateral sympathetic denervation surgery}

BAT denervation was performed at same time with stereotaxic surgery. After a careful dissection of interscapular BAT from surrounding muscle and white adipose tissue, five branches of the each side (right and left) intercostal nerve bundles were isolated and a section of about $5 \mathrm{~mm}$ was removed from these nerves. The effectiveness of this technique was shown by the fall of the norepinephrine content in BAT on $7^{\text {th }}$ day after the surgery. 
Measurements of glucose, free fatty acids (FFA), and catecholamines (norepinephrine and epinephrine) in blood and norepinephrine content in BAT.

Plasma glucose and FFA were determined with commercial kits from Labtest (Lagoa Santa, BR) and Randox FFA (São Paulo, BR), respectively. Catecholamines were assayed as previously described (Garófalo et al., 1996) using HPLC (LC-7A, Shimadzu Instruments) with a Spherisorb ODS-2 (5 $\mu \mathrm{m})$ (Sigma-Aldrich) reversed phase column.

Telemetric measurement of body temperature and spontaneous locomotor activity

Values of core body temperature and spontaneous locomotor activity were obtained each 5 second through E-mitter transponder (TR4000 VM-FM model, Mini Mitter Co., Sunriver, OR) i.p. implanted at same time of stereotaxic surgery. The signal emitted from transponder to receiving plate AM (RA1000 TH model, Mini Mitter Co.) was decoded by Vital View software (Mini Mitter). During acclimatization, basal values were recorded for 30 min and the record continued for $24 \mathrm{~h}$ after C75 injection. Means each $10 \mathrm{~min}$ were calculated to analyze these parameters. Heat variation rate $\left(\mathrm{cal} . \mathrm{min}^{-1}\right)$ reflects the balance of adjustments between heat gain and heat loss. It was calculated by the following formula: Heat variation rate $=\left(\mathrm{BW} \times \operatorname{sh} \times \Delta \mathrm{T}_{\text {core }}\right) / \Delta \mathrm{t}$; were $\mathrm{BW}$, body weight at begin of experiment $(\mathrm{g})$; sh, tissues specific heat $\left(0.82586\right.$ cal. $\left.\mathrm{g}^{-1} . \mathrm{C}^{-1}\right) ; \Delta \mathrm{T}_{\text {core, }}$ variation of body temperature between the time selected $(\underline{\circ})$ ); and $\Delta t$, length of time interval selected $(h)$. 


\section{Telemetric measurement of BAT temperature}

Small transponders (IPPT-3000 model, BMDS Co., Delaware, USA) were implanted under the interscapular BAT at same time of stereotaxic surgery. Temperature data were taken each $20 \mathrm{~min}$ for $8 \mathrm{~h}$ through the data acquisition system DAS 7008-9 (BMDS Co.).

\section{Heat dissipation}

Tail temperature was measured on the lateral surface $\sim 2 \mathrm{~cm}$ from the base of the tail (Young and Dawson, 1982) every 5 min using a thermocouple (AG 2000 model, Braile Biomédica, São Paulo, BR) for $4 \mathrm{~h}$.

\section{Cytochrome c oxidase activity assay}

BAT mitochondria were isolated as described by Cannon and Lindberg (1979) and suspended in $0.25 \mathrm{M}$ sucrose to a final protein concentration $100 \mu \mathrm{g} \cdot \mathrm{mL}^{-1}$. Mitochondrial protein was determined by the method of Lowry et al. (1951), with bovine serum as the standard. The activity of cytochrome c oxidase [EC 1.9.3.1.] was determined by colorimetric assay kit (Sigma-Aldrich) based on decrease in absorbance at $550 \mathrm{~nm}$ of ferrocytochrome $\mathrm{c}$ caused by its oxidation by cytochrome c oxidase activity.

\section{Quantitative real-time RT-PCR}

Interscapular BAT was quickly dissected on ice from decapitated rats after 1 and $4 \mathrm{~h}$ after $\mathrm{C} 75$ central injection, weighed and storage at $-80^{\circ} \mathrm{C}$. Total RNA was subsequently isolated from individual BAT using TRIzol (Invitrogen ${ }^{\oplus}$, Carlsbad, CA). Reverse transcription into cDNA was performed using $2 \mu \mathrm{g}$ of total cellular RNA, 20 pmol oligo(dT) primer (Invitrogen ${ }^{\circledR}$ ) and Advantage ImProm-II reverse transcriptase (Promega ${ }^{\circledR}$, Madison, WI). Real- 
time PCR was carried out using an ABI7000 sequence detection system (Applied Biosystems Foster City, CA), a SuperScript III Platinum SYBR Green One-Step RT-qPCR Kit with ROX (Invitrogen '), and primers for rat ucp-1 (forward 5'-CCGGTGGATGTGGTAAAAAC-3' and reverse 5'-ATCCGAGTCGCAGAAAAGAA-3') and $\beta$-actin (forward 5'TTGCTGACAGGATGCAGAAG-3' and reverse 5'-CAGTGAGGCCAGGATAGAGC-3') genes. The relative quantitation of mRNA levels was plotted as the fold increase compared with the control group values. Transcripts were normalized to $\beta$-actin levels. The level of the target transcripts was calculated using the standard curve method (Cikos et al., 2007).

\section{Statistical Analyzes}

Distribution and variance homogeneity were tested and the appropriate statistical test (ANOVA Two-Way followed by Bonferroni test - weight gain, food intake, glycemia and plasma FFA, and telemetric analyzes; or ANOVA One-Way followed by Newman-Keuls test plasma catecholamines, cytochrome c oxidase, mRNA ucp-1 expression and AUC analyzes) was employed to analyze the results, as indicated in the legends to figures. The program GraphPad Prism 4.0 was used to calculate the areas under the curves (AUC) and to carry out the statistical analysis. Data are expressed as mean \pm SEM. Differences were considering significant at $\mathrm{P}<0.05$.

\section{Experimental protocols}

Experiment 1: Effects of $\mathrm{C75}$ or cerulenin on food intake, body weight gain, and fluid intake in innervated and denervated rats. Animals kept in metabolic cages were fasted for $24 \mathrm{~h}$, and then injected with vehicle, $\mathrm{C} 75$ or cerulenin into lateral ventricle at $8 \mathrm{~h}$ in the morning. Food was reintroduced and during the 3 days following injection, body weight, food intake, and 
fluid intake were monitored daily in the morning. In another set of control and C75 rats, food intake measurements were taken at $1 \mathrm{~h}$ (0-1-h interval), $3 \mathrm{~h}$ (1-3-h interval), and $12 \mathrm{~h} \mathrm{(3-12-}$ $h$ interval) after i.c.v. injection.

Experiment 2: Effects of $C 75$ on plasma levels of glucose, and FFA in awake rats. On the morning of the day that preceded i.c.v. injections, a silastic catheter was implanted under anesthesia into the right jugular vein in control and $\mathrm{C} 75$ rats. Blood samples $(0.08 \mathrm{~mL}$, replaced with saline) were collected immediately before (0 time) and 15, 30, 60, 120 and 180 min after i.c.v. injection of $\mathrm{C} 75$ or vehicle for determination of plasma glucose and FFA concentration.

Experiment 3: Effects of $\mathrm{C75}$ or cerulenin on thermoregulatory mechanisms in innervated and denervated rats. Six days after stereotaxic surgery and implantation of the transponders, innervated and denervated animals were fasted for $24 \mathrm{~h}$, and then injected with vehicle, C75 or cerulenin. Soon after the injections the telemetric measurements of body temperature, BAT, spontaneous locomotor activity and heat dissipation were determined.

Experiment 4: Effects of C75 on markers of sympathetic activity and BAT thermogenesis in innervated and denervated rats. After 1 and $4 \mathrm{~h}$ of i.c.v. injection, animals were decapitated, and their trunk blood and BAT were collected. BAT was rapidly weighed, frozen in liquid nitrogen and stored at $-80{ }^{\circ} \mathrm{C}$ for determination of cytochrome c oxidase activity, $u c p-1$ mRNA and norepinephrine levels. Catecholamines levels were measured in the plasma samples. 


\section{Results}

BAT sympathetic denervation attenuates the C75-induced decrease of food intake and weight gain

The anorectic effect of $\mathrm{C} 75$ was already detectable after $3 \mathrm{~h}$ of injection (Fig. $1 \mathrm{~A}$ ) and the total $24-\mathrm{h}$ food consumption was significantly reduced to $20 \%$ of control $(3.6 \pm 1.5 \mathrm{~g}$ vs. $18.2 \pm 1.9 \mathrm{~g})$. Interestingly, BAT sympathetic denervation $(9.8 \pm 1.5 \mathrm{~g})$ attenuated the decreased food intake induced by $\mathrm{C} 75$ in 170\% (Fig. 1B). Food intake was unchanged 2 and 3-d after i.c.v. administration of C75. There was no difference in mean daily fluid intake among the control, C75 and denervated C75 groups (Fig. 1C). As shown in Figure 1D, C75 significantly reduced weight gain in $180 \%$ and $132 \%$ over $24 \mathrm{~h}(-17.7 \pm 2.1 \mathrm{~g}$ vs. $22.1 \pm 2.7 \mathrm{~g})$ and $48 \mathrm{~h}(-5.3 \pm 6.0 \mathrm{~g}$ vs. $16.6 \pm 1.2 \mathrm{~g})$, respectively. Denervation attenuated the C75induced weight loss in $\sim 130 \%$ on the first day $(5.4 \pm 7.4 \mathrm{~g}$ ), and completely reestablished the weight gain $(12.0 \pm 3.0 \mathrm{~g})$ on the second day (Fig. 1D). Taken together these data suggest that BAT sympathetic innervation contributes to weight loss induced by central injection of $\mathrm{C} 75$, at least in part, through the suppression of feeding behavior. 
Central administration of $\mathrm{C75}$ induces a transitory and slight increase in glycemia and plasma FFA levels

Increases in the activity of the SNS maintain energy balance by mobilizing triglycerides stores in WAT and promoting hyperglycemia through stimulation of hepatic glucose production (Nonogaki, 2000). Consistent with these apparent SNS-mediated effects, C75 significantly increased glycemia at $1 \mathrm{~h}(85.8 \pm 6.5$ vs. $61.8 \pm 5.5)$ and FFA at $30 \mathrm{~min}(8.6 \pm$ 1.0 vs. $6.0 \pm 0.5$ ) after i.c.v. injection in nonanesthetized, freely moving rats (Fig. 2). However, these effects were not correlated with any detectable increase in plasma levels of catecholamines (data not shown).

\section{BAT denervation prevents hyperthermia and heat loss evoked by C75}

As shown in Figs. 3A-D, the C75 injection increased core body temperature along 24 $\mathrm{h}$ of analysis (AUC $25.9 \pm 2.9$ vs. $16.5 \pm 2.5$ ) without altering the spontaneous motor activity (21.9 \pm 1.8 vs. $25.3 \pm 2.5)$. C75 also induced a higher heat variation rate (Fig. $3 E$ ), an effect that started at $30 \mathrm{~min}$, picked at $1 \mathrm{~h}$ and lasted for $6 \mathrm{~h}$ of injection. Furthermore, denervation attenuated the increase of core body temperature (AUC $16.5 \pm 2.3$ ) and body heating rate promoted by $\mathrm{C} 75$.

In order to estimate the heat exchange between the body and environment the tail skin temperature was measured (Figs. 3F and G). C75 injection enhanced tail heat loss mechanisms by increasing tail skin temperature along $4 \mathrm{~h}$ of analysis (AUC $461.2 \pm 69.2 \mathrm{vs}$. $222.8 \pm 25.2$ ). This effect was completely abolished by denervation (AUC $244.3 \pm 50.0$ ) suggesting that the heat loss is triggered as a thermoregulatory mechanism against the C75evoked hyperthermia. 


\section{C75 stimulates BAT thermogenesis via sympathetic nervous system}

To further investigate the involvement of the BAT thermogenesis in thermoregulatory responses induced by $\mathrm{C} 75$ injection, the BAT temperature was assessed in innervated and denervated rats. As shown in Figs. $4 A$ and B, C75 induced a marked increase in the BAT temperature from $1 \mathrm{~h}$ until $8 \mathrm{~h}$ of injection (AUC $16.6 \pm 1.2 \mathrm{vs.} 3.1 \pm 1.0$ ) and this thermal effect was completely abolished by BAT sympathetic denervation (AUC $4.8 \pm 1.2$ ). Concomitant with the start of heat production by BAT, there was an increase of norepinephrine content in BAT after 1 h of C75 injection (1350.8 \pm 91.1 vs. $1029.1 \pm 91.2$ ng. $\left.\mathrm{g}^{-1}\right)$, but no differences were found between $\mathrm{C75}$ and control groups after $4 \mathrm{~h}$ of treatment (Fig. 4C). This rapid increase in BAT norepinephrine after $1 \mathrm{~h}$ of $\mathrm{C75}$ injection levels was associated with an increase in the activity of BAT mitochondrial cytochrome c oxidase activity $\left(2.7 \pm 0.4\right.$ vs. $0.7 \pm 0.3$ Units. $100 \mu \mathrm{g}^{-1}$ protein; Fig. $\left.4 \mathrm{D}\right)$. The ucp-1 mRNA expression was up-regulated ( 2.5 fold) in the BAT only after $4 \mathrm{~h}$ of $\mathrm{C} 75$ injection (Fig. $4 \mathrm{E}$ ). Denervation completely abolished C75-induced increase of BAT norepinephrine and cytochrome c oxidase activity, as well as the increase of ucp-1 expression. These findings indicate that the centrally administered C75 triggers the sympathetic outflow to BAT, which leads to an increase in the core body temperature through stimulation of non-shivering thermogenesis.

\section{Cerulenin induces thermoregulatory effects but does not alter the feeding behavior}

As shown in Figs. $5 \mathrm{~A}$ and $\mathrm{B}$, the i.c.v. administration of cerulenin, a natural FAS inhibitor, did not affect either food intake or weight gain. However, it increased BAT temperature and core body temperature without altering the spontaneous locomotor activity of the animals (Figs. 5C-E). The cerulenin-induced stimulatory effects on BAT and 
core body temperature started at $3 \mathrm{~h}$ and $4 \mathrm{~h}$ of injection, respectively, and lasted only for 2 h. Both effects were abolished by sympathetic denervation. Thus, the thermoregulatory effects of cerulenin are slower and more transitory as compared to C75 effects. 


\section{Discussion}

The main finding of the present study is that BAT sympathetic denervation attenuates both the enhanced hyperthermia and anorexia induced by central administration of C75, a synthetic inhibitor of FAS. These changes in thermoregulatory responses are also observed in rats treated with cerulenin, a natural FAS inhibitor, and occur in parallel with prevention of the stimulated FAS inhibitor-induced BAT thermogenesis. Our observations suggest a new mechanism by which C75 can affect energy expenditure and feeding behavior by modulatig BAT activity.

The negative balance caused by FAS inhibitors is not entirely the result of suppressed food intake but also increased energy expenditure. In fact, indirect calorimetry experiments showed that administration of $\mathrm{C} 75$ increases whole-body $\mathrm{O}_{2}$ consumption (Thupari et al., 2002; Thupari et al., 2004; Tu et al., 2005) probably through the SNS activation. In agreement with this notion, the present study shows that C75 induces a transient increase in plasma levels of glycemia and FFA, suggesting that the mild sympathoexcitation evoked by C75 elicits activation of hepatic glucose production and lipolysis in white adipose tissue. Cha et al. (2006) were the first to demonstrate that the SNS is also implicated in the transmission of the C75 signal from brain to skeletal muscle. In these studies it was demostrated that sympathetic activation induced by $\mathrm{C} 75$ increased the fatty acid oxidation and the expression of $u c p-3$ in skeletal muscles. According to these authors the up-regulation of ucp-3 may be responsible for the C75-induced increase in energy expenditure. Our data suggest that BAT, a highly sympathetic innervated tissue, also contributes to these changes in part by activating thermogenesis. 
The innervation of BAT by the SNS is incontrovertible and its activation by central nervous system functions as the principal stimulator of BAT thermogenesis (Bartness et al., 2010). Classified as facultative/adaptive or non-shivering thermogenesis, BAT thermogenesis consists in a form of additional heat production that is activated in certain situations of demand, therefore it represents an essential mechanism to maintain the core body temperature (Silva, 2006). In this context, the BAT sympathetic denervation is a powerful tool to eliminate the connection between central signals to the BAT, blocking the rise on body temperature dependent of this mechanism of heat production. Because denervation attenuates the increase in the core body temperature and heat variation heat induced by both C75 (Figs. 3A, B and E) and cerulenin (Fig. 5D), we concluded that at least part of the FAS inhibitors-evoked hyperthermia can be attributed to BAT thermogenesis. This conclusion appears consistent with the following findings: 1) the local BAT temperature is clearly increased by FAS inhibitors (C75 and cerulenin) and this thermal effect is completely abolished in denervated rats (Figs. 4A and 5C); 2) the FAS inhibitors-induced heat production is not due to physical activity because spontaneous locomotor activity stayed unaffected for $24 \mathrm{~h}$ of injection (Figs. $3 \mathrm{C}$ and $5 \mathrm{E}$ ); and 3) the enhanced heat loss, estimated by means of tail skin temperature (Figs. $4 \mathrm{~F}$ and $\mathrm{G}$ ), in $\mathrm{C75}$-treated rats excludes the possibility that the hyperthermia is due to a decrease in heat dissipation (peripheral vasoconstriction). The stimulatory effect of $\mathrm{C75}$ on heat loss can be interpreted as primary autonomic defense against hyperthermia and could explain why the increased core body temperature returned to control values after $8 \mathrm{~h}$ of injection.

BAT thermogenesis is triggered by the release of norepinephrine from its sympathetic nerve terminals, stimulating $\beta_{3}$-adrenoceptors that, in turn, promote a cascade of intracellular events ending in activation of UCP-1 (Bartness et al., 2010), a key 
thermogenic enzime expressed exclusively in BAT. UCP-1 dissipates the proton gradient across the inner mitochondrial membrane to produce heat, rather than ATP. For this function, it is necessary the fuel oxidation with increased production of NADH and FADH 2 which donate electrons to the electron-transport chain, a series of protein complexes which includes the cytochrome c oxidase (Krauss et al., 2005). Consistent with the hypothesis that BAT thermogenesis is activated by central administration of C75 via a direct sympathetic innervation, the BAT norepinephrine was rapidly $(1 \mathrm{~h})$ increased and closely correlated with a higher activity of the cytochrome c oxidase. Furthermore, this increase coincides with the peak response of core body temperature and the onset of heat production by BAT. The stimulating effect of $\mathrm{C} 75$ on $u c p-1$ mRNA expression was detected after $4 \mathrm{~h}$ of injection, a period in which the core body temperature and BAT temperature are still high. The fact that all these responses, including the weight loss, were abolished or attenuated by denervation strongly suggest that BAT thermogenesis contributes to the hyperthermia evoked by C75. Such a thermogenic response might be expected to contribute to whole-body energy expenditure and result in weight loss after the pharmacologic inhibition of FAS.

In 1995, Himms-Hagen proposed a novel role of BAT thermogenesis on feeding behavior. Thus, it was postulated that the satiety is induced by the high level of core temperature brought about by the episode of stimulated BAT thermogenesis, and the size of the meal depends on the balance between BAT thermogenesis and heat loss (Himms-Hagen, 1995). This view is consistent with the finding that denervation attenuated the reduced food intake induced by $\mathrm{C} 75$ during the first $24 \mathrm{~h}$ of injection. Therefore, the increase in the core body temperature promoted by C75 may play a direct role in suppressing feeding behavior. In contrast to $\mathrm{C75}$, the administration of cerulenin did not affect feeding behavior but induced hyperthermia. These thermoregulatory responses, however, were less potent and 
more transitory (only $2 \mathrm{~h}$ ) as compared to those of $\mathrm{C} 75$ and could explain the lack of effect of cerulenin on food intake. Further experiments are needed to confirm this hypothesis.

In summary, the present work is the first to show that a single central injection of FAS inhibitors (C75 and cerulenin) increase the sympathetic outflow to BAT which leads to the activation of thermogenesis and, consequently, the increase in core body temperature. In addition, BAT thermogenesis may contribute to weight loss induced by central injection of C75 through the suppression of feeding behavior. The ability of FAS inhibitors to stimulate BAT, a tissue metabolically inactive in most overweight or obese subjects (van Marken Lichtenbelt et al., 2009), suggests that modulation of this pathway may serve as a potential target for satiety and weight control. 


\section{References}

Aja S, Landree LE, Kleman AM, Medghalchi SM, Vadlamudi A, McFadden JM, Aplasca A, Hyun J, Plummer E, Daniels K, Kemm M, Townsend CA, Thupari JN, Kuhajda FP, Moran TH \& Ronnett GV (2008). Pharmacological stimulation of brain carnitine palmitoyl-transferase-1 decreases food intake and body weight. Am J Physiol Regul Integr Comp Physiol 294, R352-R361.

Bamshad M, Song CK \& Bartness TM (1999). CNS origins of the sympathetic nervous system outflow to brown adipose tissue. Am J Physiol Regul Integr Comp Physiol 276, R1569R1578.

Bartness TJ, Vaughan CH \& Song CK (2010). Sympathetic and sensory innervation of brown adipose tissue. Int J Obes 34, S36-S42.

Bentebibel A, Sebastian D, Herrero L, Lopez-Vinas E, Serra D, Asins G, Gomez-Puertas P \& Hegardt FG (2006). Novel effect of C75 on carnitine palmitoyltransferase I activity and palmitate oxidation. Biochemistry 45, 4339-4350.

Cannon B \& Lindberg O (1979). Mitochondria from brown adipose tissue: isolation and properties. Meth Enzimol 55, 65-78.

Cannon B \& Nedergaard J (2004). Brown adipose tissue: function and physiological significance. Physiol Rev 84, 277-359.

Cha S-H, Hu Z \& Lane MD (2004). Long-term effects of a fatty acid inhibitor on obese mice: food intake, hypothalamic neuropeptides and UCP3. Biochem Biophys Res Commun 317, 301-308.

Cha S-H, Hu Z, Lane MD \& Chohnan S (2005). Inhibition of hypothalamic fatty acid synthase triggers rapid activation of fatty acid oxidation in skeletal muscle. Proc Natl Acad Sci USA 102(41), 14557-14562.

Cha S-H, Rodgers JT, Puigserver P, Chohnan S \& Lane MD (2006). Hypothalamic malonyl-CoA triggers mitochondrial biogenesis and oxidative gene expression in skeletal muscle: Role of PGC-1 $\alpha$. Proc Natl Acad Sci USA 103(42), 15410-15415. 
Cikos S, Bukovska A \& Koppel J (2007). Relative quantification of mRNA: comparison of methods currently used for real-time PCR data analysis. BMC Mol Biol 8, 113-127.

Cypess AM, Lehman MB, Williams G, Tal I, Rodman D, Goldfine AB, Kuo FC, Palmer EL, Tseng Y-H, Doria A, Kolodny GM \& Kahn R (2009). Identification and importance of brown adipose tissue in adult humans. N Engl J Med 360, 1509-1517.

Garófalo MAR, Kettelhut IC, Roselino JES \& Migliorini RH (1996). Effect of acute cold exposure on norepinephrine turnover rates in rat white adipose tissue. J Auton Nerv Syst 60, 206-208.

Himms-Hagen J (1989). Brown adipose tissue thermogenesis and obesity. Prog Lipid Res 28, 67-115.

Himms-Hagen J (1995). Role of brown adipose tissue thermogenesis in control of thermoregulatory feeding in rats: a new hypothesis that links thermostatic and glucostatic hypotheses for control of food intake. Proc Soc Exp Biol Med 208(2), 159-169.

Krauss S, Zhang C-Y \& Lowell BB (2005).The mitochondrial uncoupling-protein homologues. Nature Rev Mol Cell Biol 6, 248-261.

Lane DM, Hu Z, Cha S-H, Dai Y, Wolfgang M \& Sidhaye A (2005). Role of malonyl-CoA in the hypothalamic control of food intake and energy expenditure. Biochem Soc Trans 33, 1063-1067.

Loftus TM, Jaworsky DE, Frehywot GL, Townsend CA, Ronnett GV, Lane MD \& Kahajda FP (2000). Reduced food intake and body weight in mice treated with fatty acid synthase inhibitors. Science 288, 2379-2381.

Lowry OH, Rosebrough NJ, Farr AL \& Randall RJ (1951). Protein measurement with the Folin phenol reagent. J Biol Chem 193, 265-275.

Nonogaki K (2000). New insights into sympathetic regulation of glucose and fat metabolism. Diabetologia 43, 533-549.

Paxinos G, Watson C (1982).The rat brain in stereotaxic coordinates. 2nd edn. Academic Press, Sydney. 
Shimokawa T, Kumar MV \& Lane D (2002). Effect of a fatty acid synthase inhibitor on food intake and expression of hypothalamic neuropeptides. Proc Natl Acad Sci USA 99(1), 6671.

Silva JE (2006). Thermogenic mechanisms and their hormonal regulation. Physiol Rev 86, 435-464.

Thupari JN, Landree LE, Ronnett GV \& Kuhadja FP (2002). C75 increases peripheral energy utilization and fatty acid oxidation in diet-induced obesity. Proc Natl Acad Sci USA 99(14), 9498-9502.

Thupari JN, Kim E-K, Moran TH, Ronnett GV \& Kuhadja FP (2004). Chronic C75 treatment of diet-induced obese mice increases fat oxidation and reduces food intake to reduce adipose mass. Am J Physiol Endocrinol Metab 287, E97-E104.

Tu Y, Thupari JN, Kim E-K, Pinn ML, Moran TH, Ronnett GV \& Kuhajda FP (2005). C75 alters central and peripheral gene expression to reduce food intake and increase energy expenditure. Endocrinology 146(1), 486-493.

van Marken Lichtenbelt WD, Vanhommerig JW, Smulders NM, Drossaerts JMAFL, Kemerink GJ, Bouvy ND, Schrauwen P \& Teule GJJ (2009). Cold-activated brown adipose tissue in healthy men. N Engl J Med 360, 1500-1508.

Virtanen KA, Lidell ME, Orava J, Heglind M, Westergren R, Niemi T, Taittonen M, Laine J, Savisto N-J, Enerbäck S \& Nuutila P (2009). Functional brown adipose tissue in healthy adults. N Engl J Med 360, 1518-1525.

Young AA \& Dawson NJ (1982). Evidence for on-off control of heat dissipation from the tail of the rat. Can J Physiol Pharmacol 60, 392-398. 


\section{Figures Legends}

Figure 1. Effect of $\mathrm{C} 75$ on feeding and drinking behavior and weight gain in innervated and denervated rats. Standard chow (40 g) and water (in graduated bottle) were offered to $24 \mathrm{~h}$ fasted animals habituated individually to metabolic chambers after i.c.v. injection of C75 (150 $\mu \mathrm{g}$ in $7.5 \mu \mathrm{L})$ or vehicle (7.5 $\mu \mathrm{L}$ RPMI). A, food intake at the intervals of 0-1 $\mathrm{h}, 1-3 \mathrm{~h}$ and 3-12h. $B$, food intake at each $24 \mathrm{~h}$ for 3 days. $C$, water intake at each $24 \mathrm{~h}$ for 3 days. $D$, weight gain at each $24 \mathrm{~h}$ for 3 days. Values represent means \pm SEM ( $n=6-8 /$ group). Two-Way ANOVA test, Bonferroni posttest used to statistical analyzes. $* \mathrm{P}<0.05$ vs. control group and ${ }^{\#} \mathrm{P}<0.05$ vs. $\mathrm{C} 75$ group.

Figure 2. Temporal profile of C75-induced changes on plasma levels of free fatty acids and glucose in awake rats. $24 \mathrm{~h}$-fasted animals with cannula in the jugular vein received i.c.v. injection of C75 (150 $\mu \mathrm{g}$ in $7.5 \mu \mathrm{L}$ ) or vehicle (7.5 $\mu \mathrm{L}$ RPMI). $A$, free fatty acids levels taken for $3 \mathrm{~h} . B$, glycemia taken for $3 \mathrm{~h}$. Values represent means $\pm \operatorname{SEM}(\mathrm{n}=7 /$ group). Two-Way ANOVA test, Bonferroni posttest used to statistical analyzes. ${ }^{*} \mathrm{P}<0.05$ vs. control group.

Figure 3. Temporal profile of $\mathrm{C75}$-induced changes on core body temperature, physical activity and tail skin temperature in innervated and denervated awake rats. Temperature and physical activity were recorded after i.c.v. injection of C75 (150 $\mu \mathrm{g}$ in $7.5 \mu \mathrm{L})$ or vehicle (7.5 $\mu \mathrm{L}$ RPMI) in $24 \mathrm{~h}$-fasted animals. $A$, core body temperature for $24 \mathrm{~h}$ (abdominal measurements at 10 min intervals). $B, A U C$ of core body temperature from 0 to $24 \mathrm{~h}$. $C$, Spontaneous locomotor activity for $24 \mathrm{~h}$ (through the same transponder of core body temperature). $D, A U C$ of spontaneous locomotor activity from 0 to $24 \mathrm{~h}$. $E$, heat variation rate calculated from body core temperature values at $0.5,1,2,4,6,8$ and $10 \mathrm{~h}$ of injection. $F$, change of tail skin temperature for $4 \mathrm{~h}$ measured at 5 min intervals. $G$, AUC of tail skin temperature from 0 to $4 \mathrm{~h}$. Values represent means \pm SEM ( $n=7 /$ group). Two-Way ANOVA test, Bonferroni posttest to core body temperature, spontaneous locomotor activity and tail temperature analyzes and One-Way ANOVA test, Newman-Keuls posttest to AUC and heat variation rate analyzes. ${ }^{*} \mathrm{P}<0.05$ vs. control group; ${ }^{\#} \mathrm{P}<0.05$ vs. $\mathrm{C} 75$ group. 
Figure 4. Effect of C75 on BAT temperature and markers of thermogenesis in innervated and denervated rats. Temperature and thermogenesis markers were analyzed in BAT after i.c.v. injection of C75 (150 $\mu \mathrm{g}$ in $7.5 \mu \mathrm{L})$ or vehicle (7.5 $\mu \mathrm{L}$ RPMI) in innervated or denervated $24 \mathrm{~h}$-fasted animals. A, temporal profile of $\mathrm{C} 75$-induced changes on BAT temperature in awake rats for $8 \mathrm{~h}$ (change of basal values at $20 \mathrm{~min}$ intervals). B, AUC of BAT temperature from 0 to $8 \mathrm{~h}$. $C$, content of norepinephrine in BAT after $1 \mathrm{~h}$ and $4 \mathrm{~h}$ of injection. $D$, cytochrome c oxidase activity after $1 \mathrm{~h}$ of injection. $E$, ucp-1 mRNA expression in BAT after 1 $\mathrm{h}$ and $4 \mathrm{~h}$ of injection. Values represent means \pm SEM ( $n=4-7 /$ group). Two-Way ANOVA test, Bonferroni posttest to change of BAT temperature analyze and One-Way ANOVA test, Newman-Keuls posttest to AUC, norepinephrine, enzymatic assay and mRNA expression analyzes. ${ }^{*} \mathrm{P}<0.05$ vs. control group; ${ }^{\#} \mathrm{P}<0.05$ vs. $\mathrm{C} 75$ group.

Figure 5. Effects of cerulenin on food intake, weight gain, BAT and core body temperatures, and physical activity. Cerulenin $(150 \mu \mathrm{g}$ in $7.5 \mu \mathrm{L})$ or vehicle (7.5 $\mu \mathrm{L}$ RPMI) were i.c.v. injected in innervated or denervated $24 \mathrm{~h}$-fasted animals. $A$, food intake at intervals of $24 \mathrm{~h}$ for 3 days. $B$, weight gain of $24 \mathrm{~h}$ for 3 days. $C$, temporal profile of cerulenininduced changes on BAT temperature in awake rats for $8 \mathrm{~h}$ (change of basal values at 20 min intervals). $D$, temporal profile of cerulenin-induced changes on core body temperature in awake rats for $8 \mathrm{~h}$ (abdominal measurements at $10 \mathrm{~min}$ intervals). $E$, temporal profile of cerulenin-induced changes on spontaneous locomotor activity in awake rats for $8 \mathrm{~h}$ (through the same transponder of core body temperature). Values represent means \pm SEM $(n=4$ 7/group). Two-Way ANOVA test, Bonferroni posttest used to statistical analyzes. ${ }^{*} \mathrm{P}<0.05$ vs. control group and ${ }^{\#} \mathrm{P}<0.05$ vs. cerulenin group. 
Figure 1

A

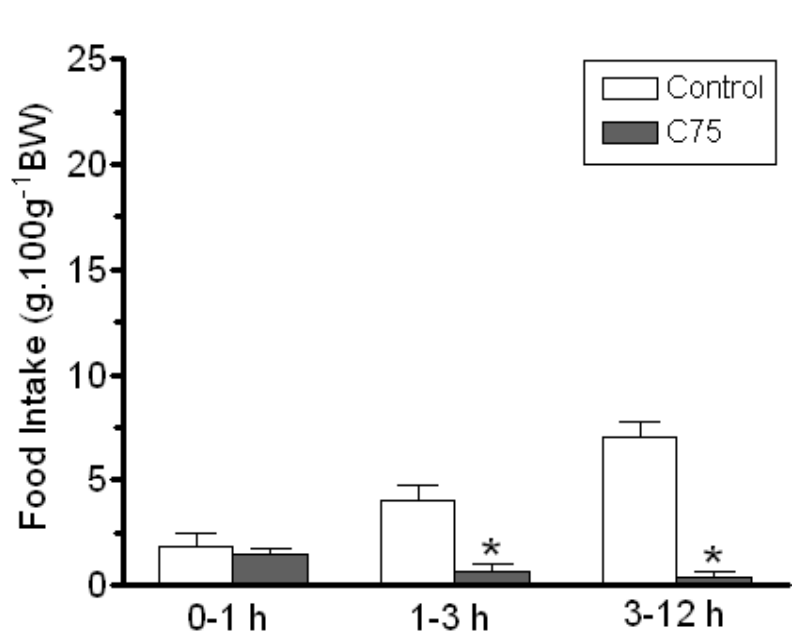

C

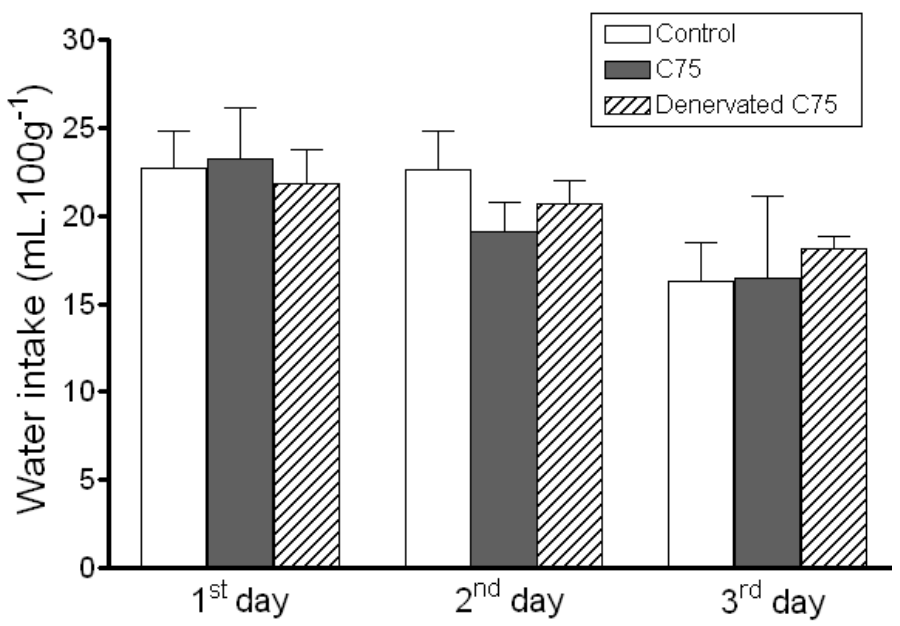

B

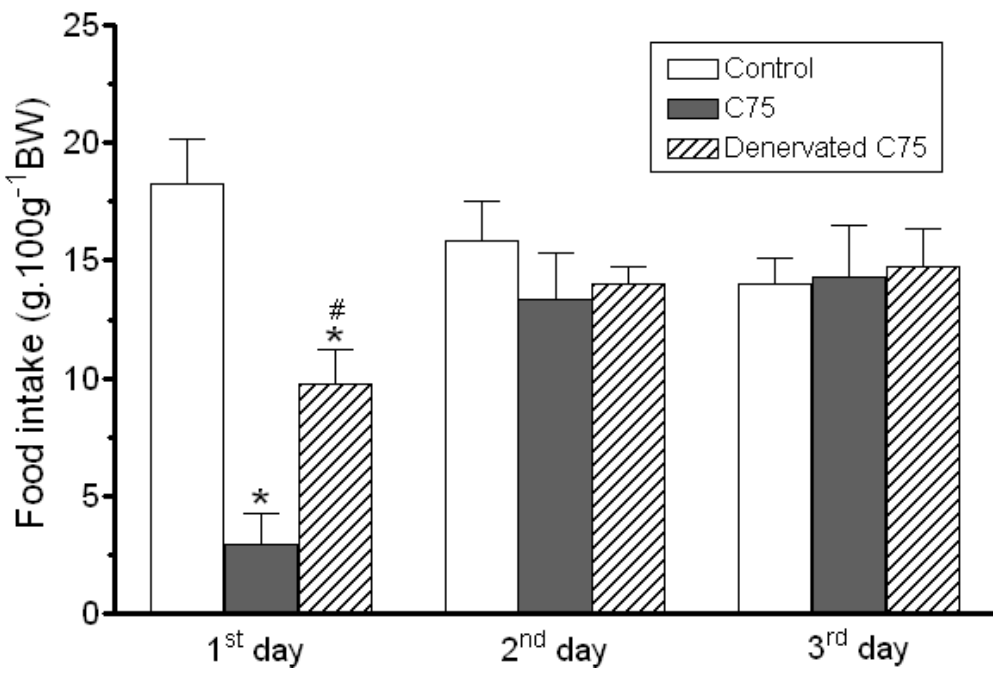

D

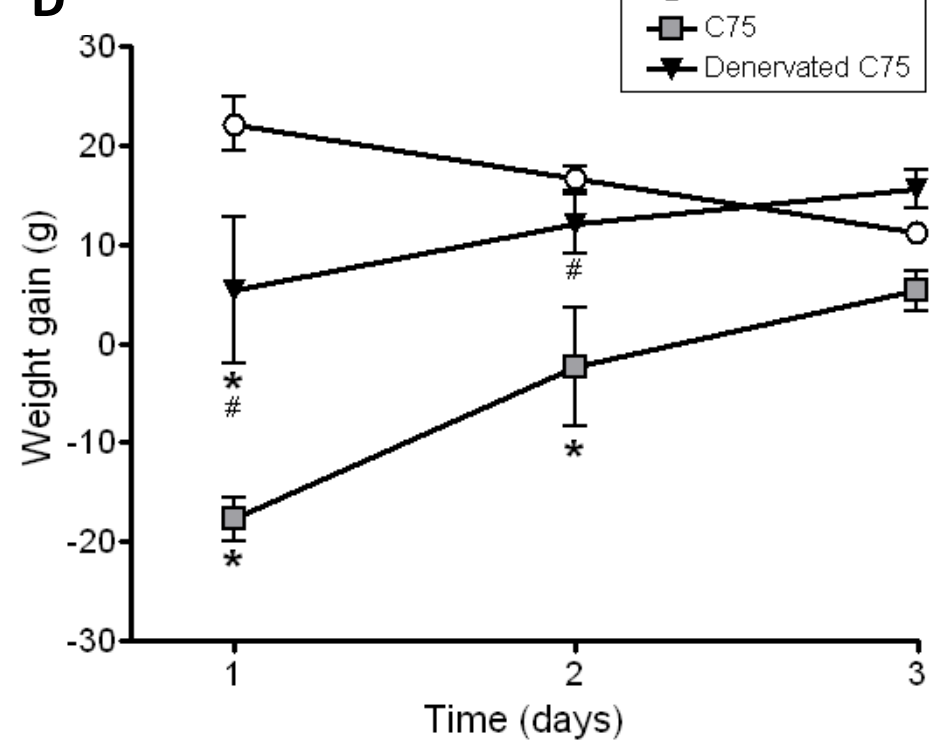


Figure 2

A

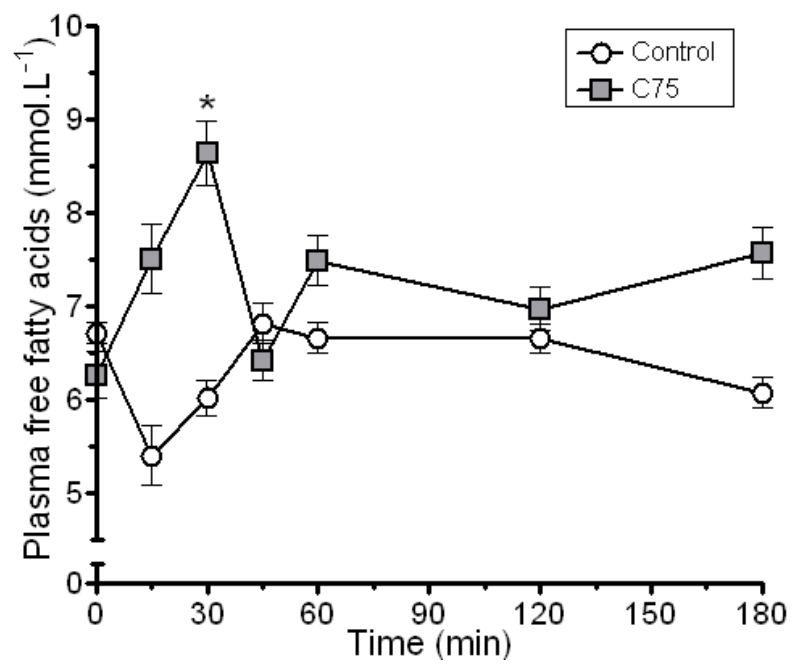

B

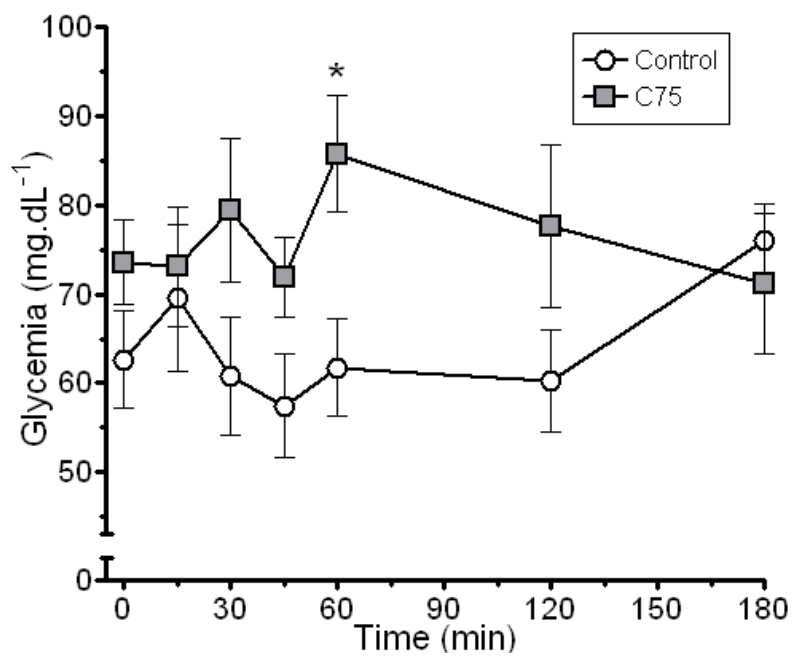


Figure 3

A

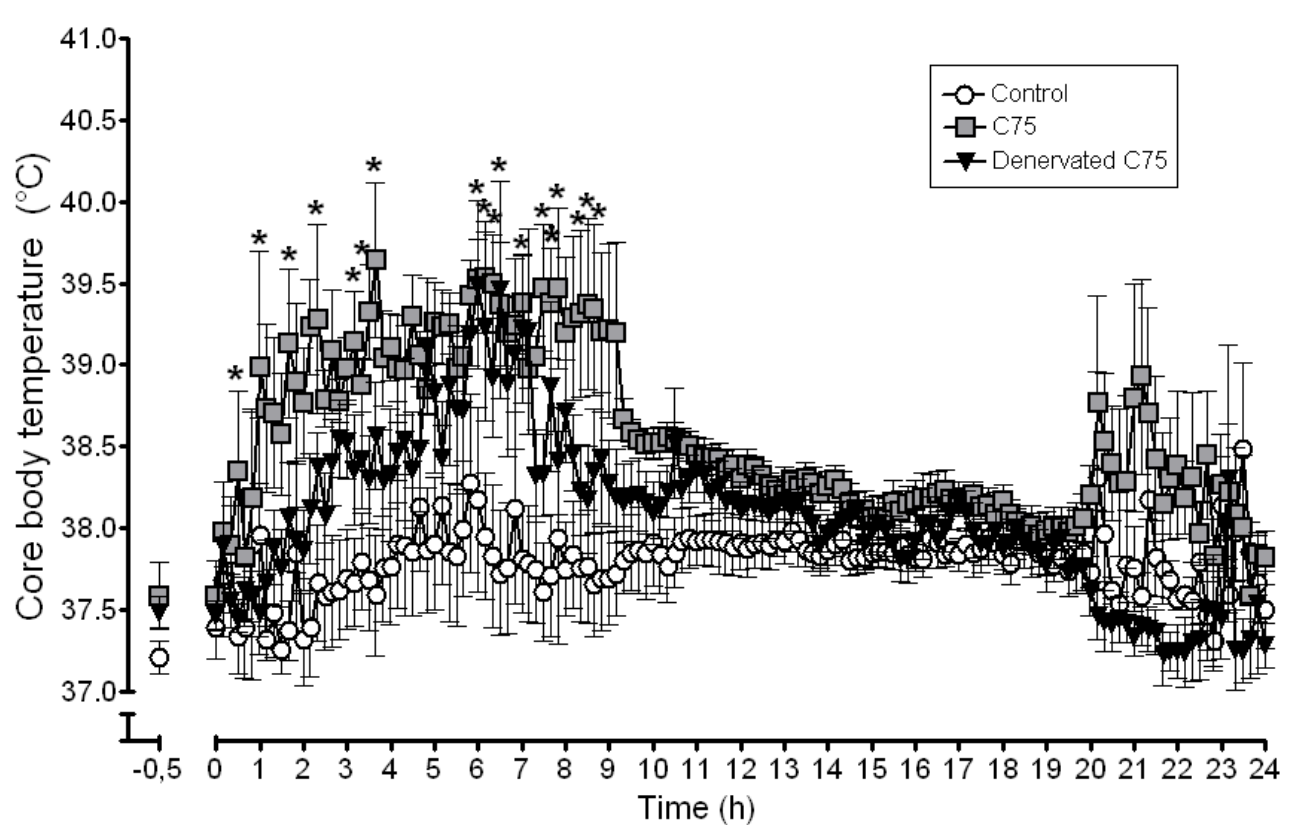

C

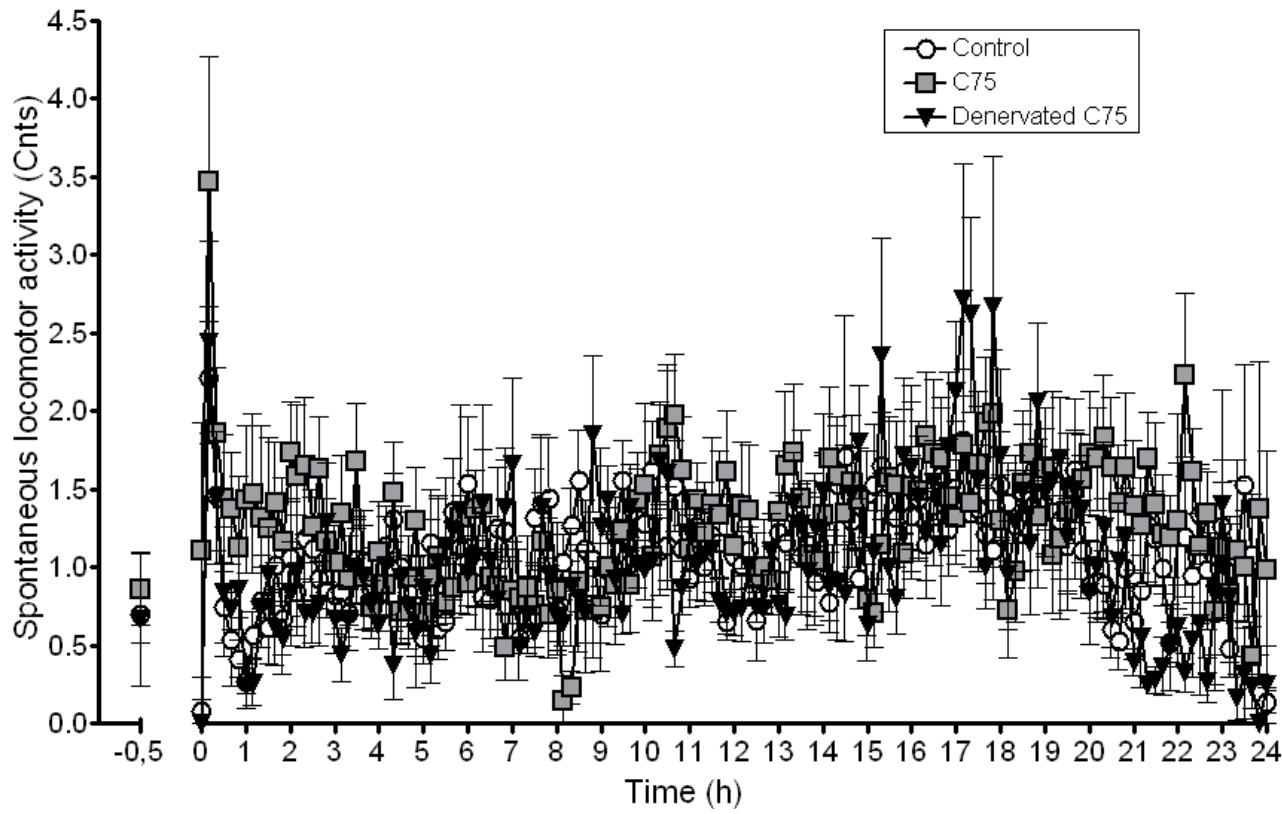

B

$\square$ Contro

$\square \mathrm{C75}$

ZZZDenervated C75

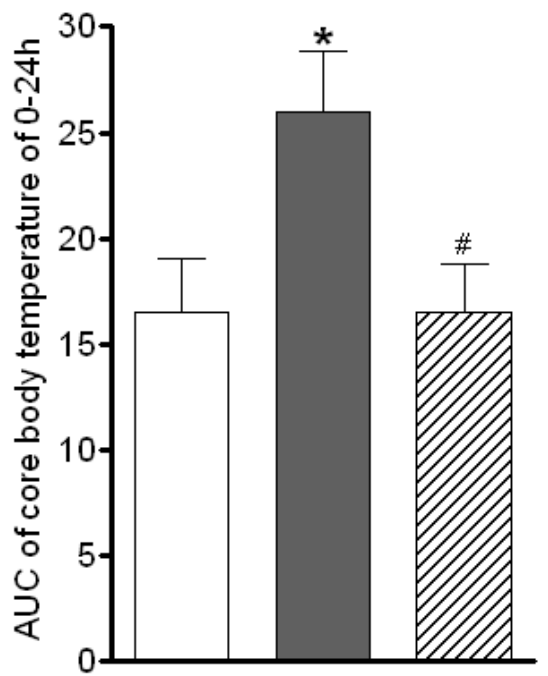

D

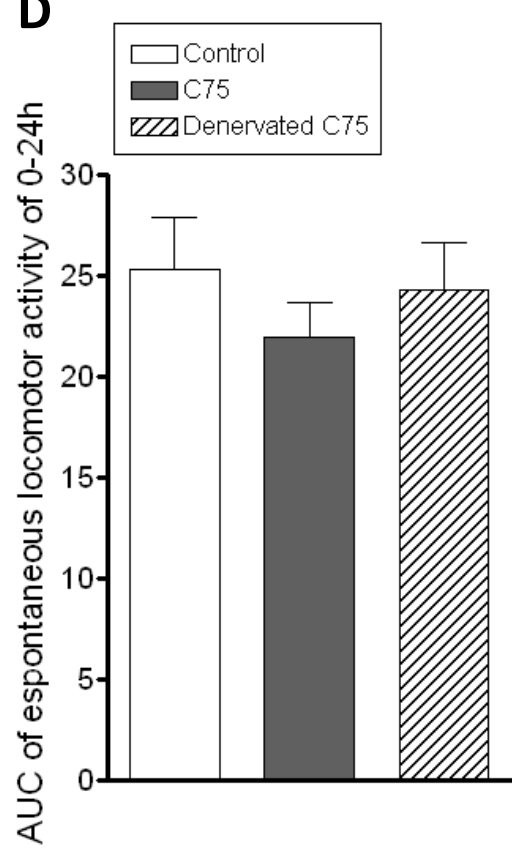




\section{E}
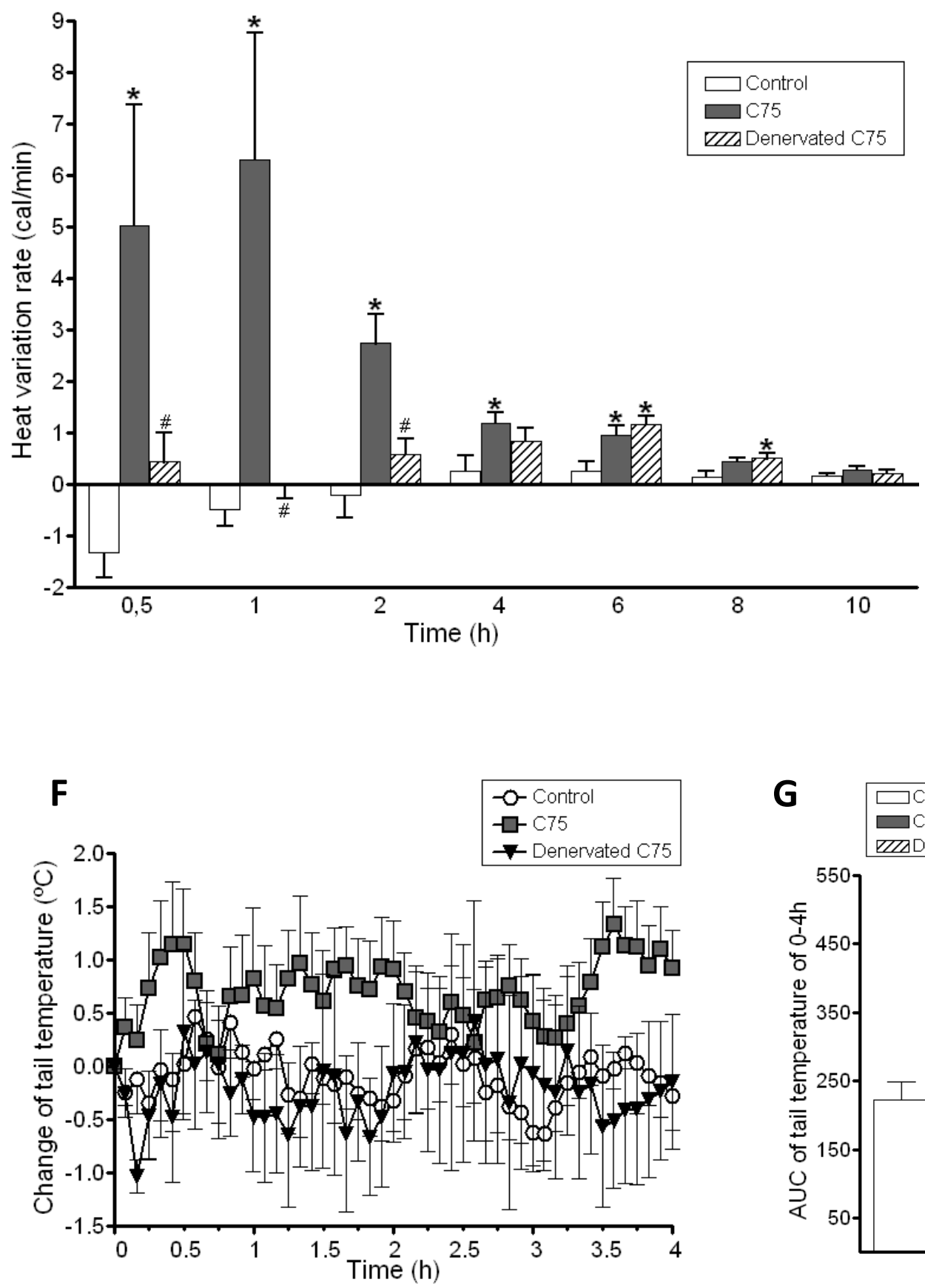
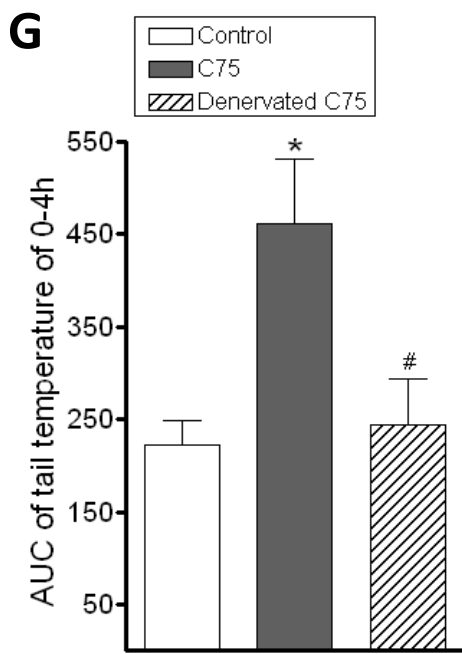
Figure 4

A

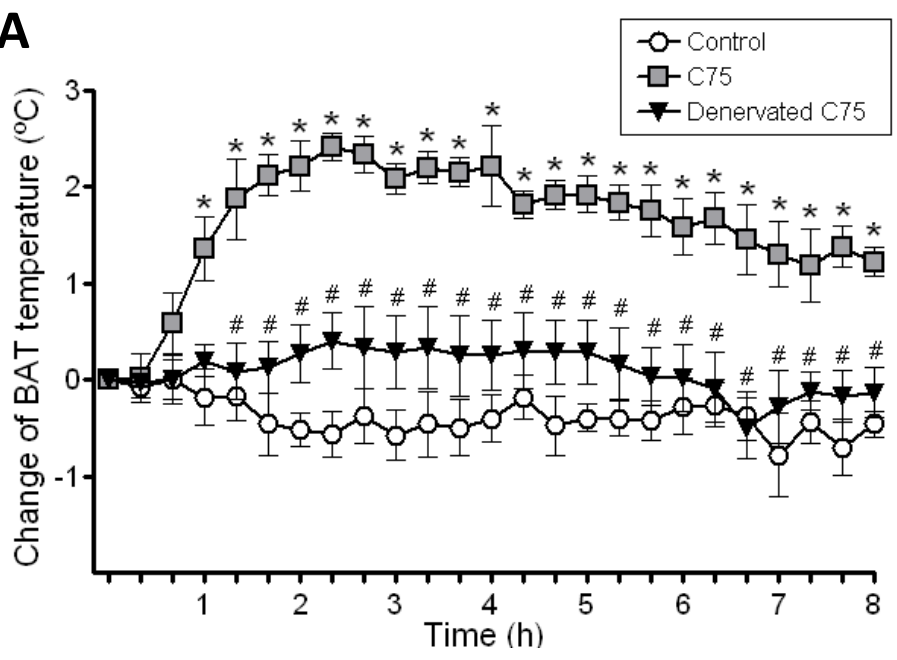

\section{C}

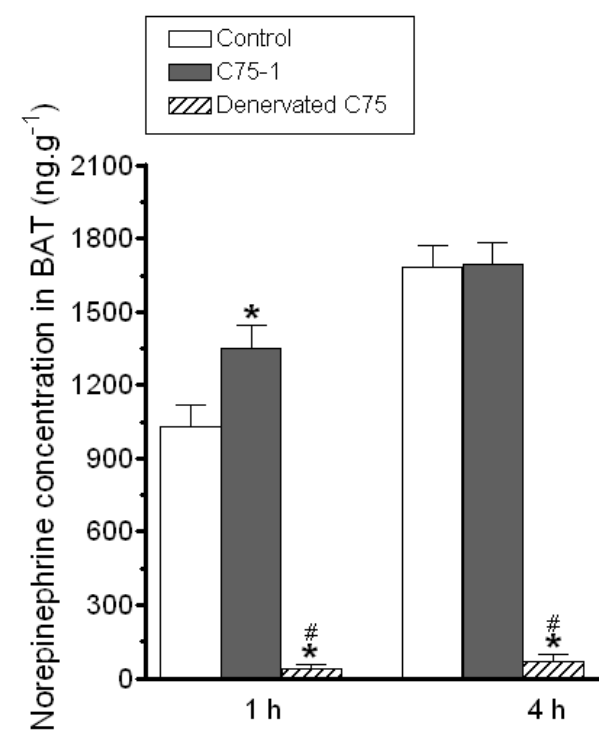

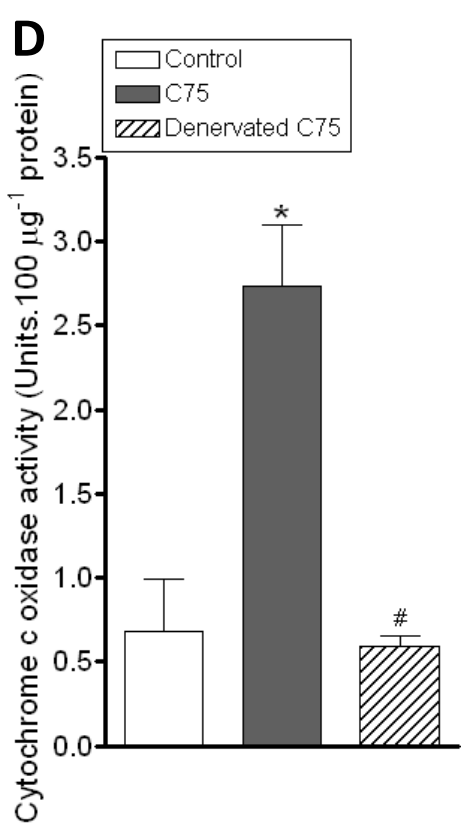
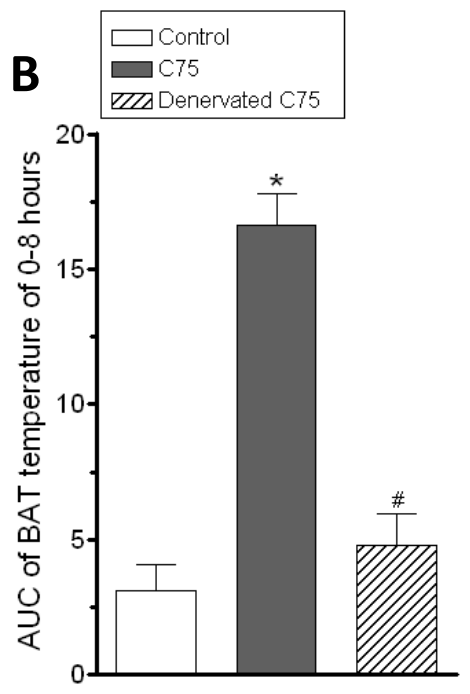

E
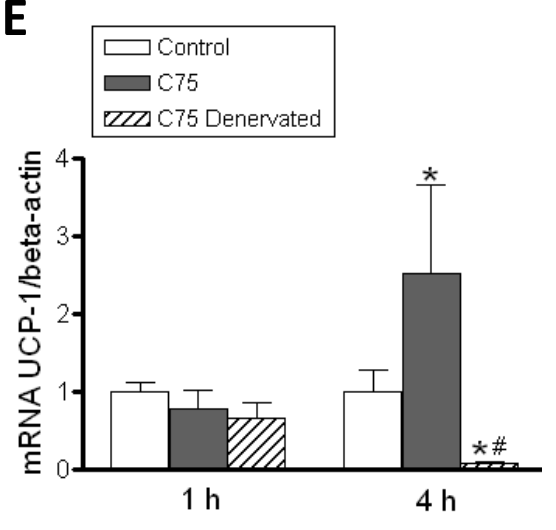
Figure 5
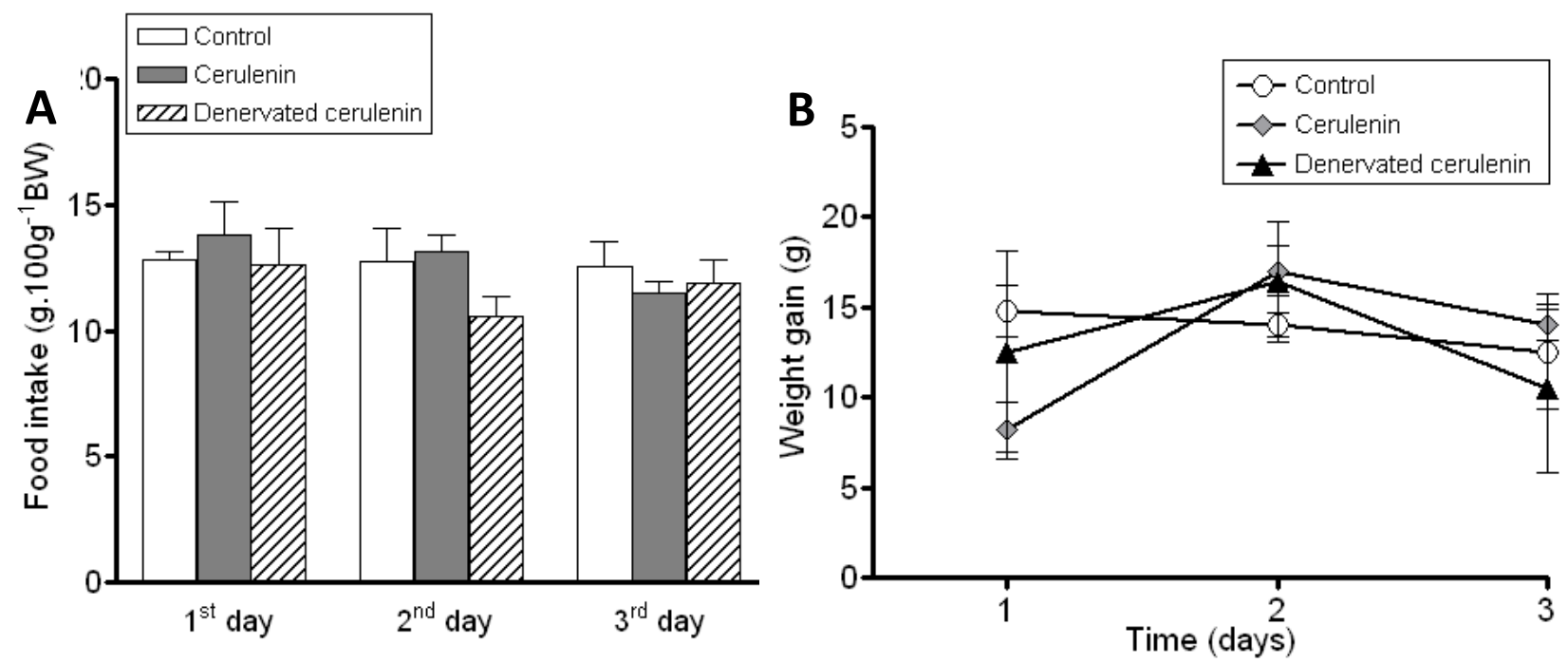

C

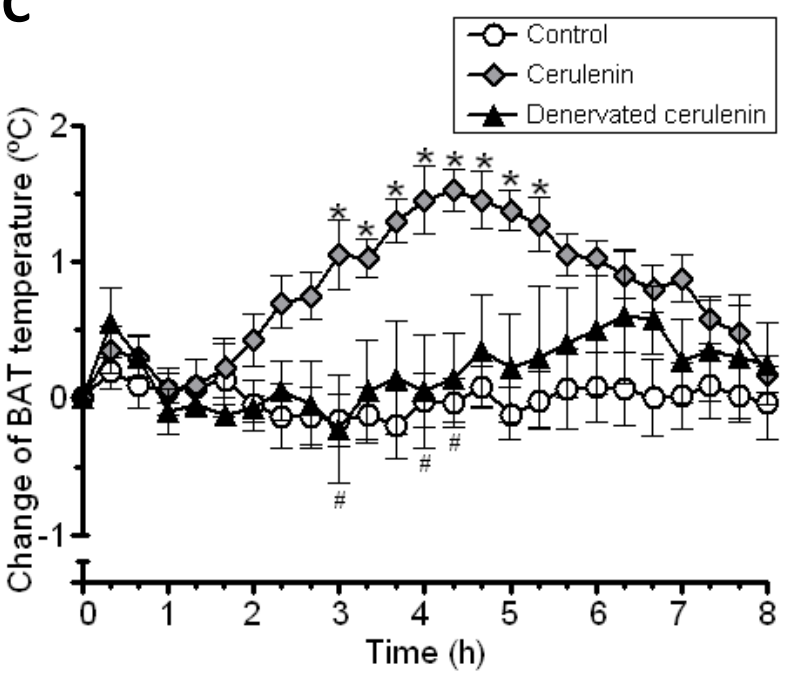

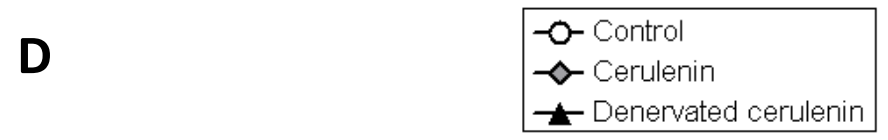

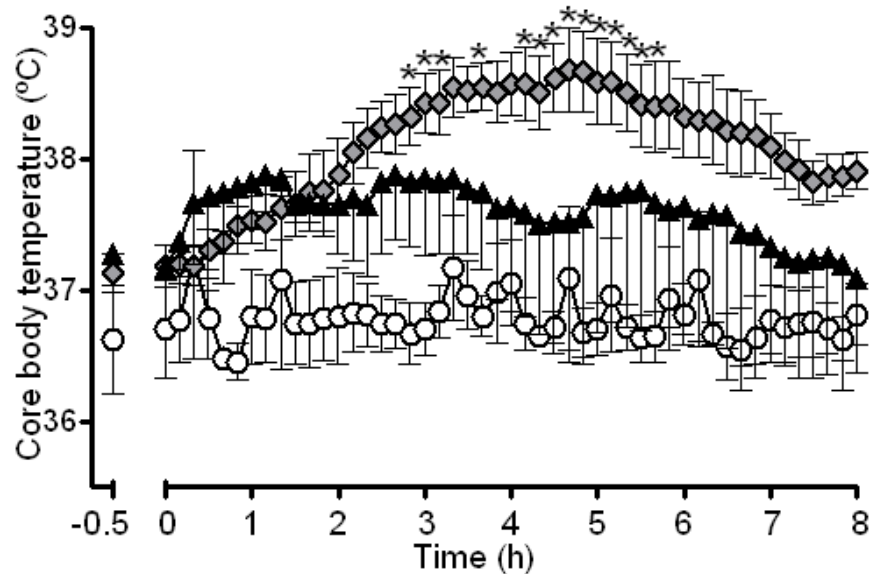

E

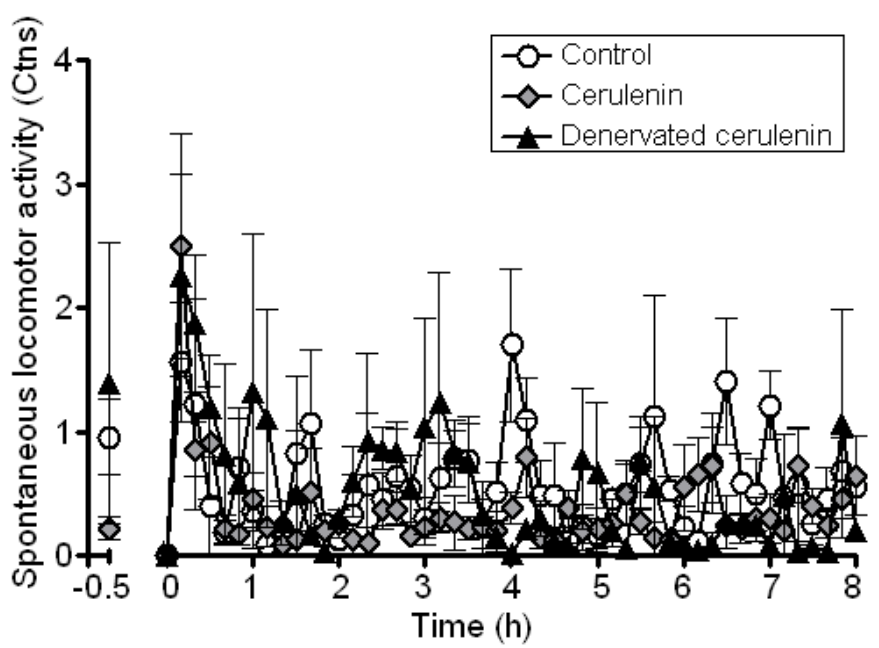

